\title{
Targeting Autophagy in Multiple Myeloma
}

Yun Dai

Center for Clinical and Translational Research

Follow this and additional works at: https://scholarscompass.vcu.edu/etd

Part of the Translational Medical Research Commons

(C) The Author

\section{Downloaded from}

https://scholarscompass.vcu.edu/etd/3933

This Thesis is brought to you for free and open access by the Graduate School at VCU Scholars Compass. It has been accepted for inclusion in Theses and Dissertations by an authorized administrator of VCU Scholars Compass.

For more information, please contact libcompass@vcu.edu. 
Targeting Autophagy in Multiple Myeloma 2015

(C)Yun Dai, June 2015

All Rights Reserved. 


\title{
TARGETING AUTOPHAGY IN MULTIPLE MYELOMA
}

A Thesis submitted in partial fulfillment of the requirement for the degree of Master of Science, Clinical and Translational Sciences, at Virginia Commonwealth University

\author{
by \\ YUN DAI \\ M.D., Ph.D.
}

\section{Director: Dr. Steven Grant}

Professor, Departments of Medicine, Biochemistry, Pharmacology, and Human and Molecular Genetics

Associate Director for Translational Research and Co-Leader, Developmental Therapeutics

Program

Virginia Commonwealth University

Richmond, Virginia

June 2015 


\section{Acknowledgements}

I would like to express my gratitude to my advisor Dr. Steven Grant for the useful comments, remarks and engagement through the designing and conducting process of this research, as well as to all my colleagues, particularly Drs. Shuang Chen, Yu Zhang, Laing Zhou, Yun Leng, Hui Lin, Maciej Kmieciak, Xin-Yan Pei, and Ms. Lora B. Kramer, for their substantial contributions to the research related to this thesis. I would also like to thank my committee members including Drs. Steven Grant, David A. Gewirtz, Charles Chalfant, and Teraya Donaldson for their valid advice and comments on this master thesis.

I thank Dr. Jorge Moscat (Sanford-Burnham Medical Research Institute) for wild-type and p62 gene knockout mouse embryonic fibroblasts (MEFs), as well as the pEGFP-p62 plasmid, Dr. Karla Kirkegaard (Stanford University) for the pEGFP-LC3 plasmid, Dr. Eric J. Brown (Genentech) for the pBABE-puro-mCherry-EGFP-LC3B plasmid, Dr. Hisashi Harada (VCU) for wild-type and Bim knockout MEFs, Drs. Robert Z. Orlowski and Richard Jones (the University of Texas MD Anderson Cancer Center) for bortezomib- and revlimid-resistant RPMI8226 cells, and Drs. Kathryn A. Rizzo, Catherine I. Dumur, and Andrea Ferreira-Gonzalez (Tissue \& Data Acquisition Core of VCU Department of Pathology) for primary samples.

This work was supported by awards P50 CA142509, CA100866, CA93738, CA167708 from the National Institutes of Health, and award R6238 from the Leukemia and Lymphoma Society of America; Plasmid preparation was performed at the VCU Macromolecule Core Facility, supported, in part, with funding from NIH-NCI Cancer Center Core Grant 5P30CA016059-29; Confocal and EM microscopies were performed at the VCU Department of Anatomy and Neurobiology Microscopy Facility, supported, in part, with funding from NIH-NINDS Center Core Grant 5P30NS047463. 


\section{TABLE OF CONTENTS}

Chapter

Page

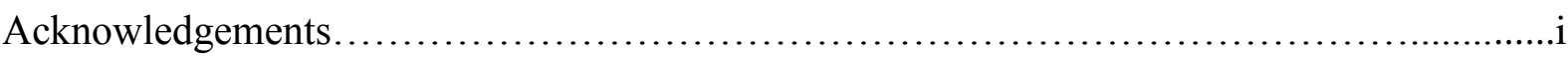

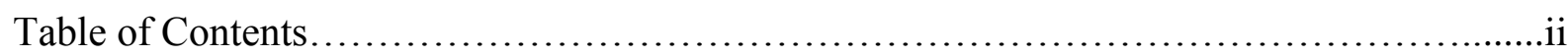

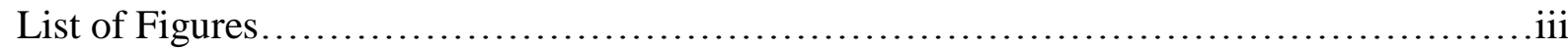

Abstract........................................................................

Part 1. Targeting SQSTM1/p62 induces "inefficient" autophagy and converts cytoprotective autophagy to apoptosis via NBK/Bik

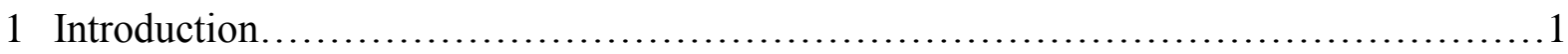

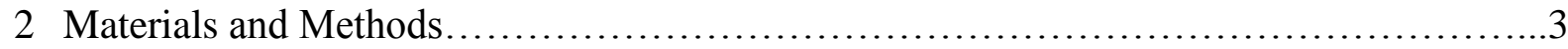

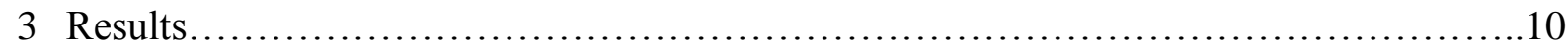

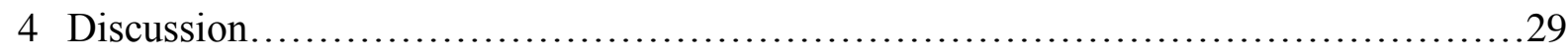

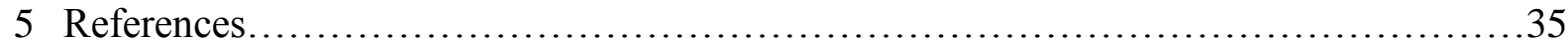

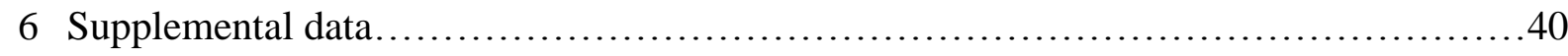

Part 2. Bim acts as a dual-agent regulating both autophagy and apoptosis in acquired drugresistance

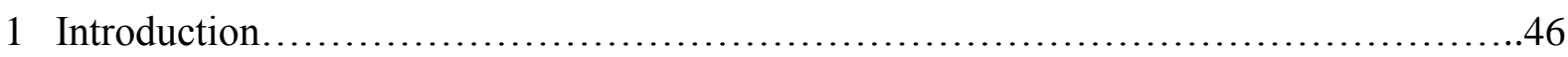

2 Materials and Methods........................................................ 48

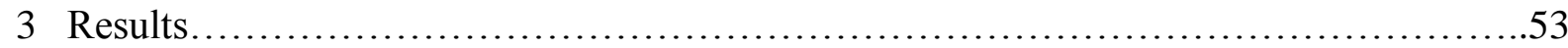

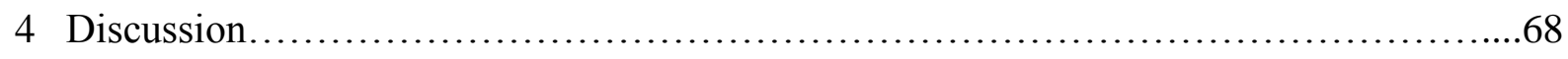

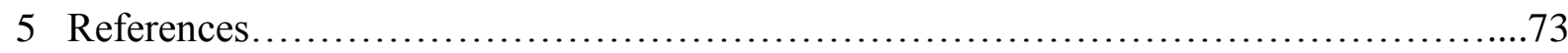

6 Supplemental data........................................................... 78

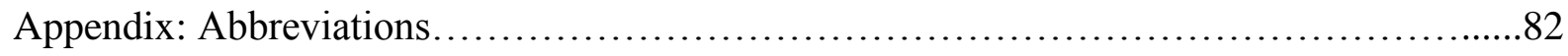




\section{LIST OF FIGURES}

Figure

Page

\section{Part 1}

1 BH3-mimetics induce autophagy and apoptosis in the presence of $\mathrm{Cdk}$ inhibitors...........12

2 Co-treatment with BH3-mimetics and Cdk inhibitors results in inefficient autophagy........14

$3 \mathrm{Cdk}$ inhibition down-regulates SQSTM1/p62 but fails to affect LC3 processing during

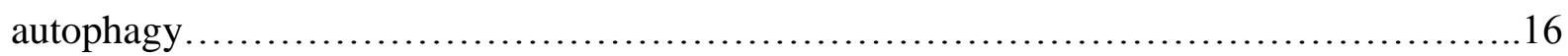

4 SQSTM1/p62 down-regulation results in cargo loading failure and inefficient autophagy....19

5 Expression of SQSTM1/p62 diminishes the increased lethality of BH3-mimetics in p62-

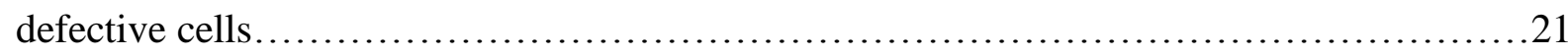

$6 \mathrm{Cdk} 9$ inhibition up-regulates NBK/Bik in cells exposed to BH3-mimetics.................23

7 NBK/Bik up-regulation occurs during autophagy in association with loading failure........26

$8 \mathrm{NBK} /$ Bik plays functional role in triggering apoptosis in vitro and in vivo.................28

9 A mechanistic model of SQSTM1/p62 and NBK/Bik acting as novel molecular switches

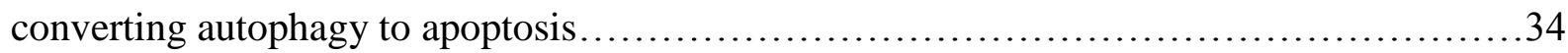

S1 The BH3 mimetic GX015-070 induces autophagy and apoptosis in the presence of Cdk

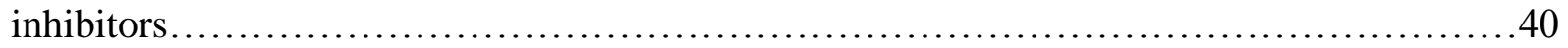

S2Cdk inhibitors down-regulate SQSTM1/p62 during BH3 mimetic-induced autophagy.......41

S3Co-treatment with GX015-070 and Cdk inhibitors up-regulates ER-localized NBK/Bik.....42

S4Bcl-2 or Bcl-xL, but not Mcl-1, dominant-negative caspase 9 or Bim shRNA, block autophagy and NBK/Bik up-regulation..........................................44

S5Knock-down of NBK/Bik by shRNA reduces the number of autophagic vacuoles (AVs) but does not modify the appearance of empty AVs....................................45

\section{Part 2}

1 Loss of Bim is associated with adaptive bortezomib-resistance in Bim ${ }^{\text {hi }}$ MM cells..........55

2 Bim acts as a determinant of ABT-737 sensitivity in Bim ${ }^{\text {hi }}$ MM cells .....................57

3 Up-regulation of Bim by SBHA potentiates ABT-737 lethality in bortezomib-resistant MM

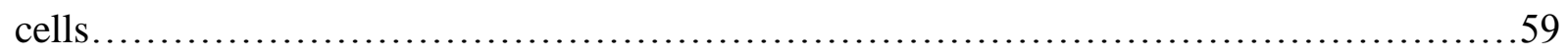

4 Bim up-regulated by SBHA attenuates ABT-737-induced autophagy $\ldots \ldots \ldots \ldots \ldots \ldots \ldots \ldots 61$ 
5 Bim is required for disruption of autophagy and induction of apoptosis induced by ABT737. .64

6 Chloroquine disrupts autophagy and sensitizes Bim $^{\text {low }} \mathrm{MM}$ cells to the HDACI/BH3 mimetic

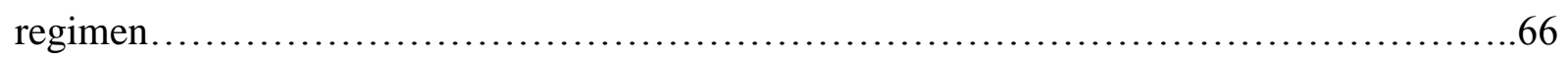

7 The HDACI/BH3-mimetic regimen displays activity in vivo which is blocked by Bim shRNA

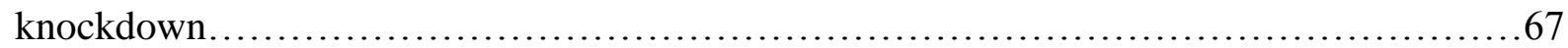

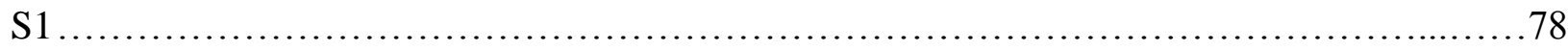

(A) Primary $\mathrm{CD} 138^{+} \mathrm{MM}$ cells display high basal Bim levels; (B) Human MM cells displaying high or low basal levels of Bim are both sensitive to bortezomib; (C) Bim plays a functional role in bortezomib sensitivity of Bim ${ }^{\text {hi }} \mathrm{MM}$ cells; (D) PS-R cells are highly resistant to bortezomib; (E) Bim mRNA is down-regulated in bortezomib-resistant MM cells; (F) Bim localizes on mitochondria; (G) Bim is down-regulated in other bortezomib-resistant MM cell lines; Primary CD138 ${ }^{+}$MM cells derived from relapsed patients display lower basal Bim levels than those from newly-diagnosed patients.

$\mathrm{S} 2$ .79

(A) ABT-737 unleashes Bim from Bcl-2 and Bcl-xL, but not Mcl-1; (B) Bim shRNA knockdown protects Bim ${ }^{\text {hi }}$ MM cells from ABT-737 lethality; Ectopic expression of Bim is lethal to bortezomib-resistant MM cells displaying Bim down-regulation; (D) SBHA significantly potentiates lethality of the clinically-relevant BH3-mimetic ABT-199 in bortezomib-resistant $\mathrm{MM}$ cells; (E) $\mathrm{CD}_{138^{+}} \mathrm{MM}$ cells from a patient with relapsed $\mathrm{MM}$ are resistant to bortezomib.

S3 .80

(A) Analysis of autophagic flux reveals inhibition of ABT-737-tiggered autophagy initiation by SBHA; (B) Primary CD $138^{+} \mathrm{MM}$ cells derived from relapsed patients display higher basal autophagy than those from newly-diagnosed patients; (C) Bortezomib-resistant PS-R cells display modestly increased basal autophagy; (D) ABT-737 releases Bim from Bcl-2 in bortezomib-resistant PS-R cells; (E) Bim shRNA knockdown prevents apoptosis induced by the autophagy inducer tunicamycin. 


\section{Abstract \\ TARGETING AUTOPHAGY IN MULTIPLE MYELOMA \\ by Yun Dai}

A Thesis submitted in partial fulfillment of the requirement for the degree of Master of Science, Clinical and Translational Sciences, at Virginia Commonwealth University Virginia Commonwealth University, 2015

\section{Director: Dr. Steven Grant}

Professor, Departments of Medicine, Biochemistry, Pharmacology, and Human and Molecular Genetics; Associate Director for Translational Research and Co-Leader, Developmental Therapeutics Program

Apoptosis (Type I) and autophagy (Type II) represent two major forms of programmed cell death. Numerous anticancer agents employed in standard chemotherapy or novel targeted therapy induce both apoptosis and autophagy. Of note, a cytoprotective autophagic response often counteracts apoptosis triggered by such agents, potentially contributing to drug-resistance. Mechanistically, autophagy and apoptosis share molecular regulatory mechanisms primarily governed by the Bcl-2 family proteins. However, since autophagy acts as the double-edge sword in cancer, whether autophagy should be inhibited or activated in cancer treatment remains the subject of debate. Here we report a) a novel autophagy-targeted strategy that targeting the adaptor SQSTM1/p62 induces "inefficient" autophagy due to cargo-loading failure and converts cytoprotective autophagic response to apoptosis via the BH3-only protein NBK/Bik (Part 1); and b) a new mechanism for acquired drug-resistance in which the $\mathrm{BH} 3$-only protein Bim acts as a dual-agent regulating both autophagy and apoptosis (Part 2). 


\section{Part 1}

\section{Targeting SQSTM1/p62 induces “inefficient” autophagy and converts cytoprotective autophagy to apoptosis via NBK/Bik}

\subsection{INTRODUCTION}

Autophagy is an evolutionarily conserved process by which damaged organelles and unneeded proteins are degraded by lysosomes to maintain intracellular homeostasis and to recycle cellular nutrients. While autophagy can promote cell death (16), in most cases it is cytoprotective and contributes to drug resistance (25). In response to chemotherapeutic agents, apoptosis (Type I) and autophagy (Type II) represent two major forms of programmed cell death (34). Autophagy and apoptosis share molecular regulatory mechanisms governed by Bcl-2 family proteins $(34,50)$. Specifically, Bcl-2/Bcl-xL prevent both apoptosis and autophagy by sequestering different BH3-only proteins (e.g., pro-apoptotic Bim, Bid (10), and pro-autophagic Beclin-1 (35,43)). As a result, antagonism of Bcl-2/Bcl-xL function releases and activates these BH3-only proteins, leading to apoptosis and autophagy respectively (6). While apoptosis represents a well-established mechanism of action of conventional and targeted anti-cancer agents (34), autophagy may play both positive and negative roles in tumorigenesis and cancer treatment $(56,57)$. Consequently, whether autophagy should be inhibited or activated remains the subject of debate. Accordingly, both autophagy inhibitors and inducers are currently undergoing clinical evaluation (1).

Protection of cells from injury by harmful macromolecules or damaged organelles through autophagy as a quality control (QC) mechanism $(1,33)$ involves sequestration and transport of cellular constituents to lysosomes for degradation (19). Autophagy is initiated by phagophore formation (initiation/nucleation stage), followed by the development of a crescent-shaped double 
membrane that expands and fuses to form a double-membrane vesicle known as an autophagosome (elongation stage). The autophagosome then fuses with lysosomes to form autolysosomes (maturation stage), resulting in degradation of vacuolar content (19). Recent evidence indicates that autophagy is a more selective process than originally thought $(13,14,32)$. Selective autophagy depends upon binding of substrates to the inner surface of the growing phagophore (22), referred to as cargo loading (55), a process mediated by adaptor proteins (29) associated with both substrate (cargo recognition) and lipidated LC3 anchored to the phagophore $(26,49)$. p62, also known as sequestosome 1 (SQSTM1), is selectively degraded by autophagy $(5,21)$, and serves as a key cargo adaptor for degradation of ubiquitinated substrates $(5,15,30)$ (45). Thus, p62 plays a central role in selective autophagy involving clearance of malfolded (e.g., unfolded or misfolded) proteins (26,30), protein aggregates/aggresomes (5), ubiquitin-labeled peroxisome (23), and Parkin-labeled mitochondria (15).

Inefficient autophagy resulting from cargo recognition failure has recently been implicated in Huntington's disease (44), a neurodegenerative disorder caused by macroautophagy malfunction and accumulation of the neurotoxic Huntington's protein (htt) (44,59). Inefficient autophagy has been defined as autophagy in which autophagic vacuoles fail to trap cytosolic cargo, despite their formation at normal or even enhanced rates and adequate lysosomal elimination (44). In this context, the autophagic adaptor protein SQSTM1/p62 acts to recognize and link, through binding to LC3, ubiquitinated protein aggregates to autophagosomes, a cargo-loading process necessary for lysosomal degradation during selective autophagy. We therefore hypothesized that targeting the cargo-loading protein p62 in neoplastic cells might lead to cargo loading failure and as a consequence, inefficient autophagy, which could be exploited to promote apoptosis. 


\subsection{MATERIALS AND MATHODS}

\subsubsection{Cells and reagents}

Human multiple myeloma U266 and RPMI8226 cells were obtained from ATCC and maintained as before (10), both of which were authenticated (Basic STR Profiling Service, ATCC $^{\circledR} 135-\mathrm{X}$ ) by ATCC before this study was completed. Bortezomib-resistant cells (PS-R) were generated by continuously culturing U266 cells in increasing concentrations of bortezomib (beginning at $0.5 \mathrm{nM}$ and increasing in stepwise increments of $0.2 \mathrm{nM}$ ) until 20nM, and maintained in medium containing 15nM bortezomib. U266/Mcl-1, U266/Bcl-2, RPMI8226/BclxL, and U266/DN-caspase 9 cells were established by stably transfecting human full-length Mcl1, Bcl-2, Bcl-xL cDNA, or dominant-negative caspase 9 (287 cysteine $\rightarrow$ alanine), respectively. All experiments utilized logarithmically growing cells $\left(3-5 \times 10^{5}\right.$ cells/ml). Wild-type and p62 gene knockout mouse embryonic fibroblasts (MEFs), as well as pEGFP-p62 plasmid, were kindly provided by Dr. Jorge Moscat (Sanford-Burnham Medical Research Institute) (36).

The pan-BH3-mimetic GX015-070 (GX, obatoclax) was provided by Teva Pharmaceuticals (North Wales, PA) in association with the Cancer Treatment and Evaluation Program (CTEP) of the NCI. The pan-Cdk inhibitors flavopiridol (alvocidib; Sanofi-Aventis, Bridgewater, NJ) and SCH727965 (dinaciclib; Merck, Whitehouse Station, N.J.) were provided by the NCI. The proteasome inhibitor bortezomib (VELCADE®) was provided by Millennium (Cambridge, MA). Cycloheximide (CHX) and MG-132 were purchased from Sigma (St. Louis, MO) and Calbiochem (San Diego, CA) respectively, dissolved in DMSO, aliquoted, and stored at $-20^{\circ} \mathrm{C}$. In all experiments, final DMSO concentrations did not exceed $0.1 \%$. If not indicated specifically, time for drug treatment was $24 \mathrm{~h}$. 


\subsubsection{Flow cytometry}

The extent of apoptosis was evaluated by flow cytometry utilizing annexin V-FITC/PI (10).

Briefly, $1 \times 10^{6}$ cells were stained with annexin V-FITC (BD PharMingen, San Diego, CA) and 5 $\mu \mathrm{g} / \mathrm{ml}$ propidium iodide (PI; Sigma) in $1 \mathrm{x}$ binding buffer for $15 \mathrm{~min}$ at room temperature in the dark. Samples were then analyzed by BD Biosciences FACSCalibur flow cytometry (BectonDickinson, San Jose, CA) within $1 \mathrm{~h}$ to determine the percentage of apoptotic (annexin V positive) cells.

\subsubsection{TUNEL analysis}

In some cases, cytospin slides were stained for TUNEL using an In Situ Cell Death Detective Kit (fluorescein; Roche, Penzberg, Germany) as per the manufacturer's instructions. Images were captured using an Olympus BX40 fluorescence microscope at 20x/0.50 (Olympus America Inc, Center Valley, PA) and a CE digital camera (Alpha Innotech Cor., San Leandro, CA) with a RS Image software Version 1.7.3. (Roper Scientific Photometrics, Tucson, AZ).

\subsubsection{Immunofluorescence}

Ubiquitin-positive protein aggregates were examined by immunofluorescence using an antiubiquitin monoclonal antibody (Cell Signaling, Beverly, MA) as reported earlier (8). Images were captured using a Zeiss LSM 700 confocal laser-scanning microscope.

\subsubsection{Autophagy analysis}

A) Whole cell lysates were prepared and subjected to immunoblotting analysis using antiLC3 antibody (Novus, Littleton, CO) to monitor LC3 processing from LC3-I to LC3-II. To 
exclude the possibility that increases in LC3-II levels may reflect reduced autophagic degradation rather than enhanced induction, analysis of autophagic flux was performed using bafilomycin A1 as previously described $(31,46)$. B) An expression construct encoding the fusion protein EGFP-LC3B (Addgene plasmid 11546) was obtained from Addgene (Cambridge, MA) (24). Autophagy was visualized in U266 and PS-R cells by stable transfection with pEGFPLC3B followed by observation of LC3 puncta using a confocal microscope. C) EM was employed to analyze ultrastructural morphology of autophagy using a Jeol JEM-1230 transmission electron microscope. D) Autophagic flux was validated by transient transfection of cells with a pBABE-puro mCherry-EGFP-LC3B plasmid (Addgene plasmid 22418) (48), followed by observation of autophagosomes (mCherry and GFP double positive, yellow) and autolysosomes (mCherry only, red) using a confocal microscope.

\subsubsection{Lysosome analysis}

To monitor lysosome mass and number, cytospin slides were stained for lysosomes using a LysoTracker Probe (Molecular Probes by Life Technology, Carsbad, CA) as per the manufacturer's instructions. Images were captured using a confocal microscope.

\subsubsection{Filter trap (retardation) assay}

Protein aggregates were assessed using a filter trap assay as described previously $(17,33)$. Briefly, cells were lysed in 1xPBS containing $1 \mathrm{mM}$ PMSF by sonication for $1 \mathrm{~min}$. Total protein was quantified using Coomassie Protein Assay Reagent (Pierce, Rockford, IL). Equal amounts of protein $(10 \mu \mathrm{g})$ were diluted in $1 \%$ SDS and filtered through a cellulose acetate membrane $(0.2$ $\mu \mathrm{M}$ pore size, Whatman, Dassel, Germany) using a dot microfiltration (BioRad, Hercules, CA) 
or slot blotting apparatus (Hoefer, San Francisco, CA). The membrane was washed with 1x PBS containing $1 \%$ SDS, followed by blocking with 5\% skim milk in 1x PBS. The SDS-insoluble aggregates trapped on the filter were probed with anti-ubiquitin (Cell Signaling, Beverly, MA), anti-p62 (Santa Cruz Biotech, Santa Cruz, CA), or anti-Bik (ProSci, Poway, CA), respectively.

\subsubsection{Quantitative real-time PCR (qPCR)}

qPCR analysis using TaqMan Gene Expression Assays and 7900HT Real-Time PCR System (Applied Biosystems, Foster City, CA) were performed to quantify mRNA levels of human NBK/Bik expression (10). Briefly, total RNA was isolated using TRIZOL Reagent (Invitrogen, Carlsbad, CA) as per the manufacturer's instructions. Genomic DNA was digested by DNase I (Amplification Grade, Invitrogen). cDNA was synthesized from $1 \mu \mathrm{g}$ of total RNA using a High Capacity cDNA Reverse Transcription Kit (Applied Biosystems). $2 \mu$ of cDNA was employed for qPCR assays (TaqMan Gene Expression Assays). Assay IDs for NBK/Bik and SQSTM1/p62 were Hs00154189_m1 and Hs01061917_g1. Reference for quantitation was human $\beta$-actin and GAPDH (Pre-Developed TaqMan Assay Reagents Control Kit, Applied Biosystems). Data were analyzed using SDS 2.3 software.

\subsubsection{Immunoblotting}

Whole-cell pellets were lysed by sonication in $1 \times$ sample buffer [62.5 mm Tris base $(\mathrm{pH} 6.8)$, $2 \%$ SDS, $50 \mathrm{~mm}$ DTT, $10 \%$ glycerol, $0.1 \%$ bromphenol blue, and $5 \mu \mathrm{g} / \mathrm{ml}$ each of chymostatin, leupeptin, aprotinin, pepstatin, and soybean trypsin inhibitor] and boiled for $5 \mathrm{~min}$. Total protein was quantified using Coomassie Protein Assay Reagent (Pierce, Rockford, IL). Equal amounts of protein $(30 \mu \mathrm{g})$ were subjected to immunoblotting following procedures previously described 
(10). Where indicated, the blots were re-probed with antibodies against $\beta$-actin (Sigma) or $\alpha$ tubulin (Oncogene, La Jolla, CA) to ensure equal loading and transfer of proteins. The following antibodies were used as primary antibodies: anti-Bik and anti-Bim (ProSci); anti-caspase 3, antiMcl-1, anti-cytochrome C (BD PharMingen); anti-cleaved caspase 3 (Asp175), anti-cleaved PARP (Asp214), anti-SQSTM1/p62, anti-ubiquitin, anti-Bcl-xL, and anti-Beclin-1, (Cell Signaling); anti-human Bcl-2 oncoprotein (DAKO, Carpinteria, CA); anti-PARP (Biomol, Plymouth Meeting, PA); anti-Bik, anti-LAMP2, anti-ULK1, anti-ATG5, anti-AIF, anti-Bax, and anti-Bak (Santa Cruz Biotech, Santa Cruz, CA).

\subsubsection{Immunoprecipitation}

(Co-)immunoprecipitation analysis was performed to evaluate ubiquitination of NBK/Bik or interactions of Beclin-1 with Bcl-2, Bcl-xL and Mcl-1 (10). For these studies, CHAPS buffer (150 mM NaCl, $10 \mathrm{mM}$ HEPES pH7.4, protease inhibitors, and 1\% CHAPS) was employed to avoid artifactual associations reported with buffers containing other detergents (e.g., NP-40 or Triton X-100). Briefly, cells were lysed in CHAPS buffer and $200 \mu \mathrm{g}$ of protein per condition were incubated with $1 \mu \mathrm{g}$ anti-Bik (Santa Cruz Biotech), anti-Bcl-2 (DAKO), anti-Bcl-xL (Cell Signaling), or anti-Mcl-1 (BD PharMingen) overnight at $4^{\circ} \mathrm{C} .20 \mu \mathrm{l} /$ condition of Dynabeads (Dynal, Oslo, Norway) were then added and incubated for an additional $4 \mathrm{~h}$. After washing, the bead-bound protein was eluted by vortexing and boiling in $20 \mu \mathrm{l} 1 \mathrm{x}$ sample buffer. The samples were separated by SDS-PAGE and subjected to immunoblotting analysis as described above. Anti-ubiquitin (Cell Signaling) and anti-Beclin-1 (Santa Cruz) were used as primary antibodies, respectively. 


\subsubsection{Endoplasmic reticulum (ER) isolation}

The ER fraction was isolated from cultured cells using an Endoplasmic Reticulum Isolation Kit (Sigma) as per the manufacturer's instructions, and subjected to immunoblotting using antiBik antibody (ProSci) to determine subcellular localization of NBK/Bik. The blots were reprobed with antibodies against calnexin (an ER membrane marker, Abcam, Cambridge, MA) as a loading control.

\subsubsection{Mitochondrion isolation}

The mitochondrial fraction was isolated from cultured cells using a Mitochondria Isolation Kit (Sigma) as per the manufacturer's instructions, and subjected to immunoblotting using antiBik and anti-Bim antibodies (ProSci) to compare subcellular localization of Bik and Bim. The blots were re-probed with antibodies against Bak (a mitochondrial membrane marker, Santa Cruz) as a loading control.

\subsubsection{RNA interference}

SureSilencing shRNA plasmids (neomycin resistance) were purchased from SABioscience (Frederick, MD), which includes SQSTM1 (NM_003900; clone ID \#4, ACTGGACCCATCTGTCTTCAA), Ulk1 (NM_003565; clone ID \#3, TACACGCCATCTCCTCAAGTT), Bik (NM_001197; clone ID \#3 CACACTTAAGGAGAACATAAT), Atg5 (NM_004849; clone ID \#3, TCATGGAATtGAGCCAATGTT), BECN1 (NM_003766; clone ID \#2, CCATGCTCTGGCCAATAAGAT), Cdk9 (NM_001261; $\quad$ clone ID \#1, GGTCAAGTTCACGCTGTCTGA), CCNT1 (NM_001240; clone ID \#1, 
TCGTGTCCCTCATTCGAAACT), and scrambled sequence control (GGAATCTCATTCGATGCATAC). U266 cells were stably transfected with these constructs by using an Amaxa Nucleofector device with Cell Line Specific Nucleofector Kit C (Amaxa $\mathrm{GmbH}$, Cologne, Germany) as per the manufacturer's instructions (10). The Lentiviral Particle Gene Silencers construct (sc-29390-V) encoding shRNA targeting human Lamp2 and Control Lentiviral Particles were purchased from Santa Cruz Biotech (Santa Cruz, CA) and used to transduce RPMI8226 cells. For all shRNA experiments, four constructs encoding shRNAs designed specifically against different sequence of the target gene of interest were obtained and tested before use. Subsequently, at least two constructs displaying the most pronounced knockdown of target expression were selected, validated, and employed in experiments. Stable clones with down-regulated expression of the targeted genes were selected with $400 \mu \mathrm{g} / \mathrm{ml}$ G418 or 2 $\mu \mathrm{g} / \mathrm{ml}$ puromycin.

\subsubsection{Animal studies}

The studies were approved by the Virginia Commonwealth University IACUC, and performed in accordance with the U.S. Department of Agriculture and Department of Health and Human Services, and the NIH. Three mouse models were employed in this study as reported previously (10), including a) athymic NCr-nu/nu mice (Jackson Laboratories, Bar Harbor, ME) were subcutaneously inoculated in flank with $5 \times 10^{6}$ RPMI8226 cells; b) NOD/SCID/gamma (NSG) mice (Jackson Laboratories) were subcutaneously inoculated in two side flanks with $1 \times 10^{7} \mathrm{U} 266$ cells expressing Bik (right) or scrambled sequence shRNA (left); and c) NSG mice were intravenously injected with $5 \times 10^{6}$ U266 cells stably expressing luciferase. GX15-070 was freshly reconstituted with 5\% Dextrose for Injection (USP) and administrated via intramuscular 
or intraperitoneal (i.p.) injection. FP in DMSO was diluted in $0.9 \%$ saline and administrated via i.p. injection. Control animals were injected with equal volumes of vehicle. Mice were monitored for tumor growth every other day visually or with the use of an IVIS 200 imaging system (Xenogen Corporation, Alameda, CA).

\subsubsection{Statistical analysis}

Values represent the means $\pm \mathrm{SD}$ for at least three independent experiments performed in triplicate. The significance of differences between experimental variables was determined using a two-tailed Student's t test. $P<0.05$ was considered significant.

\subsection{RESULTS}

\subsubsection{Cdk inhibitors convert BH3 mimetic-induced autophagy to apoptosis}

BH3-mimetics induce autophagy by dissociating Beclin-1 from Bcl-2 (43), whereas coadministration of Cdk (cyclin-dependent kinase) inhibitors which inhibit transcriptional Cdks (e.g., Cdk9) strikingly increase apoptosis (10). The question of whether Cdk inhibitors might affect BH3-mimetic-induced autophagy in human multiple myeloma (MM), a disease of malignant plasma cells which rely on clearance of excess immunoglobulins to maintain homeostasis necessary for survival (20), was first examined. The BH3-mimetic GX-015-070 (GX, also known as obatoclax), as well as the anti-MM agent bortezomib, which is known to induce autophagy in MM cells (20), sharply induced autophagy, reflected by a striking increase in LC3-II, a marker of autophagy (31,46,51), in U266 cells (Fig. 1A, left), their bortezomibresistant counterparts (PS-R, Supplemental Fig. S1A), and RPMI8226 cells (Supplemental Fig. S1B). Consistent with these findings, exposure to GX also resulted in a marked increase in GFPLC3 puncta (Fig. 1A, right). Significantly, this phenomenon was accompanied by pronounced 
activation of apoptosis, reflected by cleavage of caspase 3, 8, 9 (Supplemental Fig. S1C), and PARP (Fig. 1A, Supplemental Fig. S1A and S1B), as well as increased TUNEL positivity (Fig. 1B). Autophagy induction was also associated with release of Beclin-1 from Bcl-2 and Bcl-xL (Supplemental Fig. S1D). The Cdk inhibitor flavopiridol (FP) did not affect GX-induced LC3-II expression, but clearly increased GFP-LC3 puncta when compared to GX alone (Fig. 1A and Supplemental Fig. S1A). Moreover, analysis of autophagic flux demonstrated that when autophagic degradation was blocked by bafilomycin A1, an agent that inhibits the vacuolar type H+-ATPase complex necessary for lysosomal acidification $(31,46)$, treatment with either GX or GX + FP further increased LC3-II levels in both U266 (Fig. 1C, $P<0.05$ vs bafilomycin A1 alone). Furthermore, co-administration of GX with FP increased both autophagosome (yellow) and autolysosome (red) in U266 cells transiently transfected with mCherry-GFP LC3 (Fig. 1D). These findings support the notion that FP does not affect autophagic flux (including autophagosome formation and maturation) in cells exposed to GX.

To explore further the role of FP in responses of MM cells to GX, cells were examined by electron microscopy (EM, Fig. 2A). GX induced a striking increase in double-membraned autophagosomes and autolysosomes containing identifiable cellular organelles such as deformed mitochondria (high magnification, lower panel). Notably, whereas FP/GX co-treatment modestly increased the number of vacuolated structures, higher magnification revealed that most vesicles were double-membraned autophagic vacuoles (AVs) which appeared empty (i.e., exhibiting clear content). The double membrane and clear content of the cytosolic vacuoles were analogous to phenomena recently described in Huntington's disease neurons (44), characterized by accumulation of the neurotoxic htt protein due to cargo recognition failure responsible for inefficient autophagy $(3,44)$. 


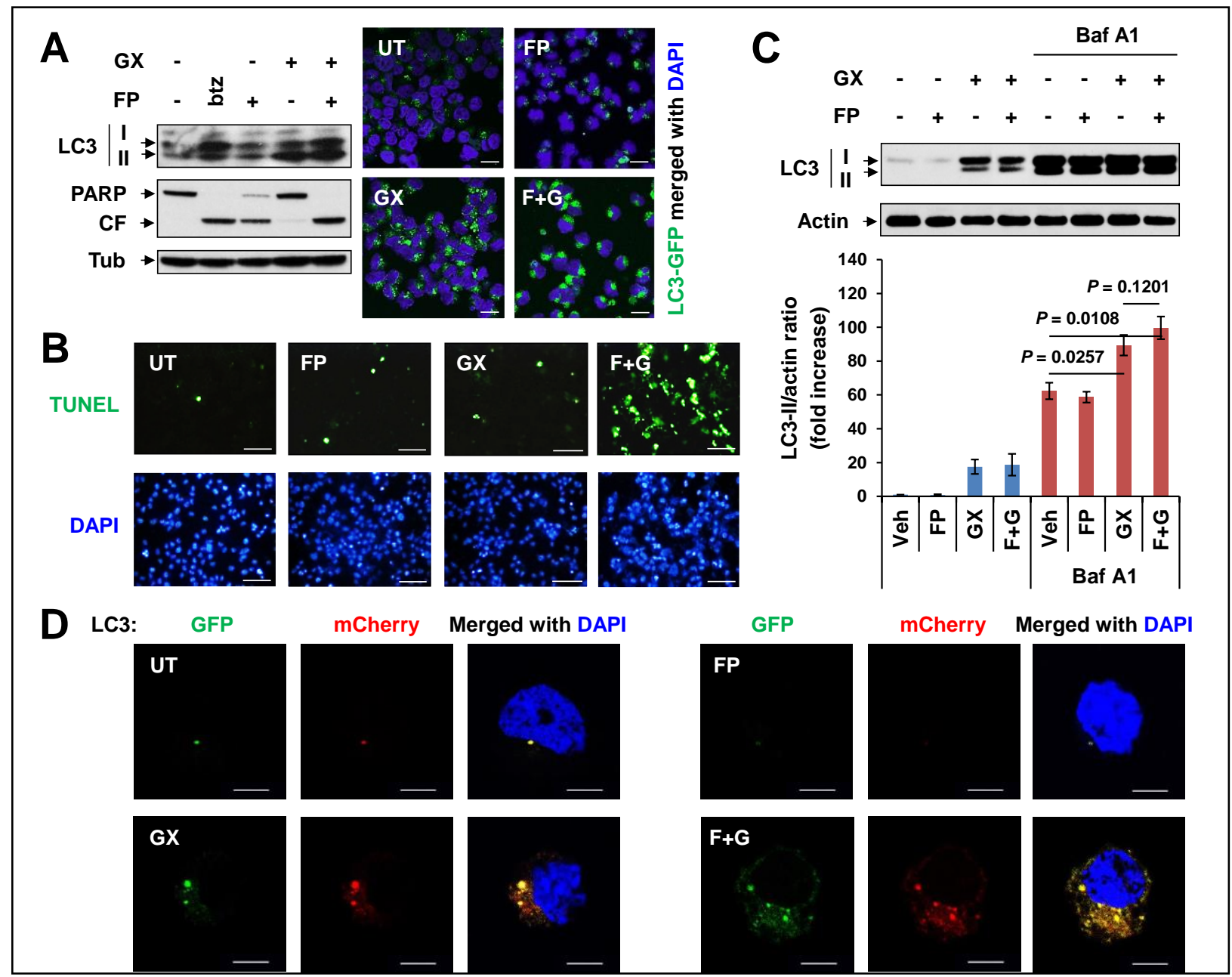

Figure 1. BH3-mimetics induce autophagy and apoptosis in the presence of Cdk inhibitors. (A) Human myeloma U266 cells were exposed to $500 \mathrm{nM}$ GX015-070 (GX) +/-100 nM flavopiridol (FP) or $4 \mathrm{nM}$ bortezomib (btz) as a positive control, followed by immunoblotting analysis for LC3 $(16 \mathrm{~h})$ and PARP cleavage $(24 \mathrm{~h})$. CF, cleaved fragment. In parallel, U266 cells were stably transfected with pEGFP-LC3, followed by exposure (16 h) to $500 \mathrm{nM} \mathrm{GX} \mathrm{+/-} 100$ $\mathrm{nM}$ FP, and then analyzed for GFP-LC3 puncta by confocal microscopy (scale bar $=10 \mu \mathrm{m})$. (B) U266 cells were exposed ( $24 \mathrm{~h})$ to $500 \mathrm{nM} \mathrm{GX} \mathrm{+/-} 100 \mathrm{nM}$ FP, followed by TUNEL staining using fluorescence microscopy (scale bar $=40 \mu \mathrm{m})$. (C) U266 cells were treated $(16 \mathrm{~h})$ with 500 $\mathrm{nM} \mathrm{GX} \mathrm{+/-} 100 \mathrm{nM}$ FP in the presence or absence of $10 \mathrm{nM}$ bafilomycin A1 (Baf A1), followed by analysis of autophagic flux using immunoblotting analysis for LC3 (upper). LC3-II was quantified relative to actin (lower). Results represent fold increase over vehicle-treated control (means \pm SD for three experiments). (D) Alternatively, U266 cells were transiently transfected with a pBABE-puro mCherry-EGFP-LC3B plasmid, After $6 \mathrm{~h}$, cells were treated with $500 \mathrm{nM}$ $\mathrm{GX}+/-100 \mathrm{nM}$ FP for additional $16 \mathrm{~h}$, followed by analysis of autophagic flux using confocal microscopy $($ scale bar $=5 \mu \mathrm{M})$.

To verify whether increased empty AVs in cells co-exposed to GX and FP reflect inefficient autophagy, a filter-trap assay was performed to assess the efficiency of autophagy in removing 
intracellular protein aggregates $(17,33)$. Co-treatment with GX and FP strikingly increased detergent-insoluble, ubiquitin-positive protein aggregates trapped on cellulose acetate filter membranes (Fig. 2B), consistent with diminished clearance of cytosolic components via selective autophagy (5,17). Moreover, both FP and another Cdk inhibitor SCH727965 (dinaciclib) (27) also clearly increased accumulation of polyubiquitinated proteins in GX-treated cells (Fig. 2C). Moreover, immunofluorescence staining using an anti-ubiquitin antibody further demonstrated that co-treatment with GX and FP resulted in a marked increase in ubiquitinpositive protein aggregates (Fig. 2D). Interestingly, LysoTracker staining revealed that GX also dramatically increased lysosome mass and number (Fig. 2E), presumably reflecting enhanced lysosome biogenesis required for increased autophagy. Nevertheless, co-administration of FP altered neither increased lysosome mass or number in cells exposed to GX (Fig. 2E), nor expression of TFEB (Supplemental Fig. S1E), a transcription factor critical for coupling of autophagosome formation and lysosome biogenesis (52). These results argue against the possibility that accumulation of $\mathrm{AVs}$ and ubiquitinated protein aggregates stems from failure of autophagosome removal due to impaired lysosome biogenesis or autophagosome maturation, disruption of which has been linked to cell death (53). Together, these findings indicate that coadministering a Cdk inhibitor with an autophagy-inducing BH3-mimetic triggers inefficient autophagy characterized by an impaired ability of cells to clear ubiquitinated, malfolded proteins. 


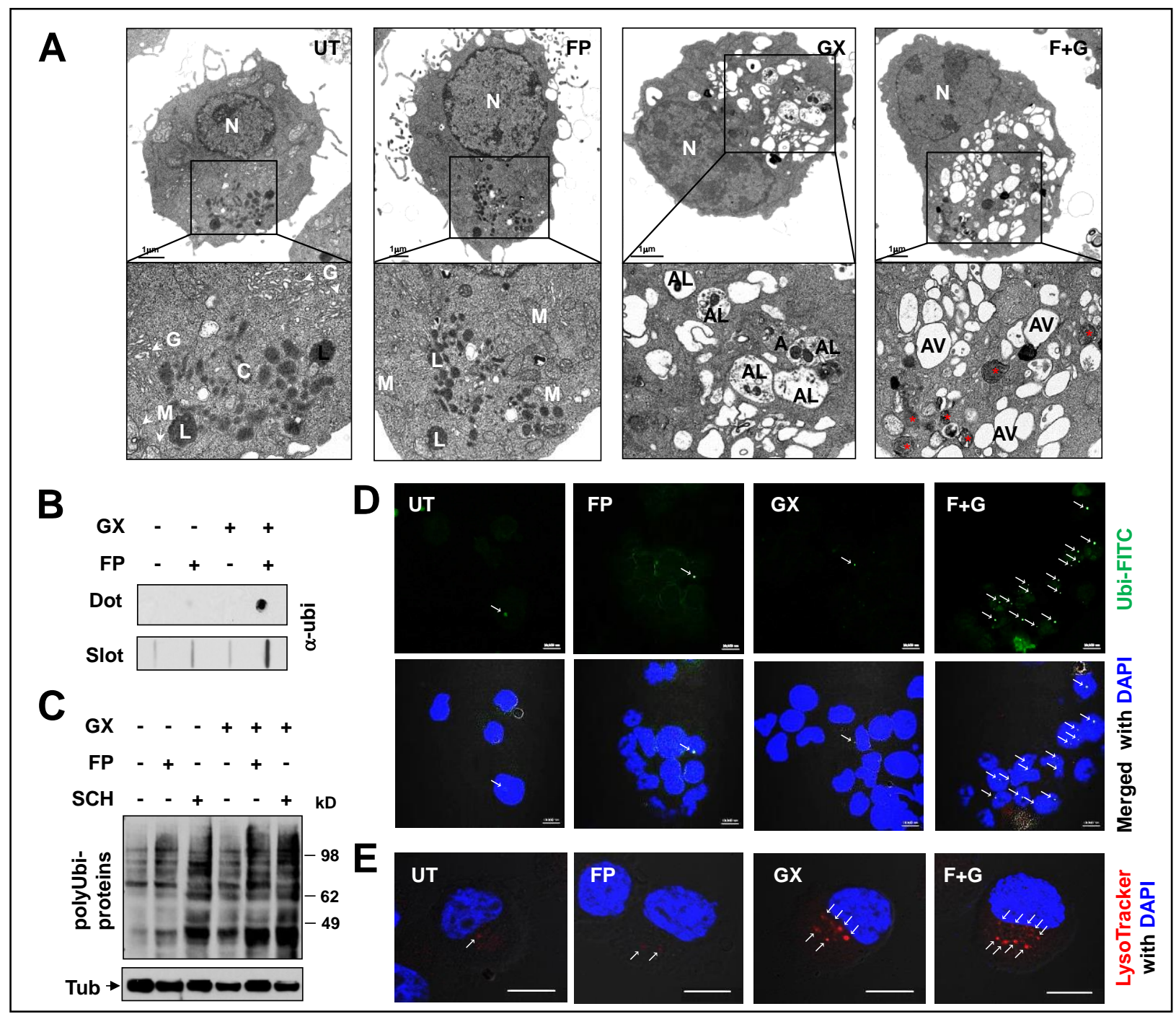

Figure 2. Co-treatment with BH3-mimetics and $\mathrm{Cdk}$ inhibitors results in inefficient autophagy. (A) U266 cells were exposed (16 h) to $500 \mathrm{nM} \mathrm{GX} \mathrm{+/-} 100 \mathrm{nM} \mathrm{FP}$, and then examined by electron microscopy (scale bar $=1 \mu \mathrm{m}$ ). N, nucleus; M, mitochondrion; L, lysosome; G, Golgi apparatus; C, centrosome; A, autophagosome; AL, autolysosome; AV, autophagic vacuoles with clear content (empty); *, deformed mitochondrion. (B) In parallel, a filter trap assay using dot or slot blot probed by anti-ubiquitin antibody ( $\alpha$-ubi) was performed to monitor intracellular accumulation of SDS-insoluble ubiquitin-positive protein aggregates. (C) U266 were treated $(16 \mathrm{~h}$ ) with $500 \mathrm{nM} \mathrm{GX} \mathrm{+/-} 100 \mathrm{nM}$ FP or $5 \mathrm{nM}$ SCH727965, after which immunoblotting analysis was performed to monitor accumulation of polyubiquitinated (polyUbi) proteins using anti-ubiquitin antibody. (D-E) Alternatively, cells were stained with anti-ubiquitin antibody to monitor intracellular ubiquitin-positive protein aggregates (arrow, D) or with LysoTracker to visualize lysosomes (arrow, E).

\subsubsection{Cdk inhibition blocks SQSTM1/p62 expression during BH3 mimetic-induced} autophagy 
As the adaptor protein p62 plays a key role in recognition and loading of cargo during selective autophagy (26), the time-course of p62 expression in cells exposed to GX $\pm \mathrm{FP}$ was monitored. Interestingly, protein levels of p62 varied at different intervals in untreated U266 cells (Supplemental Fig. S2A), presumably reflecting basal and spontaneous autophagy as observed in U266 cells expressing GFP-LC3 (Fig. 1A). GX triggered LC3 processing as early as 6h, accompanied by induction of p62 (Fig. 3A and Supplemental Fig. S2A), as reported previously (51). Quantification of immunoblots after exposure to GX (e.g., $500 \mathrm{nM}$ ) revealed that whereas LC3-II expression persisted for $48 \mathrm{~h}$ (Supplemental Fig. S2B), p62 levels fluctuated in a time-dependent manner over the entire exposure interval (Fig. 3B). As p62 itself undergoes autophagic degradation (21), p62 fluctuation reflects a dynamic balance between de novo synthesis versus elimination via autophagy $(28,47)$. Notably, FP markedly attenuated p62 expression induced by GX (Fig. 3A and 3B). Similar events were also observed in other human MM cells or when the pan-Cdk inhibitor SCH727965 was employed (Fig. 3C and Supplemental Fig. S2C). Moreover, quantitative PCR demonstrated that FP significantly blocked GX-induced p62 expression at the transcriptional level (Fig. 3D). Furthermore, inhibition of protein synthesis by cycloheximide (CHX) also blocked p62 induction by GX (Supplemental Fig. S2D). Together, these results indicate that FP inhibits de novo synthesis of $\mathrm{p} 62$ during autophagy.

To determine further whether Cdk inhibitors block p62 transcription due to inhibition of Cdk9, a key component of the positive transcription elongation factor $\mathrm{b}(\mathrm{P}-\mathrm{TEFb}$, a complex of Cdk9 and its partner cyclin T1 (12)), Cdk9 or cyclin T1 were knocked-down using the respective shRNAs. Cdk9 or cyclin T1 knock-down sharply reduced CTD phosphorylation of RNA polymerase II at serine 2 (Fig. 3E), an event specifically mediated by Cdk9 and required for mRNA elongation (12). Notably, GX failed to trigger p62 expression in these cells, while no 
effect on GX-induced LC3 processing was observed, consistent with results obtained employing pharmacologic Cdk inhibitors (Fig. 3A-3C). These findings indicate that Cdk9 inhibition blocks p62 expression but does not prevent autophagy induction in GX-treated cells.

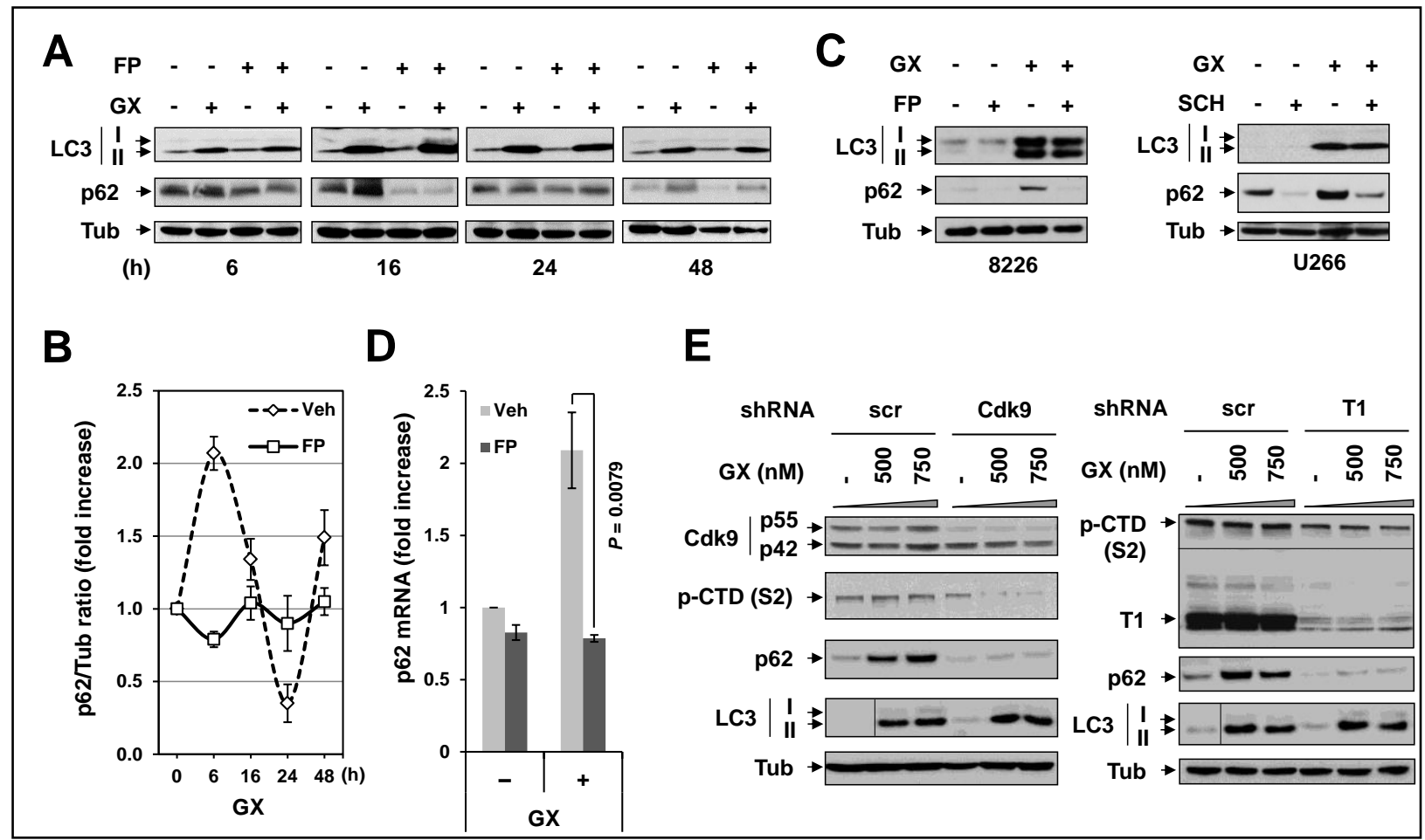

Figure 3. Cdk inhibition down-regulates SQSTM1/p62 but fails to affect LC3 processing during autophagy. (A) U266 cells were treated with $500 \mathrm{nM} \mathrm{GX} \mathrm{+/-} 100 \mathrm{nM}$ FP for 6, 16, 24, and $48 \mathrm{~h}$, after which immunoblotting analysis was performed to monitor LC3 processing and p62 expression. (B) Blots of p62 were quantified relative to tubulin (Tub, fold increase over vehicle-treated control; results represent means \pm SD for three experiments). (C) RPMI8226 and U266 cells were treated $(16 \mathrm{~h})$ with GX $(500 \mathrm{nM})+/-$ FP $(100 \mathrm{nM})$ or SCH727965 (5 nM), after which LC3-II and p62 levels were determined by immunoblotting analysis. (C) U266 cells treated $(6 \mathrm{~h})$ with $500 \mathrm{nM} \mathrm{GX}+/-100 \mathrm{nM} \mathrm{FP}$, after which qPCR was used to monitor p62 mRNA levels (fold-increase over vehicle-treated control; means \pm SD for three experiments). (D) U266 cells were stably transfected with constructs encoding shRNA targeting Cdk9 (left) or its partner cyclin $\mathrm{T} 1$ (right), which form the $\mathrm{P}-\mathrm{TEFb}$ complex, and a scrambled sequence as a negative control. They were then exposed $(16 \mathrm{~h})$ to $\mathrm{GX}$, followed by immunoblotting analysis to monitor expression of Cdk9 (p42 and p55 isoforms) or cyclin T1, CDT phosphorylation (serine 2) of RNA polymerase II, LC3 processing, and p62 expression.

\subsubsection{SQSTM1/p62 down-regulation leads to cargo loading failure during autophagy in} association with increased cell death 
The functional role of p62 down-regulation by Cdk9 inhibition in autophagy induced by GX was then examined. First, the effects of disrupting autophagy by pharmacologic or genetic approaches on p62 expression were tested in cells co-exposed to GX/FP. As anticipated, spautin1, an inhibitor of the ubiquitin-specific peptidases USP10 and USP13 which target the Beclin-1 subunit of Vps34 complexes (38), and 3-methyladenine [3-MA], which blocks autophagosome formation via inhibition of type III PI-3K (7), clearly reduced LC3 processing in cells co-treated with GX/FP (Fig. 4A and Supplemental Fig. S2E). These events were accompanied by accumulation of p62, consistent with evidence that p62 is primarily turned over through autophagy (5,21). Significantly, GX/FP co-treatment dramatically down-regulated p62 expression under these conditions (Fig. 4A and Supplemental Fig. S2E). Similar phenomena were observed when autophagy was genetically disrupted by shRNA at early stages (e.g., Ulk1 [Fig. 4B], which acts in the Atg1/Ulk complex essential for autophagy initiation (19)), or late stages of autophagy (e.g., Lamp2 [Supplemental Fig. S2F], a lysosome membrane protein essential for autophagosome maturation (19)).

Second, the effects of p62 on cargo loading were then examined using a filter trap assay employing antibodies directed against p62 or ubiquitin respectively. GX induced a marked increase in p62 bound to protein aggregates trapped on the membrane (Supplemental Fig. S2G, upper), an event required for loading of cargo to autophagosomes (22). Importantly, this process was substantially diminished by FP or SCH727965, accompanied by the marked intracellular accumulation of ubiquitin-positive protein aggregates (Fig. $\mathbf{2 B}$ and $\mathbf{2 D}$ ) as well as by accumulation of polyubiquitinated proteins (Fig. 2C), collectively indicating autophagy dysfunction due to cargo loading failure. Moreover, accumulation of polyubiquitinated proteins (Fig. 4C) or ubiquitin-positive protein aggregates (Fig. 4D) was also observed in GX-treated 
cells in which p62 was directly knocked down by shRNA, compared to the scrambled shRNA control, whereas GX-induced LC3 processing was modestly reduced. Similarly, accumulation of ubiquitin-positive protein aggregates was also observed in GX-treated cells transfected with shRNA against either Cdk9 (Fig. 4D) or its partner cyclin T1 (Fig. 4D), but not Ulk1 (Fig. 4D). However, in contrast to cells transfected with scrambled shRNA control, co-administration of either FP or SCH727965 failed to increase further accumulation of ubiquitin-positive protein aggregates in these cells (Fig. 4D), presumably because p62 up-regulation was already blocked directly by p62 shRNA or indirectly via Cdk9 inhibition/down-regulation (e.g., by Cdk9 or cyclin T1 shRNA).

Third, following exposure to GX for 16 h, p62 or Cdk9 knockdown cells were examined by electron microscopy (Fig. 4E). Consistent with observations in parental cells (Fig. 2A), GX induced a marked increase in autophagosomes/autolysosomes containing identifiable cellular organelles in U266 cells transfected with scrambled shRNA control. Notably, whereas p62 knockdown modestly reduced the number of AVs after GX treatment, most AVs exhibited clear content in cells transfected with either Cdk9 or p62 shRNA (Fig. 4E), analogous to cells coexposed to GX and FP (Fig. 2A). In contrast, knockdown of Cdk9 did not affect autophagic flux following GX treatment, manifested by equivalent increases in both autophagosomes (yellow, mCherry + GFP) and autolysosomes (red, mCherry only) compared to scramble shRNA controls (Fig. 5A). Notably, similar phenomena were also observed in p62 knockout (ko) MEFs (36), compared to wild type (wt) MEFs (Fig. 5B). 


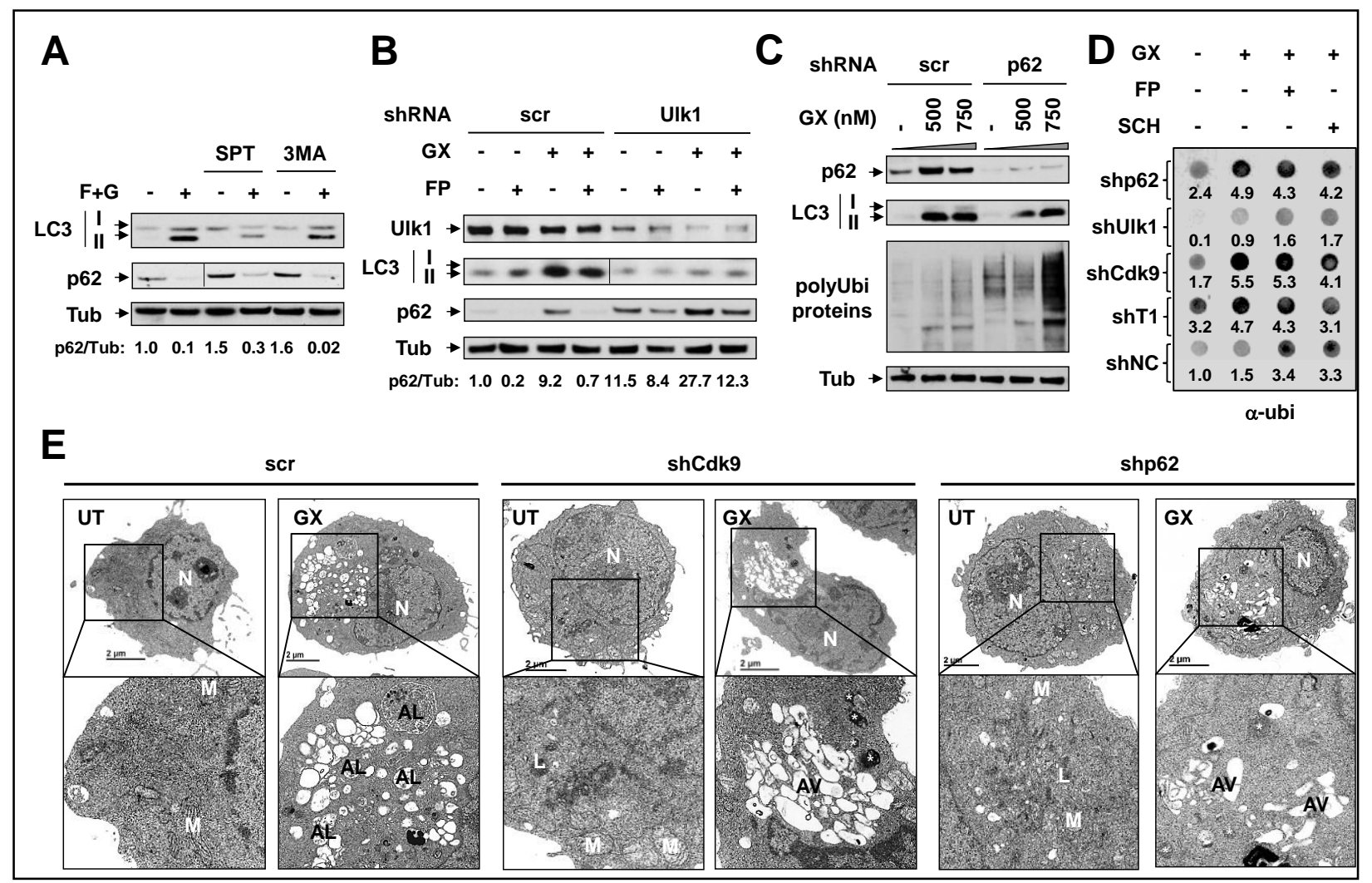

Figure 4. SQSTM1/p62 down-regulation results in cargo loading failure and inefficient autophagy. (A) U266 cells were exposed (16 h) to $100 \mathrm{nM} \mathrm{FP}+500 \mathrm{nM} \mathrm{GX}$ in the presence or absence of $7.5 \mu \mathrm{M}$ spautin-1 (SPT)or $500 \mu \mathrm{M}$ 3-methyladenine (3-MA), after which LC3 processing and p62 expression were monitored by immunoblotting analysis. Values indicate quantification of p62 relative to tubulin (fold-increase over untreated control). (B) U266 cells were stably transfected with constructs encoding shRNA targeting Ulk1 or scrambled sequence as a negative control. Cells were then exposed (16 h) to $500 \mathrm{nM} \mathrm{GX} \mathrm{+/-} 100 \mathrm{nM} \mathrm{FP}$, followed by immunoblotting analysis using the indicated antibodies. Values indicate quantification of p62 relative to tubulin (fold-increase over untreated control). (C) U266 cells were stably transfected with constructs encoding shRNA targeting p62 or scrambled sequence, and then treated $(16 \mathrm{~h})$ with the indicated concentrations of $\mathrm{GX}(\mathrm{nM})$, followed by immunoblotting analysis for p62 expression, LC3 processing, and intracellular accumulation of polyubiquitinated proteins. (D) U266 cells stably transfected with shRNA directed against p62, Ulk1, Cdk9, cyclin T1, or scrambled sequence as control were exposed (16 h) to $500 \mathrm{nM} \mathrm{GX}$ in the presence or absence of

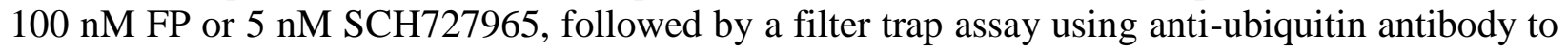
monitor ubiquitin-positive protein aggregates. Values indicate quantification of the amount of total ubiquitin-positive proteins in SDS-insoluble aggregates (values represent fold- increases over untreated controls). (E) U266 cells stably transfected with shRNA directed against Cdk9, p62, or scramble sequence as control were exposed (16 h) to $500 \mathrm{nM} \mathrm{GX}$, and examined by electron microscopy (scale bar $=2 \mu \mathrm{m})$.

Finally, transient expression of GFP-tagged p62 (36), but not GFP only, significantly rescued cells from increased GX lethality in U266 cells transfected with p62 shRNA (Fig. 5C). 
Consistent with increased GX sensitivity of p62 knockdown U266 cells, p62 ko MEFs were also significantly more sensitive to GX compared to wt MEFs (Fig. 5D). Importantly, whereas FP strikingly potentiated GX lethality in wt MEFs, it failed to do so in p62 ko MEFs, presumably due to the inability of FP to down-regulate p62 in p62 ko cells. Furthermore, transient expression of p62 significantly rescued p62 ko MEFs from enhanced GX lethality, while at the same time partially restoring the ability of FP to potentiate GX-mediated cell death (Fig. 5E). Together, these findings argue that inhibition of p62 expression (e.g., by FP) during BH3-mimetic-induced autophagy results in an inefficient form of autophagy characterized by failure of loading cargo (e.g., malfolded proteins) into autophagosomes, accompanied by significantly increased sensitivity to $\mathrm{BH} 3$-mimetics. 


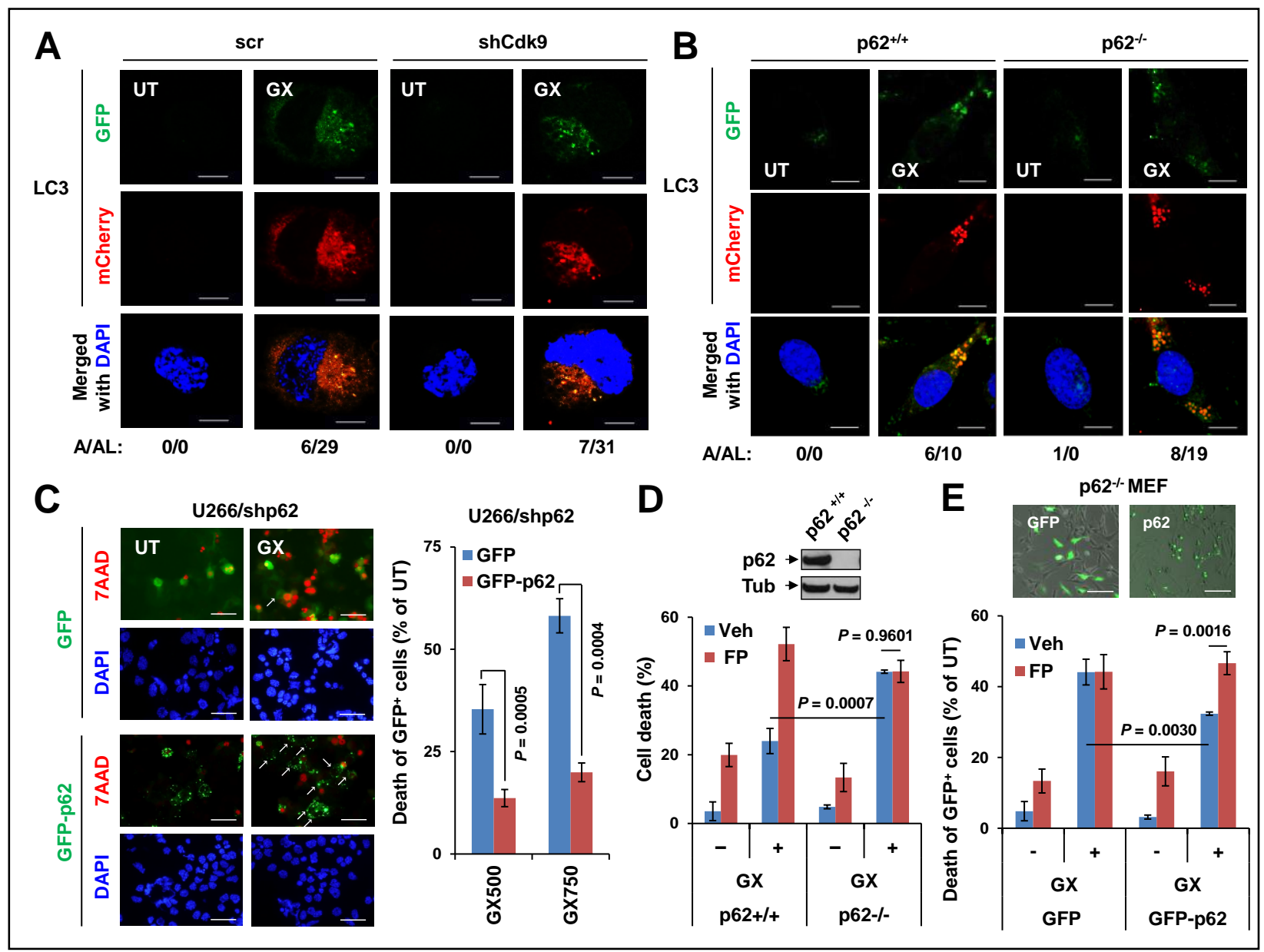

Figure 5. Expression of SQSTM1/p62 diminishes the increased lethality of BH3-mimetics in p62-defective cells. (A) U266 cells stably transfected with shRNA directed against Cdk9 or scrambled sequence (A), or wild-type $\left(\mathrm{p} 62^{+/+}\right.$) and p62 knock-out (ko, p62 $2^{-/-}$) MEFs (B) were transiently transfected with a pBABE-puro mCherry-EGFP-LC3B plasmid. After $6 \mathrm{~h}$, cells were treated with GX (U266, $500 \mathrm{nM}$; MEFs, $200 \mathrm{nM}$ ) for an additional $16 \mathrm{~h}$, followed by analysis of autophagic flux using confocal microscopy (scale bar $=5 \mu \mathrm{M}[\mathrm{A}]$ or $10 \mu \mathrm{M}[\mathrm{B}]$ ). Values indicate number of autophagosomes (A, yellow) and autolysosomes (AL, red). (C) U266 cells stably transfected with p62 shRNA were transiently transfected with a construct encoding GFP-tagged p62 or GFP. After $6 \mathrm{~h}$, cells were treated $(24 \mathrm{~h})$ with $500 \mathrm{nM} \mathrm{GX}$, followed by 7AAD staining to monitor cell death using confocal microscopy (left). GFP-positive/7AAD-negative cells (arrow) were then quantified using flow cytometry (right). (D) Immunoblotting analysis was performed to validate p62 expression in wild-type and p62 ko MEFs (inset). MEFs were then exposed to $200 \mathrm{nM} \mathrm{GX}+/-100 \mathrm{nM}$ FP for $24 \mathrm{~h}$, followed by 7AAD staining to determine the percentage of cell death using flow cytometry. (E) p62 ko MEFs were transiently transfected with GFP-tagged p62 or GFP (inset, scale bar $=30 \mu \mathrm{m}$ ). After $6 \mathrm{~h}$, cells were treated with $200 \mathrm{nM} \mathrm{GX} \mathrm{+/-} 100 \mathrm{nM}$, after which the percentage of cell death was determined as above by flow cytometry.

\subsubsection{NBK/Bik is up-regulated during inefficient autophagy}


Bik, a BH3-only endoplasmic reticulum (ER)-associated pro-apoptotic protein (18), has recently been shown to promote autophagy by facilitating release of Beclin-1 from Bcl-2 (9). As a positive control, the proteasome inhibitor bortezomib clearly induced Bik up-regulation (Fig. 6A), as previously described (62). Importantly, FP/GX co-exposure robustly up-regulated Bik (Fig. 6A), in association with sharply increased apoptosis (Supplemental Fig. S1C). Similar events occurred in cells co-exposed to GX and SCH727965 (Fig. 6B and Supplemental Fig. S3A). Notably, knock-down of either Cdk9 or cyclin T1 by shRNA recapitulated the effects of Cdk inhibitors in up-regulating Bik and potentiating GX-induced apoptosis (Fig. 6C and Supplemental Fig. S3B).

To determine the subcellular localization of Bik, ER membrane fractions were separated and subjected to immunoblot probing for Bik. As described before (18), Bik primarily localized to the ER membrane (Fig. 6D), accompanied by mitochondrial translocation of Bax and release of mitochondrial proteins (e.g., cytochrome C and AIF; Supplemental Fig. S3C), but not to the mitochondria (Supplemental Fig. S3D). In contrast, Bim, another BH3-only protein, predominantly localized to the mitochondria.

The mechanism(s) by which FP/GX up-regulates Bik were then assessed. Inhibition of de novo protein synthesis by $\mathrm{CHX}$ failed to prevent Bik up-regulation following FP/GX treatment (Fig. 6E, upper), whereas quantitative PCR revealed the absence of significant changes in Bik mRNA levels following exposure of cells to FP and GX individually or in combination (Supplemental Fig. S3E). Moreover, the proteasome inhibitor MG-132 (39) (Fig. 6E, lower) or bortezomib (Supplemental Fig. S3F) further increased FP/GX-induced Bik expression, suggesting that a protein turnover-related mechanism is responsible for Bik up-regulation. 


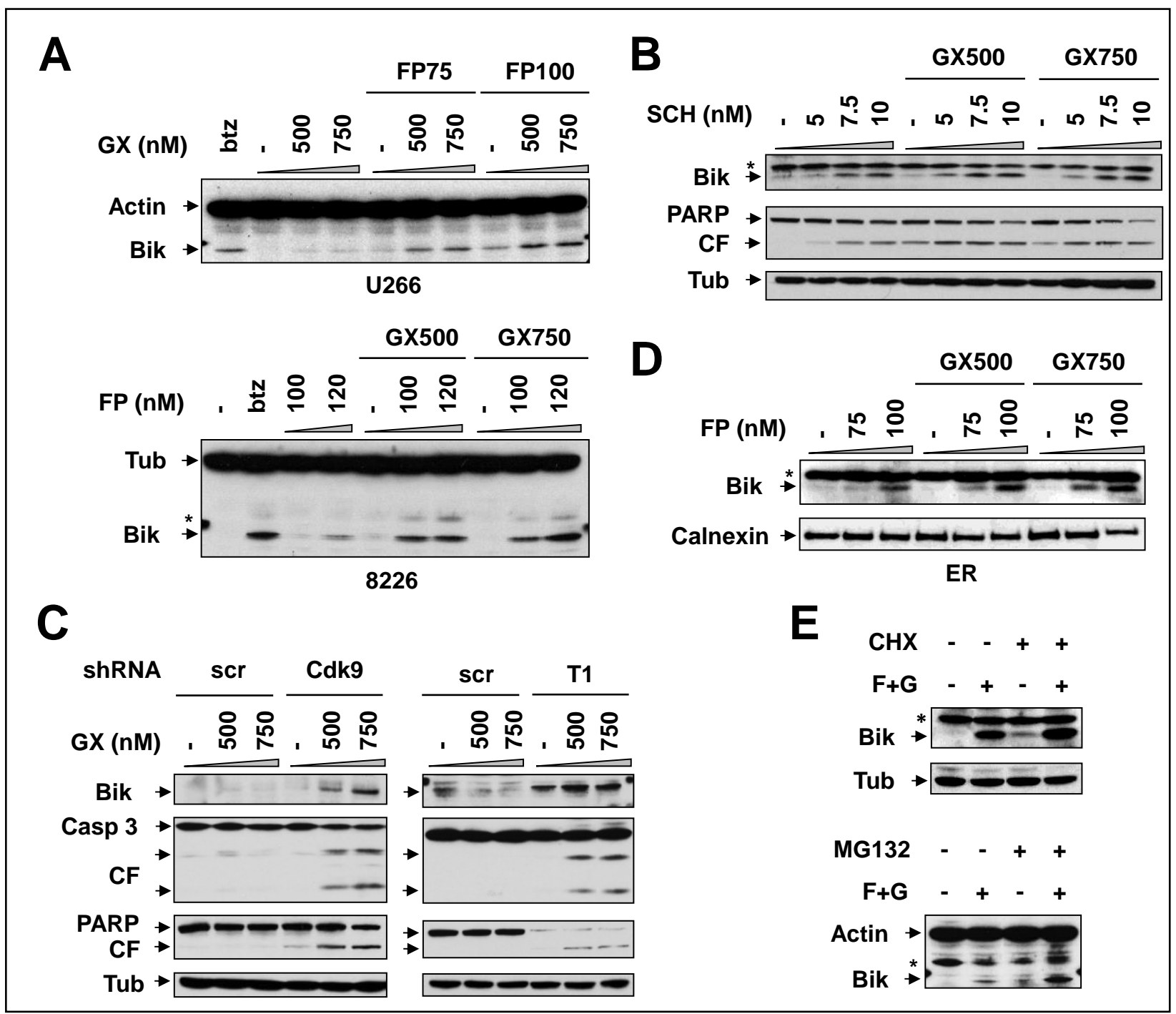

Figure 6. Cdk9 inhibition up-regulates NBK/Bik in cells exposed to BH3-mimetics. (A,B) U266 and RPMI8226 cells were treated $(24 \mathrm{~h})$ with the indicated concentrations of GX +/- FP (A) or SCH727965 (B, $5 \mathrm{nM}$ ), or bortezomib (btz, $4 \mathrm{nM}$ ) as a positive control, after which immunoblotting analysis was performed to monitor Bik expression and/or PARP cleavage. *, non-specific band. (C) U266 cells stably transfected with shRNA directed against Cdk9, T1, or scrambled sequence as a control were exposed $(24 \mathrm{~h})$ to $500 \mathrm{nM}$ or $750 \mathrm{nM} \mathrm{GX}$, followed by immunoblotting analysis to monitor expression of Bik, and cleavage of caspase 3 and PARP. (D) After U266 cells were treated (24 h) with the indicated concentrations of GX (nM) +/- FP (nM), the ER membrane fraction was isolated and subjected to immunoblotting analysis to monitor subcellular localization of Bik. The same membranes were probed by anti-calnexin antibody as a loading control for ER membranes. (E) U266 cells were treated (16 h) with $500 \mathrm{nM} \mathrm{GX}+100$ $\mathrm{nM}$ FP in the presence or absence of $1 \mu \mathrm{M}$ CHX (upper) or $300 \mathrm{nM}$ MG-132 (lower), followed by immunoblotting analysis to monitor Bik expression.

\subsubsection{NBK/Bik accumulation stems from cargo loading failure}


Because autophagic degradation represents a major mechanism regulating protein turnover, the contributions of autophagy to Bik up-regulation were evaluated. First, time-course and doseresponse analysis revealed clearly discernible increases in Bik expression (Fig. 7A). Quantification of immunoblots following exposure of cells to GX +/- FP revealed that Bik upregulation was first discernible $16 \mathrm{~h}$ after FP/GX co-exposure (Fig. 7B), an interval substantially later than autophagy induction (e.g., LC3 processing) first noted at $6 \mathrm{~h}$ (Fig. 3B), and which persisted over the ensuing $24 \mathrm{~h}$. Interestingly, disruption of autophagy by spautin-1 or 3-MA, which blocks autophagy initiation (7), diminished Bik up-regulation and reduced apoptosis (e.g., PARP cleavage) induced by FP/GX (Fig. 7C). Similar phenomena were observed in cells transfected with shRNA directed against Ulk1 (Fig. 7D), Beclin-1, or Atg5 (Fig. 7E and Supplemental Fig. S3G), proteins critical for autophagy initiation (19). In sharp contrast, chloroquine (CQ), which blocks autophagy maturation (7), further enhanced Bik up-regulation induced by FP/GX, accompanied by increased PARP cleavage (Fig. 7C). Analogous results were obtained in U266 cells stably transfected with p62 shRNA (Supplemental Fig. S3H). Similarly, Lamp2 knock-down also promoted Bik accumulation and significantly sensitized cells to FP/GX (Supplemental Fig. S3I). These findings suggest that Bik up-regulation likely occur during autophagy and primarily stems from disruption of the later stages of autophagy, particularly cargo loading into autophagosomes and/or subsequent events (e.g., lysosomal degradation through autophagosome maturation).

In addition, whereas ectopic expression of either Bcl-2 (Supplemental Fig. S4A), Bcl-xL (Supplemental Fig. S4B), Mcl-1 (Supplemental Fig. S4C), or dominant-negative caspase-9 (Supplemental Fig. S4D) clearly blocked apoptosis induced by FP/GX, only Bcl-2 or Bcl-xL attenuated autophagy induction (e.g., LC3 processing), presumably due to sequestration of 
Beclin-1 $(43,50)$, in association with prevention of Bik up-regulation. In sharp contrast, Mcl-1 or dominant-negative caspase-9 failed to diminish autophagy or block Bik up-regulation. These observations further support the notion that initiation of autophagy, but not apoptosis, is required for Bik up-regulation in cells co-exposed to FP/GX.

It is noteworthy that p62 down-regulation by FP occurred at $6 \mathrm{~h}$ (Fig. 3B), clearly prior to Bik up-regulation (16 h, Fig. 7B). Consequently, the relationship between p62 down-regulation and Bik accumulation was then examined. Significantly, similar to cells transfected with Cdk9 or cyclin T1 shRNA (Fig. 6C), knockdown of p62 also substantially increased Bik up-regulation after GX treatment, accompanied by markedly increased sensitivity of cells to GX (Fig. 7F and Supplemental Fig. S4E). In accord with these findings, a filter trap assay probed with an antiBik antibody revealed that FP or SCH727965 substantially reduced the amount of Bik detected in protein aggregates (Fig. 7G, upper). Consistent with these findings, either shRNA against p62, Cdk9, or cyclin T1 also substantially reduced the amount of Bik in protein aggregates, compared to scrambled shRNA control, after GX treatment (Fig. 7G, lower). Finally, co-administration of either FP or SCH727965 with GX led to a clear accumulation of ubiquitinated Bik in cells (Fig. 7H). Together, these findings argue that p62 down-regulation disables loading of Bik into protein aggregates and subsequently autophagosomes, thereby preventing its degradation via autophagy. Consequently, these findings raise the possibility that Bik up-regulation stems from cargo loading failure and inefficient autophagy due to p62 down-regulation. 


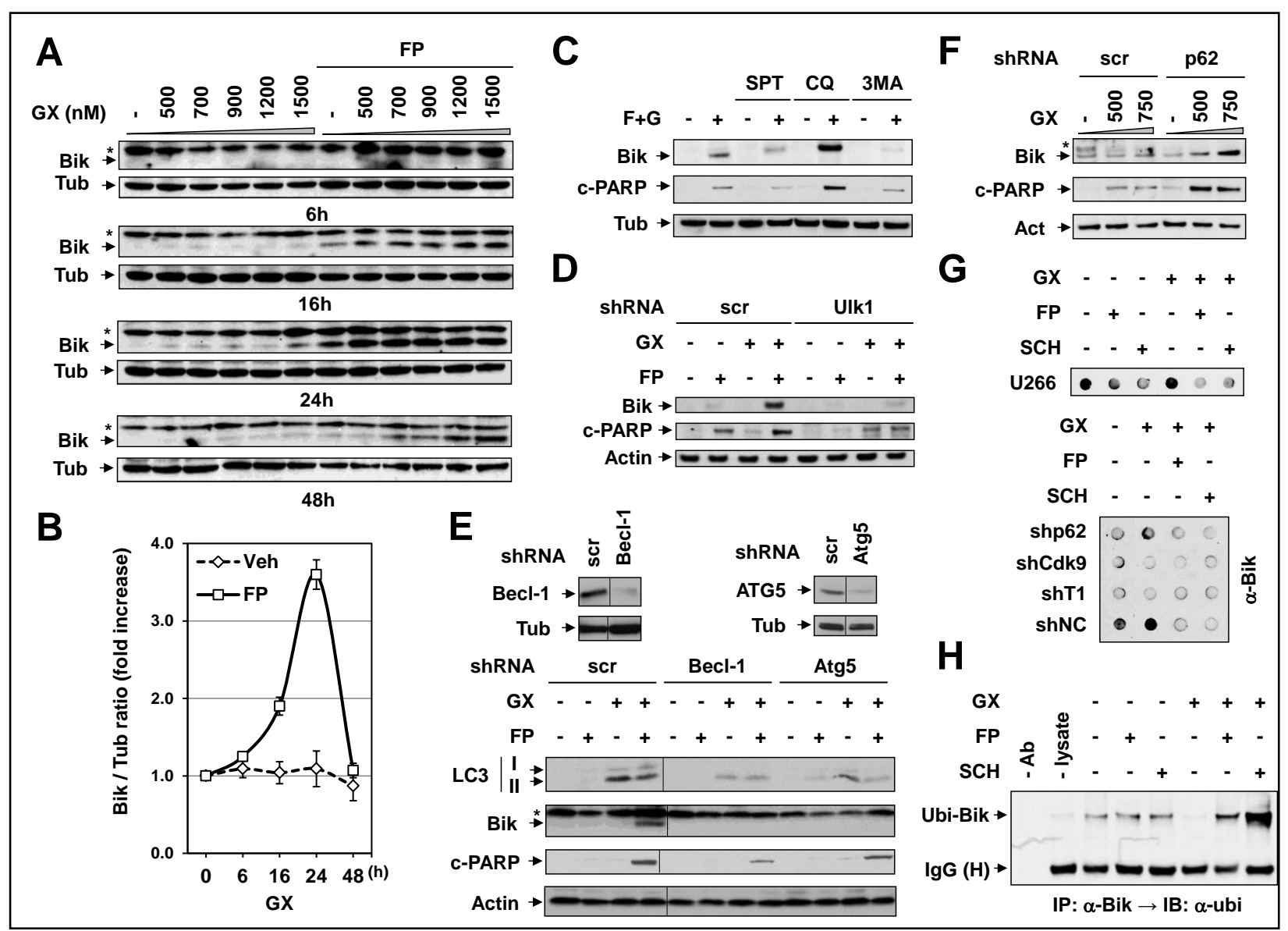

Figure 7. NBK/Bik up-regulation occurs during autophagy in association with loading failure. (A) U266 cells were treated with the indicated concentrations of GX +/- FP (100 nM) for $6,16,24$, and $48 \mathrm{~h}$, after which Bik expression were monitored by immunoblotting analysis. (B) Blots of Bik after treatment with $500 \mathrm{nM} \mathrm{GX}+/$ - FP were quantified relative to tubulin (values represent fold-increase over vehicle-treated controls; means \pm SD for three experiments). (C) U266 cells were co-treated ( $24 \mathrm{~h})$ with $500 \mathrm{nM} \mathrm{GX}$ and $100 \mathrm{nM}$ FP in the presence or absence of $7.5 \mu \mathrm{M}$ SPT, $50 \mu \mathrm{M}$ CQ, or $500 \mu \mathrm{M}$ 3-MA. After treatment, Bik expression and PARP cleavage were determined by immunoblotting analysis. (D,E) U266 cells stably transfected with shRNA directed against Ulk1 (D), Beclin-1, Atg5 (E), or scrambled sequence as control were exposed

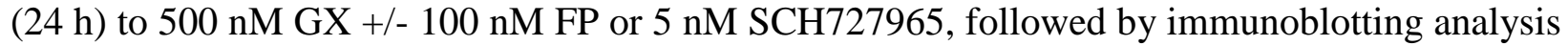
to monitor Bik expression and PARP cleavage. (F) U266 cells stably transfected with shRNA of p62 or scramble sequence as control were exposed $(24 \mathrm{~h})$ to $500 \mathrm{nM} \mathrm{GX}+/-100 \mathrm{nM} \mathrm{FP}$, followed by immunoblotting analysis for Bik expression and PARP cleavage. (G) U266 cells were exposed (16 h) to $500 \mathrm{nM} \mathrm{GX} \mathrm{+/-} 100 \mathrm{nM}$ FP or $5 \mathrm{nM} \mathrm{SCH727965} \mathrm{(upper);} \mathrm{U266} \mathrm{cells}$ stably transfected with shRNA directed against p62, Cdk9, cyclin T1, or scrambled sequence as

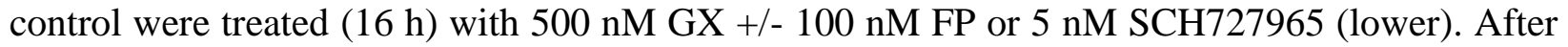
drug treatment, a filter trap assay using anti-Bik antibody $(\alpha$-Bik) was performed to monitor the amount of Bik in SDS-insoluble protein aggregates. (H) U266 cells were exposed (16 h) to 500 $\mathrm{nM} \mathrm{GX}+/-100 \mathrm{nM}$ FP or $5 \mathrm{nM} \mathrm{SCH}$, followed by immunoprecipitation (IP) using anti-Bik antibody $(\alpha-B i k)$ and subsequent immunoblotting analysis using anti-ubiquitin antibody ( $\alpha$-ubi). IP without $\alpha$-Bik $(-\mathrm{Ab}$, lane 1$)$ or cell lysate (- lysate, lane 2$)$ were used as controls. IgG $(\mathrm{H})=$ IgG heavy chain . 


\subsubsection{NBK/Bik switches inefficient autophagy to apoptosis}

Bik plays dual roles in the regulation of both apoptosis (18) and autophagy (9). The functional roles of Bik in this setting were then examined using cells stably transfected with Bik shRNA. In these cells, FP/GX failed to up-regulate Bik (Fig. 8A, bortezomib treatment shown as a positive control). Bik knock-down partially but discernibly reduced LC3 processing following GX \pm FP exposure, consistent with evidence that Bik contributes to autophagy induction (9). In contrast, knockdown of another BH3-only protein, Bim, failed to attenuate GX/FP-induced autophagy (e.g., LC3 processing), although it substantially blocked apoptosis (Supplemental Fig. S4F). Autophagy inhibition by Bik shRNA clearly increased p62 levels (Fig. 8A), presumably due to inhibition of autophagy initiation (9). Importantly, prevention of Bik up-regulation sharply diminished apoptosis, reflected by the virtually complete abrogation of PARP cleavage (Fig. 8A) and annexin V-positivity (Fig. 8B) induced by FP/GX, as well as by bortezomib (62). However, while EM analysis confirmed a marked reduction in the number and size of AVs in Bik shRNA cells exposed to GX, Bik knockdown did not prevent the formation of empty AVs following FP/GX co-treatment (Supplemental Fig. S5).

Of note, administration of GX induced LC3 processing and p62 expression in tumor samples excised from a xenograft RPMI8226 flank model. Significantly, FP co-administration diminished GX-mediated p62 up-regulation, accompanied by a clear increase in Bik expression and PARP cleavage in vivo (Fig. 8C). Furthermore, in a dual-sided flank mouse model, tumors generated from Bik shRNA cells (right flank) displayed pronounced resistance to combined treatment with FP and GX, compared to those derived from scrambled sequence shRNA cells (left flank, Fig. 8D). Finally, in an tail-vein intravenous (i.v.) orthotopic mouse model, co-administration of FP 
and GX substantially reduced tumor burden, reflected by low luciferase signals (Fig. 8E, upper), and strikingly eliminated human CD138-positive tumor cells (lower), while restoring normal bone marrow structure (lower right, HE staining). Together, these findings argue strongly that Bik up-regulation plays an important functional role in converting inefficient autophagy to apoptosis.

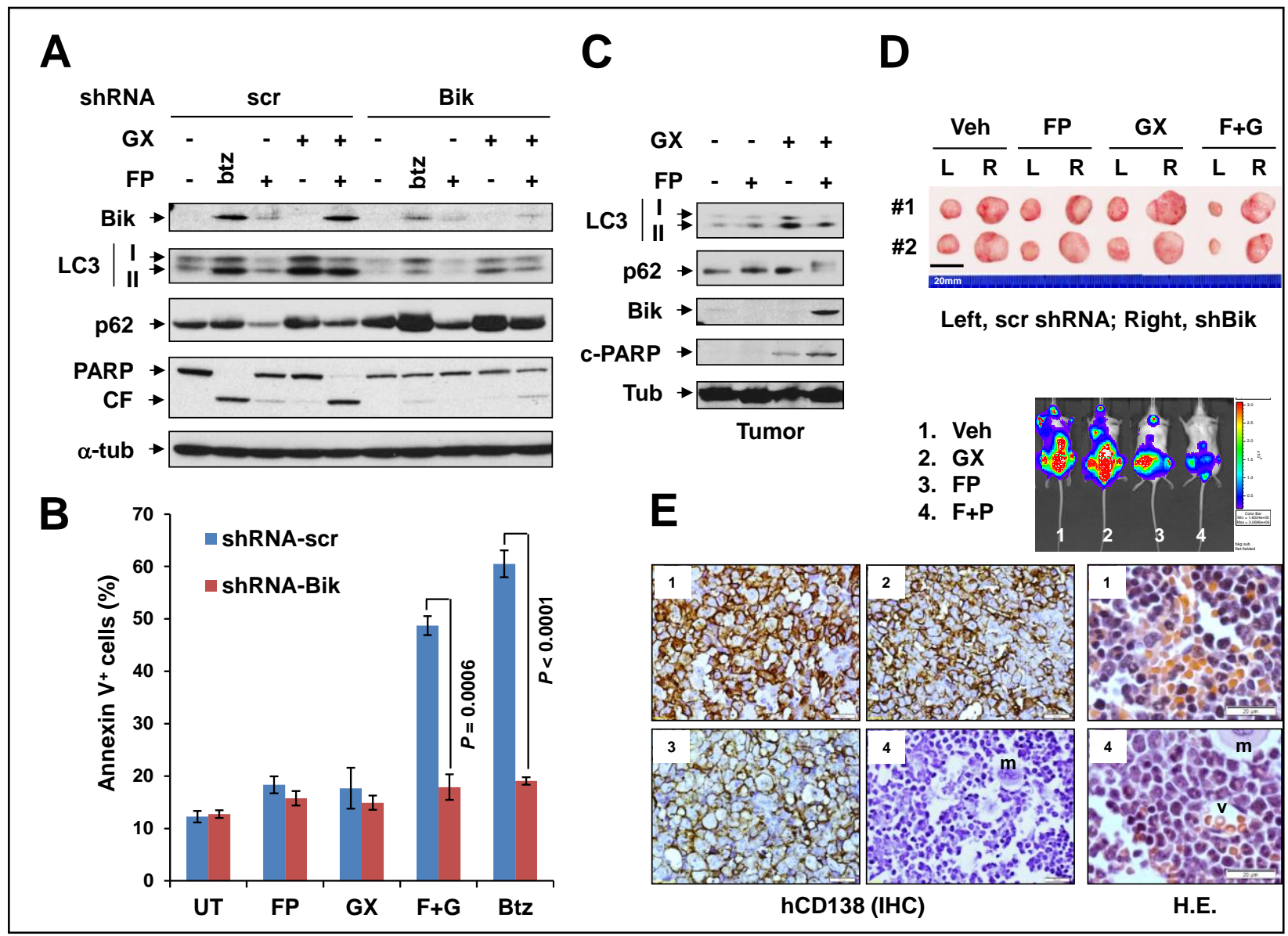

Figure 8. NBK/Bik plays functional role in triggering apoptosis in vitro and in vivo. (A, $\mathrm{B})$ U266 cells were stably transfected with a construct encoding shRNA directed against Bik or scrambled sequence as control, and then treated ( $24 \mathrm{~h})$ with $500 \mathrm{nM} \mathrm{GX}+/-100 \mathrm{nM} \mathrm{FP}$, or $4 \mathrm{nM}$ bortezomib (btz) as a positive control. Immunoblotting analysis (A) and flow cytometry (B) were conducted to monitor expression of the indicated proteins or to determine percentage of apoptotic (Annexin $\mathrm{V}^{+}$) cells (values represent means \pm SD for three experiments), respectively. (C) Athymic NCr-nu/nu mice subcutaneously inoculated in the flank with $5 \times 10^{6}$ RPMI8226 cells were treated with GX $(3 \mathrm{mg} / \mathrm{kg}$, i.m. $)+/-$ FP $(5 \mathrm{mg} / \mathrm{kg}$, i.p.). Tumors were excised at day 28 after tumor cell inoculation, and then homogenized and subjected to immunoblotting analysis using the indicated antibodies. (D) NOD/SCID/gamma (NSG) mice were subcutaneously inoculated in each flank with $1 \times 10^{7}$ U266 cells stably transfected with shRNA directed against Bik (right 
flank) or scrambled sequence as a control (left flank).FP (3mg/kg, i.p.) \pm GX (3mg/kg, i.p.) were then administered daily for total 11 days. Images of tumors removed from two representative mice were captured at day 49 after tumor cell inoculation (scale bar $=20 \mathrm{~mm}$ ). (E) NSG mice were intravenously injected (i.v.) via tail vein with $5 \times 10^{6}$ U266 cells carrying luciferase, after which FP (3mg/kg, i.p.) \pm GX (3mg/kg, i.p.) were administered daily for total 19 days. The bioluminescent images of representative mice were captured at day 35 after inoculation of cells. Lumbar vertebrae removed from mice were immunohistochemically stained with anti-human CD138 antibody (IHC, scale bar $=10 \mu \mathrm{m}$ ) or hematoxylin and eosin (H.E., scale bar $=20 \mu \mathrm{m} ; \mathrm{m}$ = megakaryocyte, $\mathrm{v}=$ blood vessel $)$.

\subsection{DISCUSSION}

Apoptosis (Type I) and autophagy (Type II) represent the two major forms of programmed cell death. Importantly, these processes share common molecular pathways regulated by Bcl-2 family proteins $(34,50)$, and often occur in concert e.g., following exposure to agents such as BH3-mimetics (i.e., GX-015-070/obatoclax and ABT-737) that target Bcl-2 family proteins (e.g. Bcl-2, Bcl-xL) (6). While apoptosis represents an important pro-death mechanism through which chemotherapeutic agents and ionizing radiation induce tumor cell demise, autophagy generally functions as a pro-survival mechanism by maintaining cellular homeostasis and metabolism $(13,25)$, thus conferring resistance to various types of therapy $(2,25)$. While the optimal autophagy-targeting strategy remains the subject of debate $(56,57)$, improving the efficacy of and circumventing resistance to anti-cancer drugs by converting a cytoprotective autophagic response to apoptosis would represent an attractive approach, e.g., by targeting cross-talk between these processes. For example, multiple autophagy-related proteins such as Beclin-1 $(11,40,58)$, Atg5 (61), and Atg4D (or LC3) (4) are substrates for caspases or calpains activated during apoptosis, while their cleaved fragments sensitize cells to apoptosis. Consequently, this form of cross-talk generally represents a mechanism of apoptosis amplification through modification of autophagyregulatory proteins. The findings described herein highlight a novel mechanism underlying cross-talk between autophagy and apoptosis, and suggest that the adaptor protein SQSTM1/p62 
and the BH3-only protein NBK/Bik represent key switches governing the critical decision of cells undergoing autophagy to survive or die. Specifically, the present observations argue that targeting SQSTM1/p62 results in an inefficient form of autophagy due to cargo loading failure, leading to up-regulation of the pro-apoptotic $\mathrm{BH} 3$-only protein NBK/Bik, which in turn triggers activation of the intrinsic apoptotic pathway.

The concept of inefficient autophagy was initially described in Huntington's disease (44), a genetic neurodegenerative disorder caused by an expanded polyglutamine tract in the huntingtin (htt) protein (54). In Huntington's disease neurons, autophagic vacuoles form at normal or increased rates, but fail to recognize and trap cytosolic cargo in their lumen. Inefficient engulfment of cytosolic components by autophagosomes leads to slow turnover, functional decay, and accumulation of mutant htt within Huntington's disease cells $(3,44)$, which is noxious to neurons (5). Thus, whereas autophagy protects neurons (54), inefficient autophagy has been identified as a primary defect in Huntington's disease (44). Notably, in the present study, similar phenomena were observed in neoplastic cells exposed to autophagy inducers (e.g., BH3 mimetics) under conditions in which the adaptor protein p62 was transcriptionally downregulated through Cdk9 inhibition e.g., by pharmacologic Cdk inhibitors, or shRNA directed against Cdk9 or cyclin T. Features of inefficient autophagy due to cargo loading failure in the present setting resemble those previously described in the case of Huntington's disease, including a) normal autophagic flux induced by GX in the presence or absence of Cdk inhibition; b) no discernible change in lysosome biogenesis in cells exposed to GX +/- Cdk inhibition; c) EM morphological demonstration of increased numbers of double-membraned autophagic vacuoles (AVs) with clear or empty content following GX exposure in cells in which p62 was down-regulated; d) functional evidence from filter trap assays demonstrating impaired 
autophagic removal of SDS-insoluble ubiquitinated protein aggregates $(5,17)$ when p62 was down-regulated; and d) resulting accumulation of polyubiquitinated proteins in cells exposed to GX with FP or when p62 was knocked down by shRNA $(5,17)$.

The preceding evidence suggests that the adaptor protein SQSTM1/p62, which is responsible for loading of malfolded or unwanted proteins into autophagosomes for lysosomal degradation (49), served as a switch that converted autophagy to an inefficient form. Consistent with the notion that SQSTM1/p62 acts to recognize and load cargo into autophagosomes for degradation, levels of this protein underwent dynamic changes during GX-induced autophagy, presumably reflecting the net effects of de novo synthesis versus autophagic degradation (21). Interestingly, prevention of autophagy at either the initiation phase (e.g., by shUlk1 (19), 3-MA (7), or spautin1 (38)), or at the maturation stage (e.g., by Lamp2 shRNA (19)), resulted in p62 accumulation. This suggests that p62 levels are primarily regulated via autophagic degradation (51). Importantly, knock-down of p62 by shRNA led to cargo loading failure-associated inefficient autophagy in a manner indistinguishable from that induced by genetic disruption or pharmacologic inhibition of the P-TEFb (i.e., Cdk9/cyclin T) complex (12). In this context, inhibition of RNA Pol II (e.g., by Cdk9 inhibitors) diminishes the expression of various proteins with short half-lives (10), raising the possibility that a similar mechanism may be operative in the case of down-regulation of p62, a protein characterized by a rapid turnover (21). Interestingly, p62 exerts a cytoprotective effect with respect to htt-induced cell death in Huntington's disease (5). However, evidence of a direct contribution of the p62-mediated cargo-loading process to cytoprotective autophagy in neoplastic cells is currently lacking. The robust induction of apoptosis in $\mathrm{BH} 3$-mimetic-exposed cells when de novo p62 expression was blocked (e.g., by either Cdk9 inhibition or p62 shRNA) indicate that whereas p62 down-regulation by itself is 
insufficient to trigger cell death, it may sensitize tumor cells to autophagy inducers such as GX by disabling the cargo-loading process, resulting in inefficient autophagy. Finally, p62 has been reported to contribute to tumorigenesis either directly (45), or indirectly through NF- $\kappa \mathrm{B}$ stimulation unrelated to its function in autophagy (37). Collectively, these observations argue that p62 represents a rational candidate target in cancer treatment. However, inasmuch as Cdk inhibitors (e.g., FP) inhibit global transcription, the possibility that other proteins implicated in autophagy regulation (particularly e.g., cargo recognition/loading and autophagy maturation) might also contribute to autophagy dysfunction in the present setting cannot be excluded.

The present findings identify NBK/Bik as a key molecule that converts inefficient autophagy to apoptosis. NBK/Bik exerts dual functions in regulating both autophagy and apoptosis (42). For example, Bik cooperates with NAF-1 to induce autophagy by releasing Beclin-1 from Bcl-2 at the ER (9). However, in addition to its role as a regulator of autophagy and apoptosis, the disposition of Bik appears to be reciprocally governed by the former process. In support of this concept, the absence of changes in Bik mRNA and the failure of CHX to block Bik up-regulation argue that increases in Bik protein levels involve post-translational events. Indeed, inhibition of the two major mechanisms (i.e., proteasomal and autophagic degradation) responsible for removal of ubiquitinated proteins (60) resulted in marked Bik accumulation. These findings argue that Bik may be a substrate for ubiquitination and degradation (39) through both the proteasomal and autophagic systems (60). Consistent with this notion, concomitant inhibition of proteasome function (e.g., by MG-132 or bortezomib) and autophagic degradation (e.g., by inefficient autophagy induced by GX in the setting of p62 down-regulation) led to further increases in Bik accumulation compared to inhibition of either arm individually. Interestingly, Bik accumulation appeared to be linked to autophagy, as inhibition of autophagy at the initiation 
stage (e.g., by Beclin-1 (35,43,50), Ulk1, or Atg5 (19) shRNA, 3-MA (7), or spautin-1 (38)) significantly diminished Bik up-regulation and apoptosis. In this context, it has been reported that suppression of autophagy initiation attenuates cell death associated with impaired removal of autophagosomes (41). In contrast, dysfunction of later stages of autophagy (e.g., by CQ (7) or Lamp2 shRNA (19)) led to marked Bik accumulation and apoptosis induced by GX + FP. Furthermore, the present findings suggest that Bik accumulation stems from cargo-loading failure secondary to p62 down-regulation (e.g., by Cdk9 inhibition or p62 shRNA), evidenced by a reduction in amount of Bik harbored by SDS-insoluble protein aggregates and the marked accumulation of ubiquitinated Bik (39). Finally, the dual roles of Bik are highlighted by the observations that knockdown of Bik by shRNA substantially reduced autophagy induced by GX and prevented apoptosis triggered by co-treatment with GX and FP both in vitro and in vivo .

In summary, a theoretical model illustrated in Fig. 9 proposes a dynamic process in which targeting SQSTM1/p62 (e.g., via transcriptional repression by pharmacological or genetic Cdk9 inhibition) results in inefficient autophagy due to failure of cargo loading, leading to upregulation of Bik, which in turn triggers apoptosis. According to this model, SQSTM1/p62 and NBK/Bik represent two distinct but interconnected switches that convert cytoprotective autophagy to an inefficient form and subsequently to cell death. A corollary of these findings is that modulating such cross-talk between autophagy and apoptosis via the SQSTM1/p62NBK/Bik signaling axis could provide a novel avenue for therapeutic intervention. However, direct approaches disrupting the function of adaptor proteins such as p62 are currently not available; instead, interfering with p62 expression at the transcriptional level might represent an attractive alternative, as many $\mathrm{Cdk}$ inhibitors, including those undergoing clinical evaluation (e.g., FP, SCH727965/dinaciclib (27)), exhibit potent inhibitory activity toward Cdk9 (12). 
Moreover, because p62 may exert multiple oncogenic functions, including those unrelated to its role in autophagy (e.g., NF- $\kappa \mathrm{B}$ activation (37)), transcriptional down-regulation of p62 offers the theoretical advantage of circumventing p62 accumulation resulting from direct disruption of autophagy e.g., by agents such as CQ $(2,25)$. Finally, the possibility exists that targeting p62 (e.g., by Cdk9 inhibitors) to induce apoptosis via NBK/Bik accumulation due to inefficient autophagy could enhance the anti-cancer activity of agents that, like BH3-mimetics, elicit a cytoprotective autophagic response.

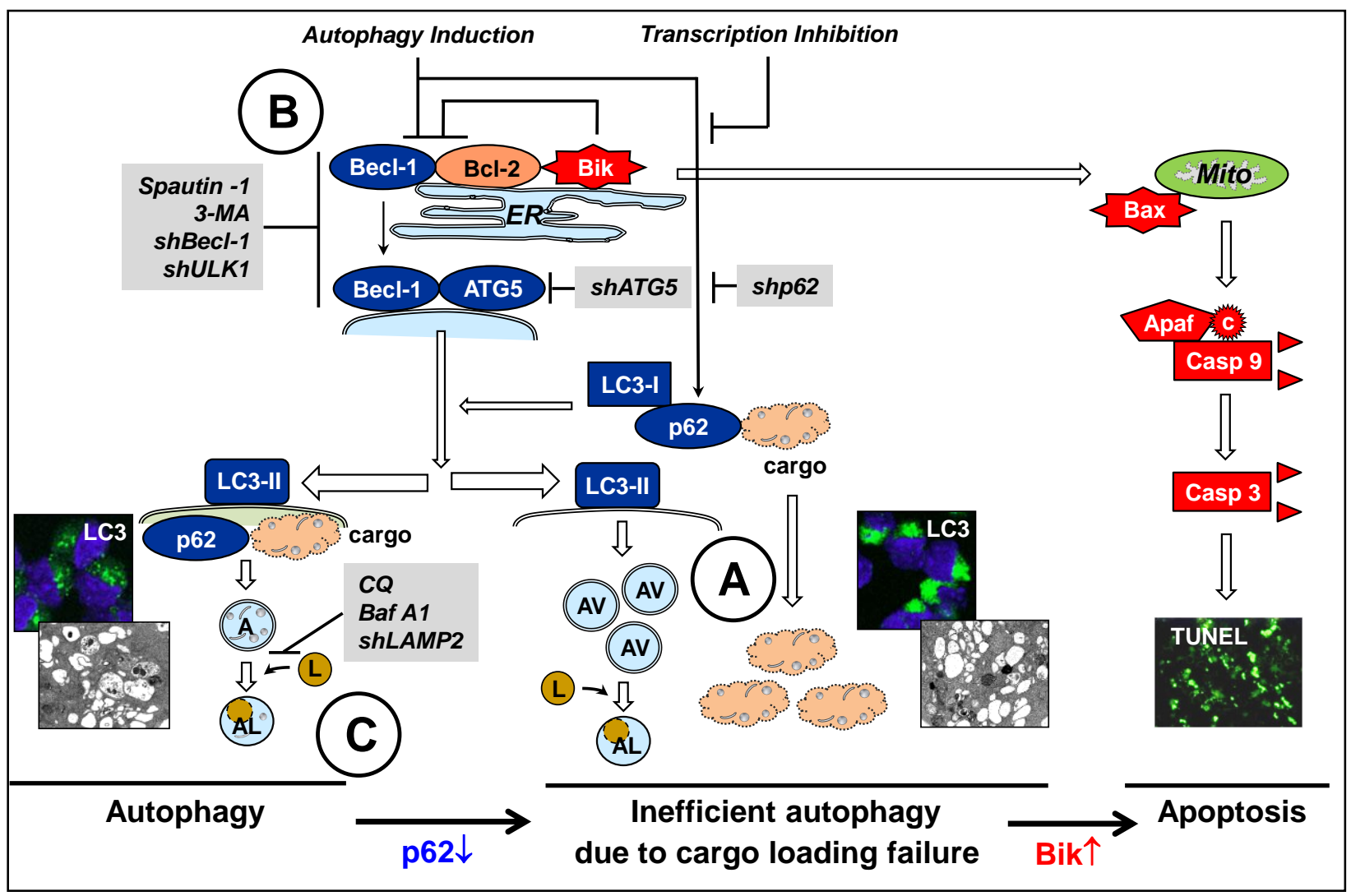

Figure 9. A mechanistic model of SQSTM1/p62 and NBK/Bik acting as novel molecular switches converting autophagy to apoptosis. During autophagy (e.g., induced by BH3mimetics), the adaptor protein SQSTM1/p62 is responsible for recognition and loading of cargo, including malfolded (unfolded or misfolded) proteins and damaged organelles, into autophagosomes for removal. Targeting p62 by blocking its re-synthesis through inhibition of transcription (e.g., by Cdk9 inhibition) disrupts this process, resulting in failure of the cargoloading process and dysfunctional removal of malfolded proteins and damaged organelles, defined herein as inefficient autophagy. The latter event promotes accumulation of the BH3-only protein NBK/Bik, a substrate of ubiquitination and degradation via autophagy, which in turn triggers activation of the apoptotic signaling cascade. Therefore, whereas targeting p62 converts 
cytoprotective autophagy into an inefficient form, NBK/Bik switches inefficient autophagy to apoptosis. Thus, SQSTM1/p62 and NBK/Bik cooperate to convert autophagy to apoptosis. This autophagy-targeting strategy (A) may provide theoretical advantages over alternatives e.g., inhibition of autophagy initiation (B) or disruption of autophagosome maturation/fusion with lysosomes (C), including 1) up-regulation of pro-death Bik, which requires autophagy initiation and does not occur in the case of (B); and 2) down-regulation of oncogenic and pro-survival p62 at the transcriptional level by $\mathrm{Cdk} 9$ inhibition, in contrast to disruption of autophagy at either early (B, e.g., initiation) or late (C, e.g., maturation or lysosome biogenesis) stages, which results in p62 up-regulation due to interference with its autophagic degradation.

\subsection{REFERENCES}

1. Amaravadi RK, Lippincott-Schwartz J, Yin XM, et al. Principles and current strategies for targeting autophagy for cancer treatment. Clin Cancer Res 17:654-666, 2011.

2. Amaravadi RK., Yu D, Lum JJ, et al. Autophagy inhibition enhances therapy-induced apoptosis in a Myc-induced model of lymphoma. J Clin Invest 117:326-336, 2007.

3. Bauer PO, Goswami A, Wong HK, et al. Harnessing chaperone-mediated autophagy for the selective degradation of mutant huntingtin protein. Nat Biotechnol 28:256-263, 2010.

4. Betin VM, Lane JD. Caspase cleavage of Atg4D stimulates GABARAP-L1 processing and triggers mitochondrial targeting and apoptosis. J Cell Sci 122:2554-2566, 2009.

5. Bjorkoy G, Lamark T, Brech A, et al. p62/SQSTM1 forms protein aggregates degraded by autophagy and has a protective effect on huntingtin-induced cell death. J Cell Biol 171:603614, 2005.

6. Bonapace L, Bornhauser BC, Schmitz M, et al. Induction of autophagy-dependent necroptosis is required for childhood acute lymphoblastic leukemia cells to overcome glucocorticoid resistance. J Clin Invest 120:1310-1323, 2010.

7. Boya P, Gonzalez-Polo RA, Casares $\mathrm{N}$, et al. Inhibition of macroautophagy triggers apoptosis. Mol Cell Biol 25:1025-1040, 2005.

8. Calvo-Garrido J, Escalante R. Autophagy dysfunction and ubiquitin-positive protein aggregates in Dictyostelium cells lacking Vmp1. Autophagy 6:100-109, 2010.

9. Chang NC, Nguyen M, Germain M, Shore GC. Antagonism of Beclin 1-dependent autophagy by BCL-2 at the endoplasmic reticulum requires NAF-1. EMBO J 29:606-618, 2010.

10. Chen S, Dai Y, Pei XY, et al. CDK inhibitors up-regulate BH3-only proteins to sensitize human myeloma cells to BH3 mimetic therapies. Cancer Res 72:4225-4237, 2012.

11. Cho DH, Jo YK, Hwang JJ, Lee YM, Roh SA, Kim JC. Caspase-mediated cleavage of ATG6/Beclin-1 links apoptosis to autophagy in HeLa cells. Cancer Lett 274: 95-100, 2009. 
12. Dai Y, Grant S. Small molecule inhibitors targeting cyclin-dependent kinases as anticancer agents. Curr Oncol Rep 6:123-130, 2004.

13. Deretic V. A master conductor for aggregate clearance by autophagy. Dev Cell 18:694-696, 2010.

14. Dikic I, Johansen T, Kirkin V. Selective autophagy in cancer development and therapy. Cancer Res 70:3431-3434, 2010.

15. Ding WX, Ni HM, Li M, et al. Nix is critical to two distinct phases of mitophagy, reactive oxygen species-mediated autophagy induction and Parkin-ubiquitin-p62-mediated mitochondrial priming. J Biol Chem. 285:27879-27890, 2010.

16. Elgendy M, Sheridan C, Brumatti G, Martin SJ. Oncogenic Ras-induced expression of Noxa and Beclin-1 promotes autophagic cell death and limits clonogenic survival. Mol Cell 42:23$35,2011$.

17. Gamerdinger M, Kaya AM, Wolfrum U, Clement AM, Behl C. BAG3 mediates chaperonebased aggresome-targeting and selective autophagy of misfolded proteins. EMBO Rep 12:149-156, 2011.

18. Germain M, Mathai JP, Shore GC. BH-3-only BIK functions at the endoplasmic reticulum to stimulate cytochrome c release from mitochondria. J Biol Chem. 277:18053-18060, 2002.

19. He C, Klionsky DJ. Regulation mechanisms and signaling pathways of autophagy. Annu Rev Genet 43:67-93, 2009.

20. Hoang B, Benavides A, Shi Y, Frost P, Lichtenstein A. Effect of autophagy on multiple myeloma cell viability. Mol Cancer Ther 8:1974-1984, 2009.

21. Ichimura Y, Kominami E, Tanaka K, Komatsu M. Selective turnover of p62/A170/SQSTM1 by autophagy. Autophagy 4:1063-1066, 2008.

22. Itakura E, Mizushima N. p62 Targeting to the autophagosome formation site requires selfoligomerization but not LC3 binding. J Cell Biol 192:17-27, 2011.

23. Iwata J, Ezaki J, Komatsu M, et al. Excess peroxisomes are degraded by autophagic machinery in mammals. J Biol Chem 281:4035-4041, 2006.

24. Jackson WT, Giddings TH, Taylor MP Jr., et al. Subversion of cellular autophagosomal machinery by RNA viruses. PLoS Biol 3:e156, 2005.

25. Janku F, McConkey DJ, Hong DS, Kurzrock R. Autophagy as a target for anticancer therapy. Nat Rev Clin Oncol 8:528-539, 2011.

26. Johansen T, Lamark T. Selective autophagy mediated by autophagic adapter proteins. Autophagy 7:279-296, 2011. 
27. Johnson AJ, Yeh YY, Smith LL, et al. The novel cyclin-dependent kinase inhibitor dinaciclib (SCH727965) promotes apoptosis and abrogates microenvironmental cytokine protection in chronic lymphocytic leukemia cells. Leukemia 26:2554-2557, 2012.

28. Kimmelman AC. The dynamic nature of autophagy in cancer. Genes Dev 25:1999-2010, 2011.

29. Kirkin V, Lamark T, Sou YS, et al. A role for NBR1 in autophagosomal degradation of ubiquitinated substrates. Mol Cell 33:505-516, 2009.

30. Kirkin V, McEwan DG, Novak I, Dikic I. A role for ubiquitin in selective autophagy. Mol Cell 34:259-269, 2009.

31. Klionsky DJ. Abeliovich H, Agostinis P, et al. Guidelines for the use and interpretation of assays for monitoring autophagy in higher eukaryotes. Autophagy 4:151-175, 2008.

32. Kraft C, Peter M, Hofmann K. Selective autophagy: ubiquitin-mediated recognition and beyond. Nat Cell Biol 12:836-841, 2010.

33. Lee JY, Koga H, Kawaguchi Y, et al. HDAC6 controls autophagosome maturation essential for ubiquitin-selective quality-control autophagy. EMBO J 29:969-980, 2010.

34. Levine B, Sinha S, Kroemer G. Bcl-2 family members: dual regulators of apoptosis and autophagy. Autophagy 4:600-606, 2008.

35. Liang XH, Jackson S, Seaman $\mathrm{M}$, et al. Induction of autophagy and inhibition of tumorigenesis by beclin 1. Nature 402:672-676, 1999.

36. Linares JF, Duran A, Yajima T, Pasparakis M, Moscat J, Diaz-Meco MT. K63 polyubiquitination and activation of mTOR by the p62-TRAF6 complex in nutrient-activated cells. Mol Cell 51: 283-296, 2013.

37. Ling J, Kang Y, Zhao R, et al. KrasG12D-induced IKK2/beta/NF-kappaB activation by IL1alpha and p62 feedforward loops is required for development of pancreatic ductal adenocarcinoma. Cancer Cell 21:105-120, 2012.

38. Liu J, Xia H, Kim M, et al. Beclin1 controls the levels of p53 by regulating the deubiquitination activity of USP10 and USP13. Cell 147:223-234, 2011.

39. Lopez J, Hesling C, Prudent J, et al. Src tyrosine kinase inhibits apoptosis through the Erk1/2- dependent degradation of the death accelerator Bik. Cell Death Differ 19:1459-1469, 2012.

40. Luo S, Rubinsztein DC. Apoptosis blocks Beclin 1-dependent autophagosome synthesis - an effect rescued by Bcl-xL. Cell Death Differ 17:268-277, 2010.

41. Ma X, Godar RJ, Liu H, Diwan A. Enhancing lysosome biogenesis attenuates BNIP3induced cardiomyocyte death. Autophagy 8: 297-309, 2012. 
42. Maiuri MC, Criollo A, Kroemer G. Crosstalk between apoptosis and autophagy within the Beclin 1 interactome. EMBO J 29:515-516, 2010.

43. Maiuri MC, Le TG, Criollo A, et al. Functional and physical interaction between Bcl-X(L) and a BH3-like domain in Beclin-1. EMBO J 26:2527-2539, 2007.

44. Martinez-Vicente M, Talloczy Z, Wong E, et al. Cargo recognition failure is responsible for inefficient autophagy in Huntington's disease. Nat Neurosci 13:567-576, 2010.

45. Mathew R, Karp CM, Beaudoin B, et al. Autophagy suppresses tumorigenesis through elimination of p62. Cell 137:1062-1075, 2009.

46. Mizushima N, Yoshimori T, Levine B. Methods in mammalian autophagy research. Cell 140:313-326, 2010.

47. Myeku N, Figueiredo-Pereira ME. Dynamics of the degradation of ubiquitinated proteins by proteasomes and autophagy: association with sequestosome 1/p62. J Biol Chem 286:22426$22440,2011$.

48. N'Diaye EN, Kajihara KK, Hsieh I, Morisaki, Debnath J, Brown EJ. PLIC proteins or ubiquilins regulate autophagy-dependent cell survival during nutrient starvation. EMBO Rep 10:173-179, 2009.

49. Pankiv S, Clausen TH, Lamark T, et al. p62/SQSTM1 binds directly to Atg8/LC3 to facilitate degradation of ubiquitinated protein aggregates by autophagy. J Biol Chem 282:2413124145, 2007.

50. Pattingre S, Tassa A, Qu X, et al. Bcl-2 antiapoptotic proteins inhibit Beclin 1-dependent autophagy. Cell 122:927-939, 2005.

51. Schwartz-Roberts JL, Shajahan AN, Cook KL, Warri A, Abu-Asab M, Clarke R. GX15-070 (obatoclax) induces apoptosis and inhibits cathepsin D- and L-mediated autophagosomal lysis in antiestrogen-resistant breast cancer cells. Mol Cancer Ther 12:448-459, 2013.

52. Settembre C, Di Malta C, Polito VA, et al. TFEB links autophagy to lysosomal biogenesis. Science 332:1429-1433, 2011.

53. Su H, Li F, Ranek MJ, Wei N, Wang X. COP9 signalosome regulates autophagosome maturation. Circulation 124:2117-2128, 2011.

54. Tsvetkov AS, Miller J, Arrasate M, Wong JS, Pleiss MA, Finkbeiner S. A small-molecule scaffold induces autophagy in primary neurons and protects against toxicity in a Huntington disease model. Proc Natl Acad Sci U.S.A 107:16982-16987, 2010.

55. Weidberg H, Shvets E, Elazar Z. Biogenesis and cargo selectivity of autophagosomes. Annu Rev Biochem 80:125-156, 2011.

56. White E. Deconvoluting the context-dependent role for autophagy in cancer. Nat Rev Cancer 12:401-410, 2012. 
57. White E, Dipaola RS. The double-edged sword of autophagy modulation in cancer. Clin Cancer Res 15:5308-5316, 2009.

58. Wirawan E, Vande Walle L, Kersse K, et al. Caspase-mediated cleavage of Beclin-1 inactivates Beclin-1-induced autophagy and enhances apoptosis by promoting the release of proapoptotic factors from mitochondria. Cell Death Dis 1:e18, 2010.

59. Wong E, Bejarano E, Rakshit M, et al. Molecular determinants of selective clearance of protein inclusions by autophagy. Nat Commun 3:1240, 2012.

60. Wong E, Cuervo AM. Integration of clearance mechanisms: the proteasome and autophagy. Cold Spring Harb Perspect Biol 2:a006734, 2010.

61. Yousefi S, Perozzo R, Schmid I, et al. Calpain-mediated cleavage of Atg5 switches autophagy to apoptosis. Nat Cell Biol 8:1124-1132, 2006.

62. Zhu H, Zhang L, Dong F, et al. Bik/NBK accumulation correlates with apoptosis-induction by bortezomib (PS-341, Velcade) and other proteasome inhibitors. Oncogene 24:4993-4999, 2005. 


\subsection{Supplemental data}

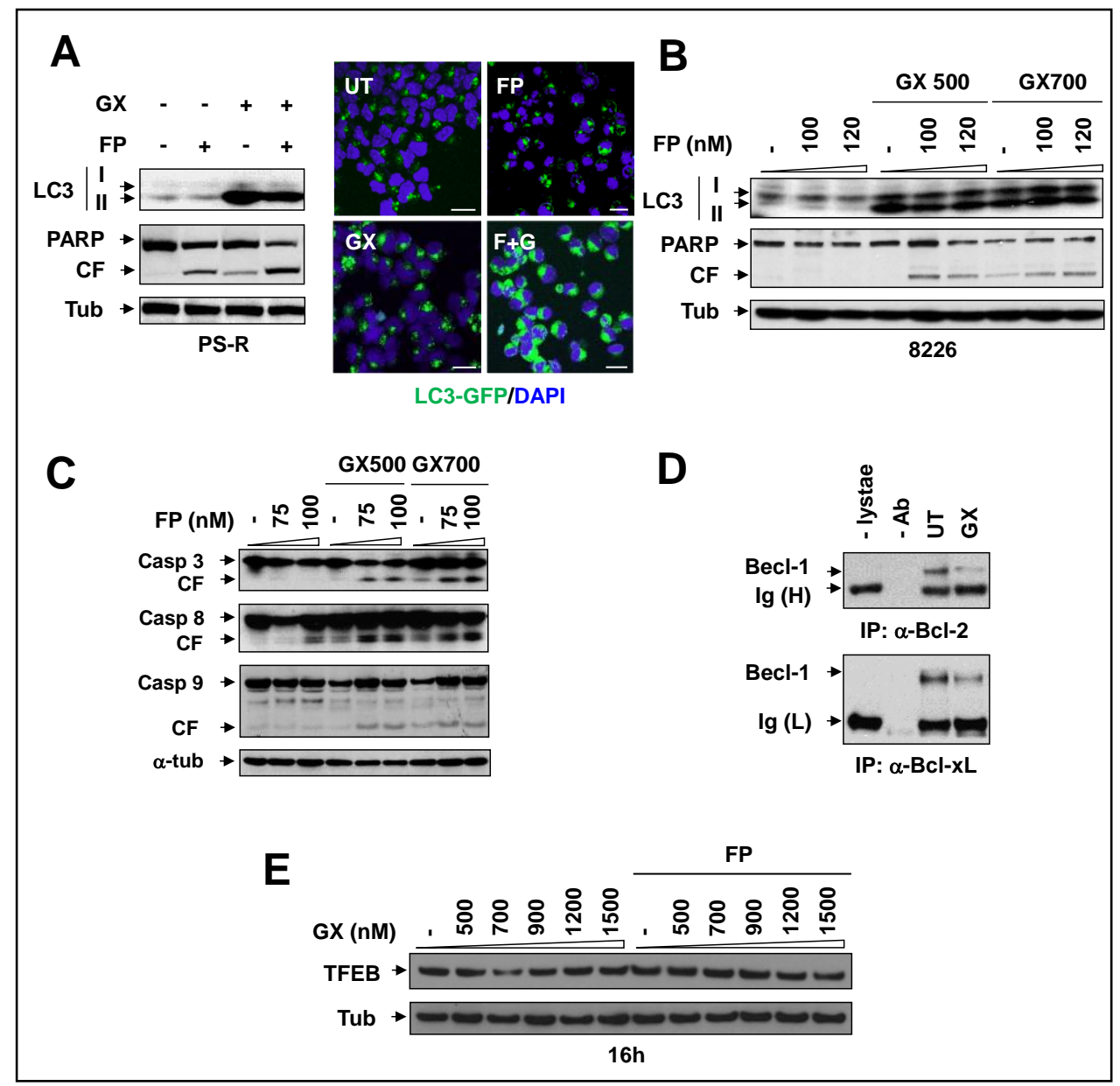

Figure S1. The BH3 mimetic GX015-070 induces autophagy and apoptosis in the presence of Cdk inhibitors. (A,B) Human bortezomib-resistant U266 myeloma cells (PS-R) were exposed to $500 \mathrm{nM} \mathrm{GX015-070} \mathrm{(GX)} \mathrm{+/-} 100 \mathrm{nM}$ flavopiridol (FP); human myeloma RPMI8226 cells were exposed to the indicated concentrations of GX +/- FP, after which immunoblotting analysis was performed to monitor LC3 processing $(16 \mathrm{~h})$ and PARP cleavage $(24 \mathrm{~h})$. CF, cleaved fragment. Alternatively, PS-R cells stably transfected with pEGFP-LC3 were exposed $(16 \mathrm{~h})$ to $500 \mathrm{nM} \mathrm{GX}+/-100 \mathrm{nM} \mathrm{FP}$, followed by confocal microscopy to monitor formation of GFP-LC3 puncta (scale bar $=10 \mu \mathrm{m}$ ). (C) U266 cells were treated with the indicated concentrations of GX +/- FP, after which immunoblotting analysis was performed to monitor cleavage of caspases. (D) U266 cells were exposed $(16 \mathrm{~h})$ to $500 \mathrm{nM}$ GX, followed by coimmunoprecipitation (IP) with either anti-Bcl-2 or anti-Bcl-xL antibody, and then immunoblotting analysis using anti-Beclin-1 antibody. IP without antibody $(-\mathrm{Ab})$ or cell lysate (- lysate) was performed as controls. UT = untreated, $\mathrm{H}=\mathrm{Ig}$ heavy chain, $\mathrm{L}=\mathrm{Ig}$ light chain. (E) U266 cells were treated $(16 \mathrm{~h})$ with the indicated concentrations of GX $(\mathrm{nM})+/-100 \mathrm{nM} \mathrm{FP}$, after which immunoblotting analysis was performed to monitor expression of TFEB, a transcription factor which links autophagy to lysosomal biogenesis. 


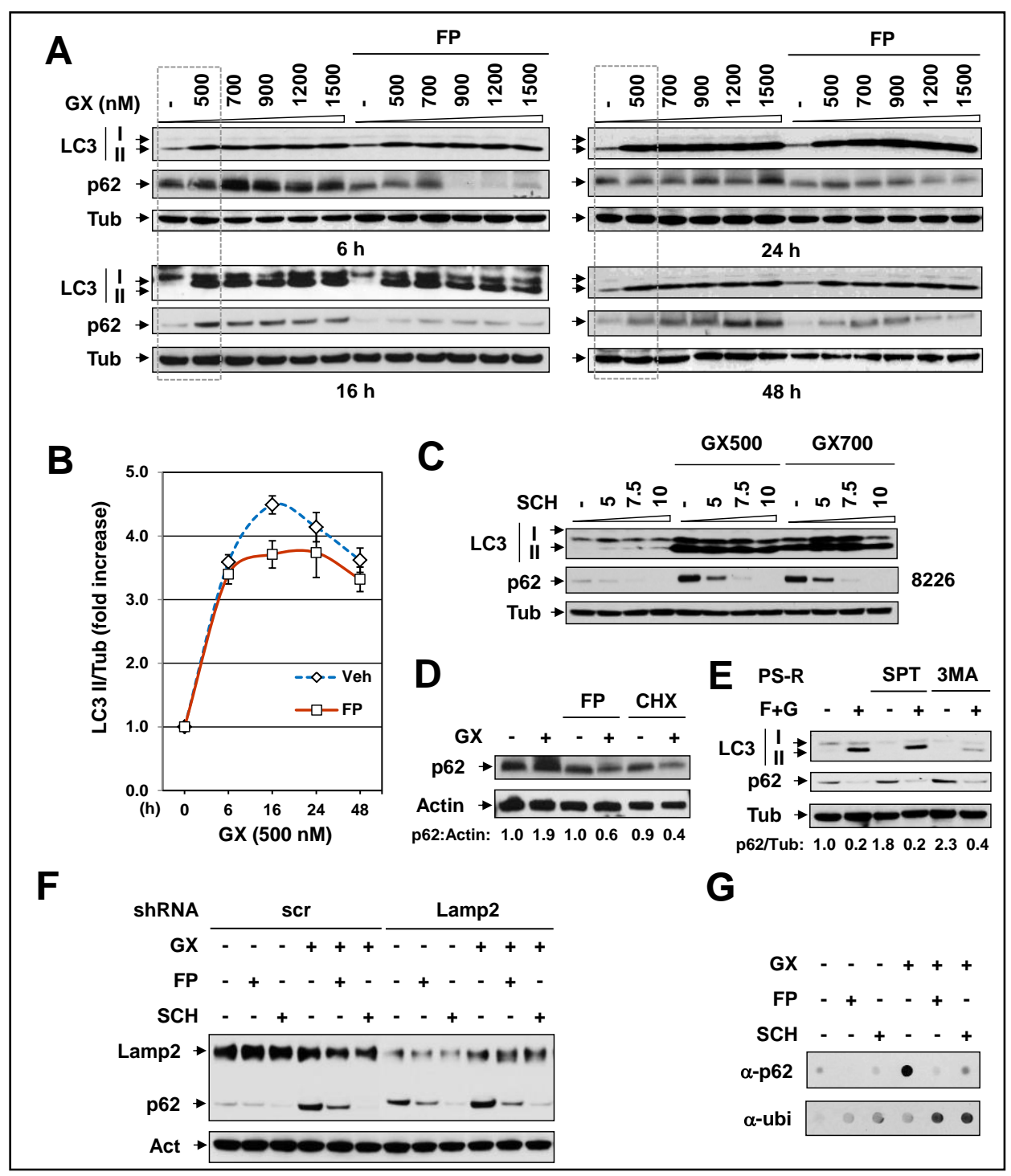

Figure S2. Cdk inhibitors down-regulate SQSTM1/p62 during BH3 mimetic-induced autophagy. (A) U266 cells were treated with the indicated concentrations of GX +/- FP (100 $\mathrm{nM}$ ) for $6,16,24$, and $48 \mathrm{~h}$, after which immunoblotting analysis was performed to monitor LC3 processing and p62 expression. (B) Blots of LC3-II for $500 \mathrm{nM} \mathrm{GX} \mathrm{+/-} \mathrm{FP} \mathrm{were} \mathrm{quantified}$ relative to tubulin (results represent fold-increase over vehicle-treated control; means $\pm \mathrm{SD}$ for three experiments). (C) RPMI8226 cells were treated $(16 \mathrm{~h})$ with the indicated concentrations of GX (nM) +/- SCH727965 (nM), after which immunoblotting analysis was performed to monitor LC3 processing and p62 expression. (D) U266 cells were treated (16 h) with $500 \mathrm{nM} \mathrm{GX}$ in the presence or absence of either $100 \mathrm{nM}$ FP or $1 \mu \mathrm{M}$ cycloheximide (CHX), after which p62 levels were determined by immunoblotting analysis. Values indicate quantification of p62 relative to actin (fold-increase over untreated control). (E) PS-R cells were exposed (16 h) to $500 \mathrm{nM} \mathrm{GX+}$ $100 \mathrm{nM}$ FP in the presence or absence of $7.5 \mu \mathrm{M}$ spautin-1 (SPT) or $500 \mu \mathrm{M} 3$-methyladenine (3-MA), after which LC3 processing and p62 expression were monitored by immunoblotting analysis. Values indicate quantification of p62 relative to tubulin (fold-increase over untreated control). (F) RPMI8226 cells were stably transfected with the constructs encoding shRNA directed against Lamp2 or scrambled sequence as negative control. Cells were then exposed (16 
h) to $500 \mathrm{nM} \mathrm{GX}+/-100 \mathrm{nM}$ FP or $5 \mathrm{nM}$ SCH727965, followed by immunoblotting analysis using the indicated antibodies. (G) U266 were incubated (16 h) with $500 \mathrm{nM} \mathrm{GX}+/-100 \mathrm{nM}$ FP or $5 \mathrm{nM} \mathrm{SCH727965,} \mathrm{after} \mathrm{which} \mathrm{a} \mathrm{filter} \mathrm{trap} \mathrm{assay} \mathrm{was} \mathrm{performed} \mathrm{to} \mathrm{assess} \mathrm{the} \mathrm{amount} \mathrm{of} \mathrm{p62}$ or ubiquitinated protein in SDS-insoluble aggregates using anti-p62 ( $\alpha$-p62) or anti-ubiquitin $(\alpha-$ ubi) antibody, respectively.

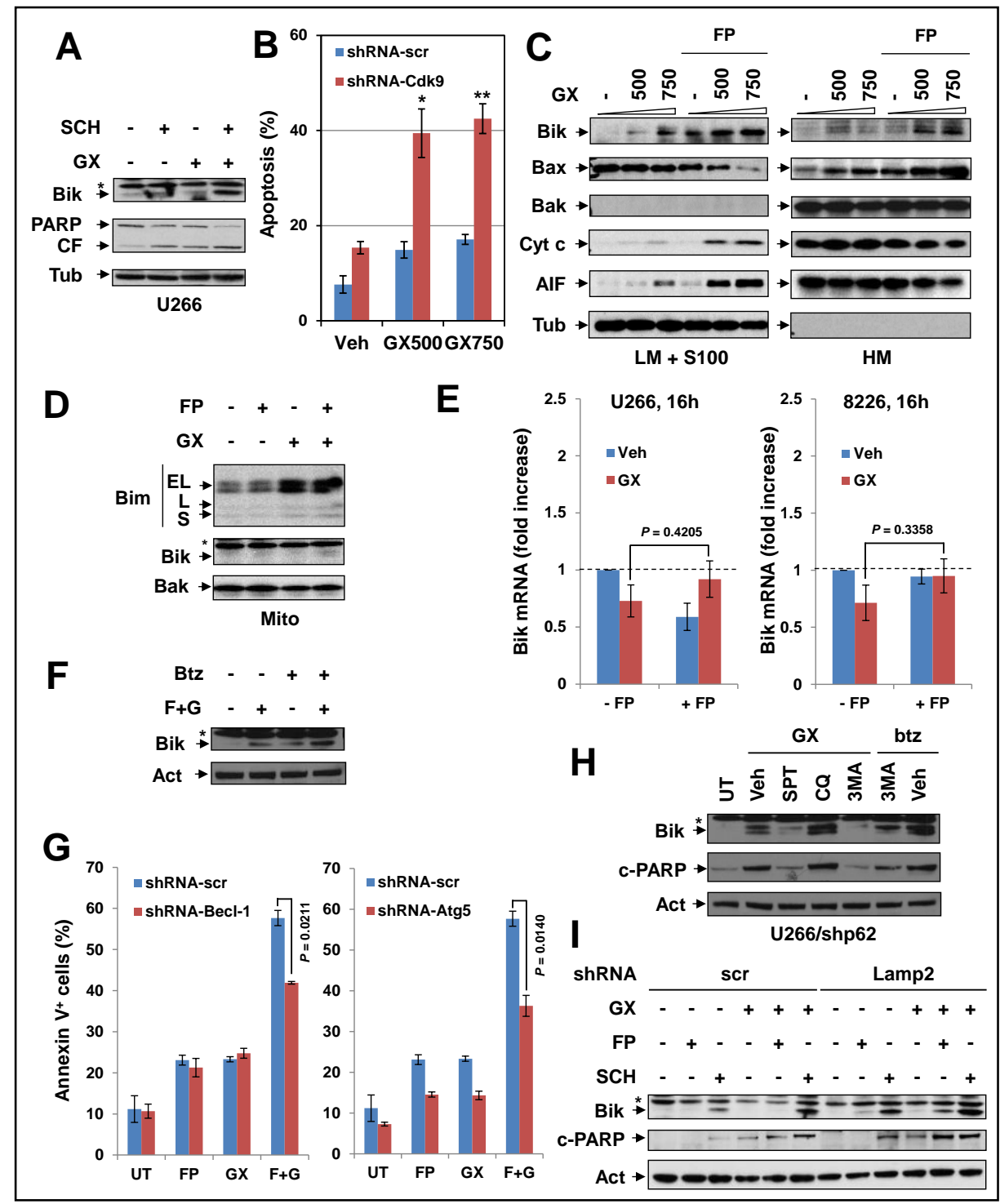

Figure S3. Co-treatment with GX015-070 and Cdk inhibitors up-regulates ER-localized NBK/Bik. (A) U266 cells were treated (24 h) with the $500 \mathrm{nM} \mathrm{GX} \mathrm{+/-} 5$ nM SCH727965, after which immunoblotting analysis was performed to monitor Bik expression and PARP cleavage. *, non-specific band. (B) U266 cells stably transfected with shRNA directed against Cdk9 or scrambled sequence as control were exposed $(24 \mathrm{~h})$ to $500-750 \mathrm{nM} \mathrm{GX}$, after which the percentage of cell death was determined by 7AAD staining and flow cytometry. $* \mathrm{P}<0.05$, ** $\mathrm{P}$ $<0.01$. (C) U266 cells were treated $(24 \mathrm{~h})$ with the indicated concentrations of GX (nM) +/- 100 $\mathrm{nM}$ FP, after which subcellular fractions were separated and subjected to immunoblotting using the indicated antibodies. Briefly, 10x106 cells were homogenized in HIM buffer (200 mM 
mannitol, $70 \mathrm{mM}$ sucrose, $10 \mathrm{mM}$ HEPES, pH 7.4, $1 \mathrm{mM}$ EGTA). The homogenate was then centrifuged at $1000 \mathrm{x} \mathrm{g}$ for $10 \mathrm{~min}$ to remove nuclei and cell debris. The supernatant was collected and then centrifuged at $9000 \mathrm{x}$ g for $10 \mathrm{~min}$, after which the resulting pellet was resuspended in HIM buffer and re-centrifuged at $9000 \mathrm{x} g$ for $10 \mathrm{~min}$ to yield the heavy membrane fraction (HM, predominantly enriched with mitochondria but also containing small amounts of ER proteins), while the supernatant was collected as a mixture of cytosol (S100) and light membrane (LM) fractions. For all steps, Eppendorf Microcentrifuge 5415R with Eppendorf F45-24-11 Rotor and SealRite 1.5ml Natural Microcentrifuge Tubes were used. (D) U266 cells were treated with $500 \mathrm{nM} \mathrm{GX}+/-100 \mathrm{nM}$ FP, after which the mitochondrial (Mito) fraction was isolated and subjected to immunoblotting for Bik and Bim (EL, L, and S isoforms). The blots were then re-probed with anti-Bak antibody as loading control. (E) U266 and RPMI8226 cells treated $(16 \mathrm{~h})$ with $500 \mathrm{nM} \mathrm{GX}+/-100 \mathrm{nM}$ FP, after which qPCR was conducted to detect mRMA level of NBK/Bik (means \pm SD for three experiments). (F) U266 cells were treated with $500 \mathrm{nM} \mathrm{GX}+100 \mathrm{nM}$ FP in the presence or absence of $4 \mathrm{nM}$ bortezomib (btz), followed by immunoblotting analysis to monitor expression of Bik. (G) U266 cells stably transfected with shRNA of Beclin-1 (left) or Atg5 (right) and scrambled sequence as control were exposed to 500 $\mathrm{nM}$ GX +/- $100 \mathrm{nM}$ FP for $24 \mathrm{~h}$, after which flow cytometry was performed to determine percentage of apoptotic (Annexin V+) cells. (H) U266 cells stably transfected with p62 shRNA were treated with $500 \mathrm{nM}$ GX in the presence or absence of $7.5 \mu \mathrm{M}$ SPT, $50 \mu \mathrm{M}$ CQ, $500 \mu \mathrm{M} 3-$ MA, after which immunoblotting analysis was performed to monitor Bik expression and PARP cleavage. In parallel, cells were treated with $4 \mathrm{nM}$ bortezomib +/- 3-MA for comparison. (I) RPMI8226 cells stably expressing shRNA targeting Lamp2 were exposed (24 h) to $500 \mathrm{nM} \mathrm{GX}$ +/- $100 \mathrm{nM}$ FP or $5 \mathrm{nM}$ SCH727965, after which immunoblotting analysis was performed to monitor Bik expression and PARP cleavage. 


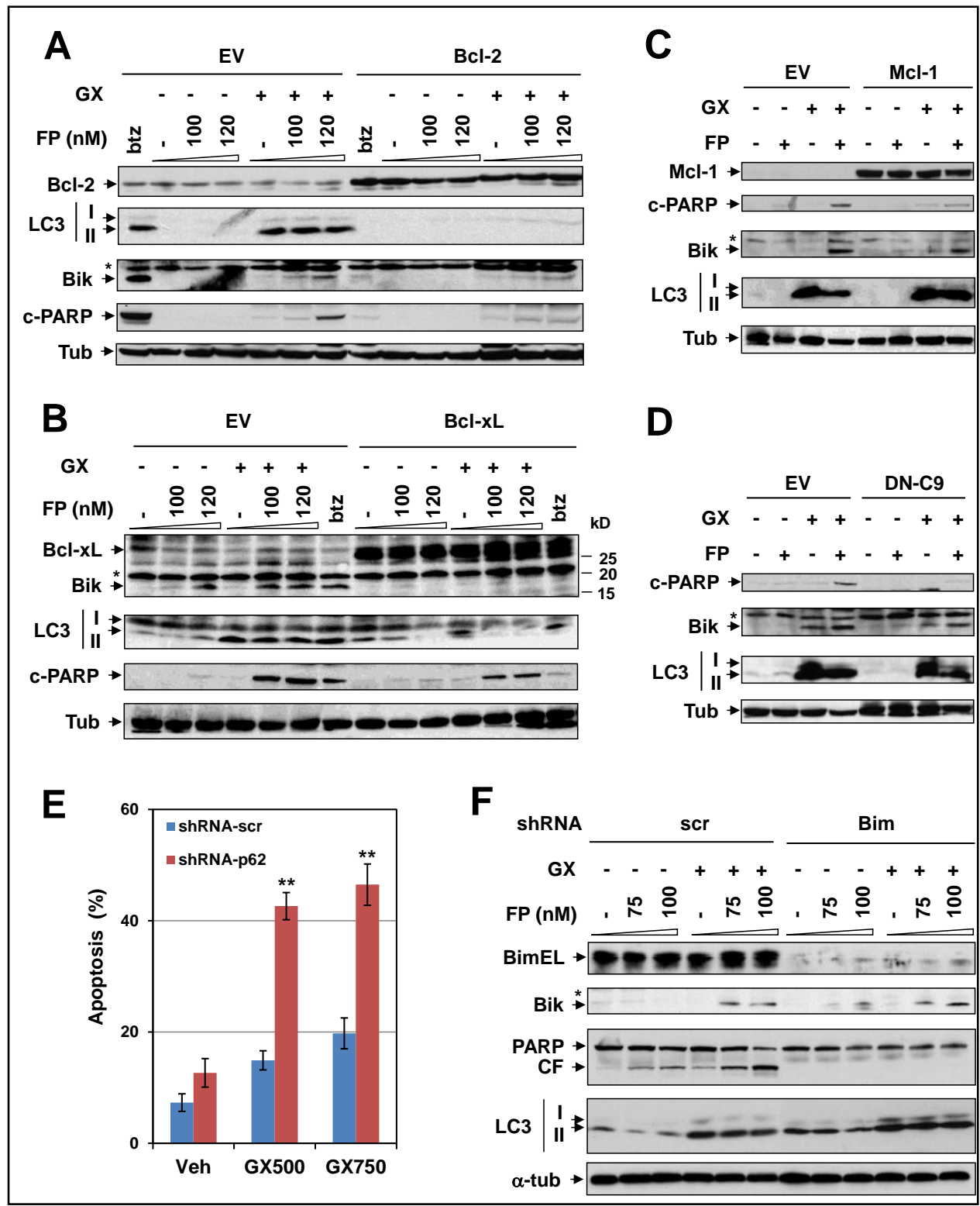

Figure S4. Bcl-2 or Bcl-xL, but not Mcl-1, dominant-negative caspase 9 or Bim shRNA, block autophagy and NBK/Bik up-regulation. (A,B) U266 and RPMI8226 cells were stably transfected with human full-length Bcl-2 (A) or Bcl-xL (B), respectively. Cells were then exposed (24 h) to $500 \mathrm{nM} \mathrm{GX}+/-100-120 \mathrm{nM}$ FP or $4 \mathrm{nM}$ bortezomib (btz) for positive control. (C,D) U266 cells were stably transfected with human full-length Mcl-1 (C) or dominant-negative $(\mathrm{DN})$ caspase 9 (287 Cysteine $\rightarrow$ Alanine; D). Cells were then treated (24 h) with $500 \mathrm{nM} \mathrm{GX}$ +/- $100 \mathrm{nM}$ FP. (B) U266 cells stably transfected with shRNA directed against p62 or scrambled sequence as control were exposed ( $24 \mathrm{~h})$ to $500-750 \mathrm{nM} \mathrm{GX}$, after which the percentage of cell death was determined by 7AAD staining and flow cytometry. $* * \mathrm{P}<0.01$. (F) U266 cells were transfected with a construct encoding shRNA directed against human Bim or scrambled sequence as a negative control, followed by exposure $(24 \mathrm{~h})$ to $500 \mathrm{nM} \mathrm{GX} \mathrm{+/-} 75$ - $100 \mathrm{nM} \mathrm{FP}$. For A-E, after drug treatment, immunoblotting analysis was performed to monitor the indicated proteins. 


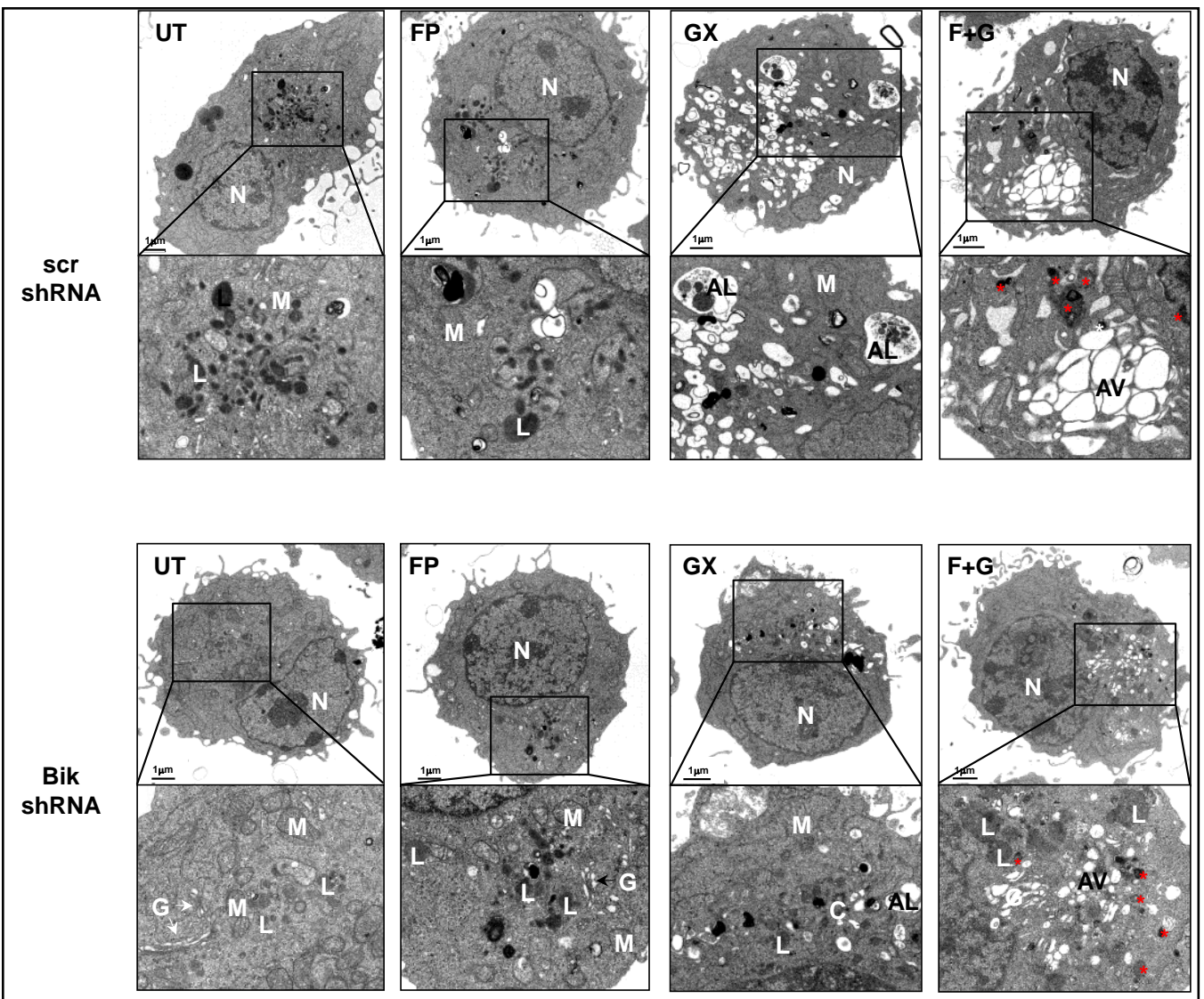

Figure S5. Knock-down of NBK/Bik by shRNA reduces the number of autophagic vacuoles (AVs) but does not modify the appearance of empty AVs. U266 stably transfected with the constructs encoding shRNA targeting Bik or scrambled sequence as control were treated (16 h) with $500 \mathrm{nM} \mathrm{GX} \mathrm{+/-} 100 \mathrm{nM} \mathrm{FP}$, followed by electron microscopy (EM). N, nucleus; M, mitochondrion; L, lysosome; G, Golgi apparatus; A, autophagosome; AL, autolysosome; AV, autophagic vacuoles with clear ("empty”) content; *, deformed mitochondrion. 


\section{Part 2}

\section{Bim acts as a dual-agent regulating both autophagy and apoptosis in acquired drug- resistance}

\subsection{INTRODUCTION}

Multiple myeloma (MM) is an accumulative disorder of mature plasma cells. Recent treatment advances, including proteasome inhibitors (e.g., bortezomib/btz, carfilzomib) and immunomodulatory agents (IMiDs) have significantly improved MM patient outcomes (1). However, relapse and drug resistance occur in virtually all responding patients (2). Like many malignancies, MM is characterized by dysregulation of the Bcl-2 family (3), divided into proand anti-apoptotic groups. The former consists of multi-domain (e.g., Bak and Bax) and BH3only proteins (e.g., Bim, Bid, Puma, Noxa, Bad, Bik, Bmf, and Hrk, etc.), while the latter include multi-domain proteins e.g., Bcl-2, Bcl-xL, Mcl-1 (4). Whereas Bax/Bak are absolutely required for apoptosis, BH3-only proteins include "activators" (e.g., Bim) and "sensitizers/derepressors" (e.g., Noxa, Bik) (5). Attention has focused on Bim because it determines the activity of diverse agents targeting oncogene-driven pathways $(6,7)$. Bim is up-regulated by inhibition of pathways (e.g., MEK/ERK and PI3K/AKT) that repress expression through transcriptional regulation and/or post-translational modifications, particularly phosphorylation (8). Bim phosphorylation promotes ubiquitination and proteasomal degradation $(9,10)$. Notably, proteasome inhibitors (e.g., btz) block the latter process, resulting in Bim accumulation, representing a mechanism of action (MOA) of these agents (11). However, not all MM patients respond to btz (intrinsic resistance), and initial responders eventually relapse (adaptive or acquired resistance) (12), prompting efforts to understand and overcome these events. 
BH3-mimetics such as ABT-737 bind and inactivate anti-apoptotic Bcl-2 family proteins, inducing apoptosis in MM cells $(3,13)$. Its clinical analog ABT-263 (navitoclax) and the newergeneration ABT-199, which targets Bcl-2 only, show promising activity in certain cancers (14), including hematopoietic malignancies (15). Mechanistically, Bim release from $\mathrm{Bcl}-2 / \mathrm{Bcl}-\mathrm{xL}$ represents a major ABT-737 MOA (16). Notably, BH3-mimetics also induce autophagy by releasing Beclin-1 from $\mathrm{Bcl}-2 / \mathrm{Bcl}-\mathrm{xL}$ (17). In contrast to apoptosis, autophagy is generally a cytoprotective mechanism maintaining intracellular homeostasis by removing harmful malfolded proteins, protein aggregates, and damaged organelles (18), while autophagy inhibition promotes BH3-mimetic lethality (19). Importantly, a recent study demonstrated that Bim inhibits autophagy by sequestering Beclin-1 at microtubules (20). On the other hand, histone deacetylase inhibitors (HDACIs) up-regulate Bim in tumor cells, including MM cells $(21,22)$. Among HDACIs, romidepsin and vorinostat have been approved for cutaneous T-cell lymphoma and peripheral T-cell lymphoma (23). HDACI lethality involves multiple mechanisms, including oxidative injury, death receptor up-regulation, anti-apoptotic protein down-regulation, Bim upregulation, and disabling of chaperone and DNA repair proteins, among others (24). Notably, HDACIs also modulate autophagy (25-28).

Currently, the role of Bim in resistance to proteasome inhibitors such as btz is largely unknown. Here we report that Bim is widely expressed in MM cells, and while basal Bim levels do not correlate with intrinsic btz-resistance, Bim down-regulation confers adaptive btzresistance in Bim ${ }^{\text {hi }}$ MM cells. Furthermore, HDACIs prime btz-resistant cells displaying Bim down-regulation to BH3-mimetic lethality by increasing Bim expression. Mechanistically, Bim up-regulation by HDACIs disables cytoprotective autophagic responses to $\mathrm{BH} 3$-mimetics. Finally, in Bim ${ }^{\text {low }} \mathrm{MM}$ cells which display minimal Bim up-regulation in response to HDACIs, 
autophagy disruption (e.g., by CQ) is required for full response to this strategy. Collectively, these findings provide proof of principle for a Bim-targeting strategy in which HDACIs, which up-regulate Bim, are combined with BH3-mimetics (e.g., ABT-737), which unleash Bim from anti-apoptotic Bcl-2 family proteins, in btz-resistant MM.

\subsection{MATERIALS AND METHODS}

\subsubsection{Cells and reagents}

Human MM U266, H929, RPMI8226, and IL-6-dependent KAS 6/1 cell lines were obtained from ATCC and maintained as before (29,30). To establish human MM cells adaptively resistant to btz, RPMI8226 and U266 cells were continuously cultured in gradually increasing concentrations of btz (initially $0.5 \mathrm{nM}$ and increasing in stepwise increments of $0.2 \mathrm{nM}$ ) to $10 \mathrm{nM}$ or 20nM, respectively. Dexamethasone-sensitive (MM.1S) and -resistant (MM.1R) cell lines were provided by Dr. Steven T. Rosen (Northwestern University, Chicago, Ill). All experiments utilized logarithmically growing cells $\left(3-5 \times 10^{5}\right.$ cells $\left./ \mathrm{ml}\right) . \mathrm{CD}_{138^{+}}$and $\mathrm{CD} 138^{-}$cells were isolated from bone marrow (BM) samples were obtained with informed consent according to the Declaration of Helsinki and VCU IRB approval from three patients with MM undergoing routine diagnostic aspirations. $\mathrm{Bim}^{+/+}$and $\mathrm{Bim}^{-/-}$MEFs derived from wild type (wt) or Bim knockout mice were kindly provided by Dr. Hasashi Harada (31).

The Bcl-2/Bcl-xL/Bcl-w antagonist ABT-737 and ABT-199 were kindly provided by Abbott Laboratories (Abbott Park, IL) (32). Suberoyl bishydroxamic acid (SBHA) ${ }^{33}$, and chloroquine (CQ) were purchased from Calbiochem (San Diego, CA) and Sigma (St. Louis, MO), respectively. Drugs were dissolved in sterile DMSO (final concentration $<0.1 \%$ ), aliquoted and stored at $-20^{\circ} \mathrm{C}$. 


\subsubsection{Isolation of primary MM cells}

Fresh bone marrow (BM) samples were obtained from patients with MM undergoing routine diagnostic aspirations. $\mathrm{CD}_{138^{+}}$and $\mathrm{CD} 138^{-}$cells were separated using a MACS magnetic separation technique (Miltenyi Biotech, Auburn, CA) as per the manufacturer's instructions. The purity (> 90\%) and viability (>95\%) of $\mathrm{CD} 138^{+}$fractions was determined by flow cytometry and trypan blue exclusion, respectively. Isolated cells were maintained in RPMI1640 medium containing $10 \%$ FBS.

\subsubsection{PCR array}

Human Apoptosis $\mathrm{RT}^{2}$ Profiler Array Kit (Qiagen, Valencia, CA) was used to profile the expression of key genes involved in apoptosis as per the manufacturer's instructions. Briefly, total RNA was isolated using RNeasy Mini Kit (Qiagen). Genomic DNA was digested by DNase I (Amplification Grade, Invitrogen). cDNA was synthesized from $1 \mu \mathrm{g}$ of total RNA using $\mathrm{RT}^{2}$ First Strand Kit (Qiagen), followed by PCR array using RT2 SYBR Green ROX ${ }^{\mathrm{TM}}$ qPCR Mastermix (Qiagen) and 7900HT Real-Time PCR System (Applied Biosystems, Foster City, CA).

\subsubsection{Real-time PCR (qPCR)}

qPCR analysis using TaqMan Gene Expression Assays and 7900HT Real-Time PCR System (Applied Biosystems, Foster City, CA) were performed to quantify mRNA levels of human Bim expression. Briefly, total RNA was isolated using TRIZOL Reagent (Invitrogen, Carlsbad, CA) as per the manufacturer's instructions. cDNA was synthesized from $1 \mu \mathrm{g}$ of total RNA using a High Capacity cDNA Reverse Transcription Kit (Applied Biosystems). $2 \mu$ of cDNA was 
employed for qPCR assays (TaqMan Gene Expression Assays) using a 7900HT Real-Time PCR System (Applied Biosystems). Assay ID for Bim was Hs00708019. Reference for quantitation was human $\beta$-actin (Pre-Developed TaqMan Assay Reagents Control Kit, Applied Biosystems). Data analyzed by using SDS 2.3 software.

\subsubsection{RNA interference}

SureSilencing shRNA plasmids were purchased from SABioscience (Frederick, MD), which target Bim (human BCL2L11; clone ID \#1, GAGACGAGTTTAACGCTTACT; clone ID \#2, CACCCATGAGTTGTGACAAAT) or scrambled sequence as negative control (NC, GGAATCTCATTCGATGCATAC). U266 cells were stably transfected with these constructs by using the Amaxa Nucleofector device with Cell Line Specific Nucleofector Kit C (Amaxa $\mathrm{GmbH}$, Cologne, Germany) as per the manufacturer's instructions. The Lentiviral Particle Gene Silencers construct (sc-29390-V) encoding shRNA targeting human LAMP2 and Control Lentiviral Particles were purchased from Santa Cruz Biotech (Santa Cruz, CA) and used to transduce RPMI8226 cells. Clones with down-regulated expression of Bim or LAMP2 were selected with $400 \mu \mathrm{g} / \mathrm{ml} \mathrm{G} 418$ or $2 \mu \mathrm{g} / \mathrm{ml}$ puromycin, respectively .

\subsubsection{Flow cytometry}

The extent of apoptosis was evaluated by flow cytometry utilizing annexin V-FITC/PI. Briefly, $1 \times 10^{6}$ cells were stained with annexin V-FITC (BD PharMingen, San Diego, CA) and 5 $\mu \mathrm{g} / \mathrm{ml}$ propidium iodide (PI; Sigma) in $1 \mathrm{x}$ binding buffer for $15 \mathrm{~min}$ at room temperature in the dark. Samples were then analyzed by $B D$ Biosciences FACSCalibur flow cytometry (Becton- 
Dickinson, San Jose, CA) within $1 \mathrm{~h}$ to determine the percentage of apoptotic (annexin $\mathrm{V}$ positive) cells.

\subsubsection{Autophagy analysis}

LC3 puncta were visualized after stable transfection with pEGFP-LC3B (plasmid 11546, Addgene, Cambridge, MA) (34), using a Zeiss LSM 700confocal microscope. LC3 processing from LC3-I to LC3-II was monitored by immunoblotting analysis using anti-LC3 antibody (Novus, Littleton, CO) $(35 ; 36)$. MEFs were stained with acridine orange (AO, Sigma) to detect acidic vesicular organelles (AVOs), indicating autophagy (37).

\subsubsection{Immunoblotting analysis}

Samples were prepared from whole-cell pellets. Total protein was quantified using Coomassie Protein Assay Reagent (Pierce, Rockford, IL). Equal amounts of protein $(30 \mu \mathrm{g})$ were subjected to immunoblotting. Where indicated, the blots were re-probed with antibodies against $\beta$-actin, $\alpha$-tubulin, or GAPDH to ensure equal loading and transfer of proteins. The following antibodies were used as primary antibodies: Bim (ProSci, Poway, CA; Millipore, Billerica, MA; Santa Cruz Biotech, Santa Cruz, CA); Mcl-1, caspase 3, caspase 9, and cytochrome c (BD PharMingen); cleaved caspase 3 (Asp175), cleaved caspase 9 (Asp315), cleaved PARP (Asp214), Bcl-xL, and Beclin-1, (Cell Signaling, Beverly, MA); human Bcl-2 oncoprotein (DAKO, Carpinteria, CA); PARP (Enzo, Plymouth Meeting, PA); LAMP2, Noxa, Puma, HA, Bak, and Bax (Santa Cruz Biotech, Santa Cruz, CA).

\subsubsection{Immunofluorescence}


Cytospin slides were fixed in $4 \%$ paraformaldehyde for $1 \mathrm{~h}$, permeabilized in $0.25 \%$ Triton X100 in PBS, blocked in 1\% BSA and 2\% FBS in PBS, followed by staining with anti-Bim or anti-LC3 antibodies, followed by AlexaFluor 488-conjugated secondary antibody. Slides were mounted using a Vectashield containing DAPI. Images were captured using a Olympus IX71 Research Inverted System Microscope with a DP73;17MP Color Camera.

\subsubsection{Subcellular fractionation}

$2 \times 10^{6}$ cells were lysed in digitonin lysis buffer. Lysates were centrifuged, and the supernatant (S-100 cytosolic fraction) was collected and added to an equal volume of $2 \mathrm{x}$ sample buffer. The pellets (mitochondria-enriched fractions) were washed once in cold PBS and lysed in 1x sample buffer. The S-100 and pellet samples were quantified, separated by SDS-PAGE, and subjected to immunoblotting for monitoring localization of Bax and Bim.

\subsubsection{Immunoprecipitation}

(Co-)immunoprecipitation analysis was performed to evaluate interactions between Beclin-1 or Bim and Bcl-2, Bcl-xL, or Mcl-1. Briefly, cells were lysed in CHAPS buffer (150 mM NaCl, $10 \mathrm{mM}$ HEPES pH7.4, protease inhibitors, and 1\% CHAPS) and $200 \mu \mathrm{g}$ of protein per condition were incubated with $1 \mu \mathrm{g}$ anti-Bcl-2 (DAKO), anti-Bcl-xL (Cell Signaling), or anti-Mcl-1 (BD PharMingen) overnight at $4^{\circ} \mathrm{C} .20 \mu \mathrm{l} /$ condition of Dynabeads (Dynal, Oslo, Norway) were then added and incubated for an additional $4 \mathrm{~h}$. After washing, bead-bound protein was eluted by vortexing and boiling in $20 \mu \mathrm{l} 1 \mathrm{x}$ sample buffer. The samples were separated by SDS-PAGE and subjected to immunoblotting analysis as described above. Anti-Bim (ProSci) and anti-Beclin-1 (Santa Cruz) were used as primary antibodies, respectively. 


\subsubsection{Animal studies}

Animal studies approved the VCU IACUC, were performed in accordance with the U.S. Department of Agriculture and Department of Health and Human Services, and the NIH. NOD/SCID-gamma (NSG) mice (Jackson Laboratories) were subcutaneously inoculated in the flank with $5 \times 10^{6}$ bortezomib-resistant PS-R or U266/shBim cells. After tumors were visible, ABT-737 (100 mg/kg) and SBHA (200 mg/kg) were administrated (i.p.) individually or in combination ( $\mathrm{n}=5$ per group) three days a week. Control animals received equal volumes of vehicle. Tumor size was measured by caliper and volumes calculated using the formula $(\mathrm{L} \mathrm{x}$ $\left.\mathrm{W}^{2}\right) / 2$, with $\mathrm{L}=$ length and $\mathrm{W}=$ width. Body weights were measured every other day throughout the study. When tumor size reached $2,000 \mathrm{~mm}^{3}$ or other humane endpoints (e.g., abscessed or necrotic tumors) reached, mice were euthanized in accordance with institutional guidelines.

\subsubsection{Statistical analysis}

Values represent the means \pm SD for $\geq$ three independent experiments performed in triplicate. The significance of differences between experimental variables was determined using the One-way ANOVA with Tukey-Kramer Multiple Comparisons Test and Student's t test. $P<$ 0.05 was considered significant.

\subsection{RESULTS}

2.4.1 Bim down-regulation confers adaptive rather than intrinsic bortezomib resistance in Bim $^{\text {hi }}$ MM cells 
To examine basal levels of BH3-only proteins, eight human MM cell lines were subjected to immunoblotting profiling. All untreated human MM cell lines analyzed displayed high Bim protein levels $\left(\right.$ Bim $\left.^{\text {hi }}\right)$, with one exception e.g., H929 cells (Bim ${ }^{\text {low }}$; Fig. 1A). In contrast, basal Noxa or Puma expression was relatively low and varied between lines. Similarly, Bim was clearly expressed in primary $\mathrm{CD}_{138^{+}} \mathrm{MM}$ cells, but minimally in their $\mathrm{CD}_{138^{-}}$counterparts or normal cord blood CD34 ${ }^{+}$cells (Fig. 1B and Supplemental Fig. S1A). Interestingly, H929 cells were equally, if not more, susceptible to btz compared to other lines (e.g., U266 and MM.1S; Supplemental Fig. S1B), suggesting lack of correlation between basal Bim levels and intrinsic btz sensitivity. However, in Bim ${ }^{\text {hi }}$ U266 cells, shRNA Bim knock-down sharply diminished PARP cleavage and reduced apoptosis $(P<0.0001$ compared to shNC controls $)$ induced by btz (5nM, 24 hr; Fig. 1C and Supplemental Fig. S1C), indicating a significant functional role for Bim in btz sensitivity of Bim ${ }^{\text {hi }} \mathrm{MM}$ cells.

To assess Bim functional significance in adaptive btz resistance, U266 cells were cultured in progressively higher btz concentrations up to $15 \mathrm{nM}$, generating a highly-resistant subline (PS-R). Whereas 20nM btz (24 hr) killed almost $100 \%$ of btz-naïve U266 cells, PS-R cells displayed virtually complete resistance (Fig. 1D, left, and Supplemental Fig. S1D). To identify candidate gene(s) responsible for resistance, a profiling array for 84 key apoptosis pathway genes compared PS-R cells to parental U266 cells (Fig. 1D, right). The heat map identified the gene hit BCL2L11 (mRNA 1.52-fold lower in PS-R than U266 cells), which encodes Bim, a finding validated by qPCR (Supplemental Fig. S1E). Consistently, PS-R cells displayed sharply reduced Bim protein levels, particularly the EL isoform, and to a lesser extent, L, and S isoforms, accompanied by modest increases in Mcl-1 expression (Fig. 1E). Bim localized primarily to the mitochondria-enriched fraction (38), where loss of Bim was also observed (Supplemental Fig. 
S1F). Bim expression was also clearly down-regulated in btz-resistant 8226/VR cells, which exhibited little change in Bcl-2, Bcl-xL, or Mcl-1 expression. (Supplemental Fig. S1G). Notably, CD138 ${ }^{+}$cells isolated from newly diagnosed MM patients displayed higher basal Bim levels compared to those from relapsed patients who had received prior bortezomib (Fig. 1F and Supplemental Fig. S1H). PS-R cells displayed little or no change in expression of other Bcl-2 family proteins, including anti-apoptotic (e.g., Bcl-2, Bcl-xL, Bfl1/A1, or Bcl-w) or other proapoptotic BH3-only proteins (e.g., Puma, Bid, Bad, Bmf, and Bik; not shown). Interestingly, modest Noxa increases but declines in Bfl1/A1 and Hrk expression were observed in PS-R cells (not shown). Together, these findings argue that whereas basal Bim expression per se does not predict btz responsiveness, Bim down-regulation represents a mechanism underlying adaptive forms of btz-resistance in MM cells initially expressing high Bim (i.e., Bim ${ }^{\text {hi }}$ ).

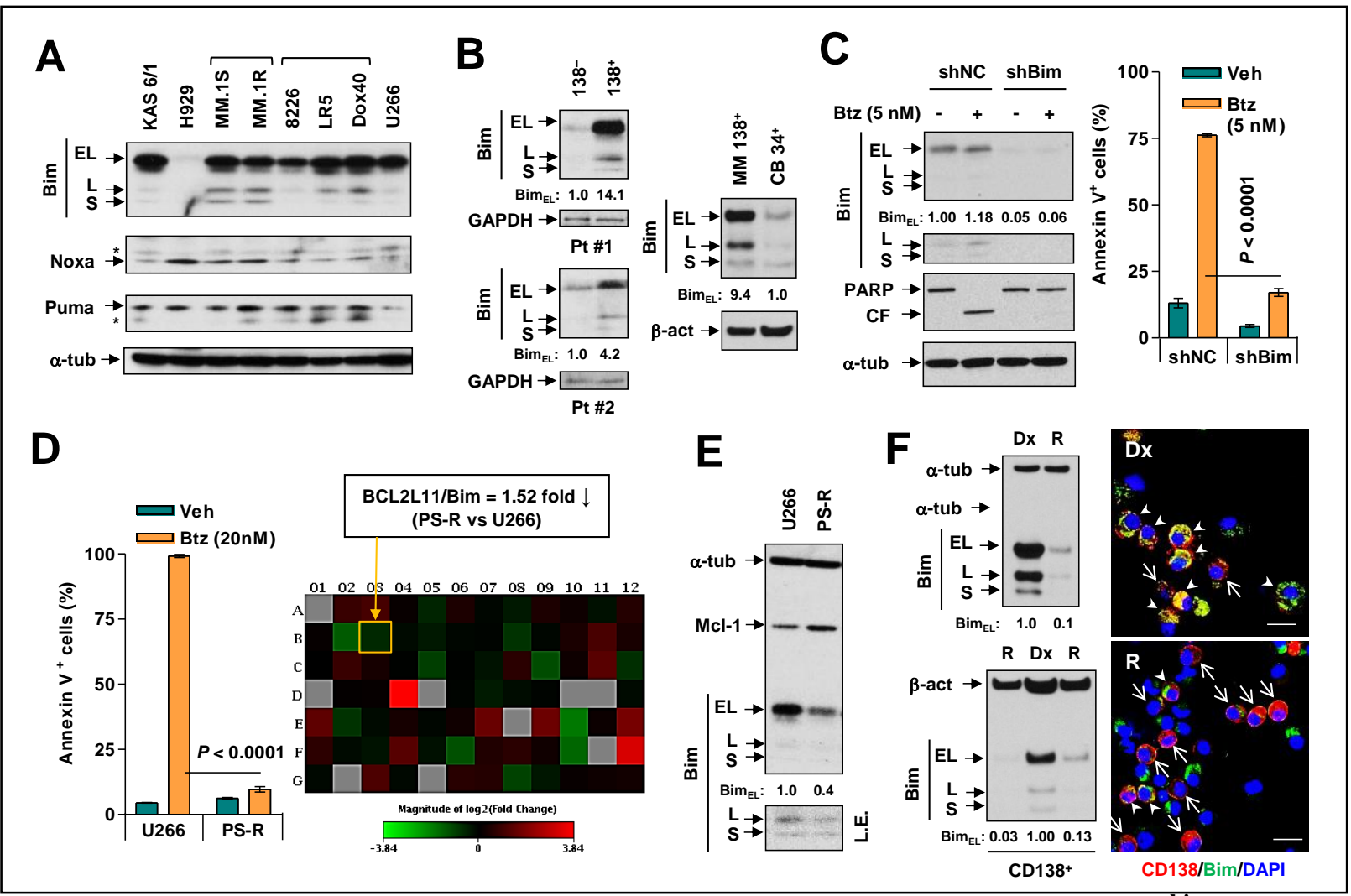

Figure 1. Loss of Bim is associated with adaptive bortezomib-resistance in Bim ${ }^{\text {hi }} \mathrm{MM}$ cells. 
(A) Immunoblotting analysis was performed to profile basal levels of the $\mathrm{BH} 3$-only proteins Bim (including EL, L and S isoforms), Noxa, and/or Puma in untreated human MM cell lines. * indicates non-specific bands. (B) Three primary samples obtained from two patients $(\mathrm{Pt})$ with $\mathrm{MM}$ as well as normal $\mathrm{CD} 4^{+}$cells isolated from cord blood were subjected to Western blot analysis for basal levels of Bim. Blots for Bim $\mathrm{EL}_{\mathrm{L}}$ were quantified using ImageJ software (available online). Values indicate fold-increase after normalization to loading controls (e.g., GADPH or $\beta$-actin). (C) Bim ${ }^{\text {hi }}$ U266 cells were stably transfected with constructs encoding shRNA targeting Bim (shBim) or scrambled sequence as a negative control (shNC). Cells were then exposed to $5 \mathrm{nM}$ bortezomib for $24 \mathrm{hr}$, followed by immunoblotting for expression of Bim and cleavage of PARP (left panels) or flow cytometry to determine the percentage of apoptotic (annexin $\mathrm{V}^{+}$) cells. CF, cleaved fragment. L.E., long exposure. (D) U266 cells were continuously cultured with gradually increasing concentrations of bortezomib until $20 \mathrm{nM}$ to generate a subline (PS-R) which acquired marked resistance to bortezomib, as determined by flow cytometry (left panel). A Human Apoptosis $\mathrm{RT}^{2}$ Profiler Array Kit was then used to compare differences in the expression (mRNA) of key genes involved in apoptosis between PS-R and U266 cells. The heat map showed genes that were up- or down-regulated in PS-R cells, compared to U266 cells (right panel). (E) In parallel, immunoblotting analysis was conducted to monitor protein levels of Bim and/or Mcl-1 in untreated parental U266 cells and their bortezomib-resistant counterparts (PS-R). (F) Primary CD $138^{+}$cells were isolated from newly diagnosed ( $D x, n=2$ ) or relapsed ( $R, n=3$, who had received prior bortezomib) MM patients, after which untreated cells were subjected to Western blot analysis (left) or immunofluorescence staining (IF) for CD138 (PE, red) or Bim (AlexaFluor 488, green). Arrows and arrowheads indicate $\mathrm{CD}_{138^{+}}$cells displaying low and high Bim positivity, respectively. Scale bar $=10 \mu \mathrm{m}$ (magnification $\mathrm{x}$ 40).

\subsubsection{Bim plays a significant functional role in BH3-mimetic sensitivity in MM cells}

BH3-mimetics (e.g., ABT-737) activate Bim by releasing it from anti-apoptotic proteins (e.g.,

Bcl-2, Bcl-xL), and BH3 peptides have been utilized to predict tumor cell susceptibility to anticancer therapies (39). Notably, exposure of various MM cells to ABT-737 clearly downregulated Bim, principally the EL isoform (Fig. 2A). ABT-737 exposure also induced Mcl-1 upregulation, consistent with reports in lymphoma cells (40). These events presumably represent compensatory responses to disruption of Bim and Bcl-2/Bcl-xL interactions (Supplemental Fig.

S2A). The functional role of Bim in ABT-737 lethality in MM cells was then assessed. Following exposure to 750nM ABT-737 for 48-72 hr, shRNA knockdown of Bim diminished Bax mitochondrial translocation, cytosolic cytochrome c release, and caspase-9 cleavage (Fig. 
2B), and apoptosis (Supplemental Fig. S2B). Conversely, stable expression of HA-tagged Bim

(Fig. 2C, inset) significantly sensitized MM cells to ABT-737, compared to empty-vector controls (Fig. 2C; $P<0.01$ in each case). Moreover, transient transfection of bortezomibresistant PS-R cells with HA-tagged Bim resulted in robust apoptosis (Fig. 2D), while ABT-737 failed to increase lethality further in these cells (Supplemental Fig. S2C). These findings suggest that $\mathrm{BH} 3$-mimetics elicit Bim down-regulation and Mcl-1 up-regulation as compensatory responses to disabling of $\mathrm{Bcl}-2 / \mathrm{Bcl}-\mathrm{xL}$, and raise the possibility that a Bim-targeting strategy might be effective in btz-resistant MM cells displaying Bim down-regulation.

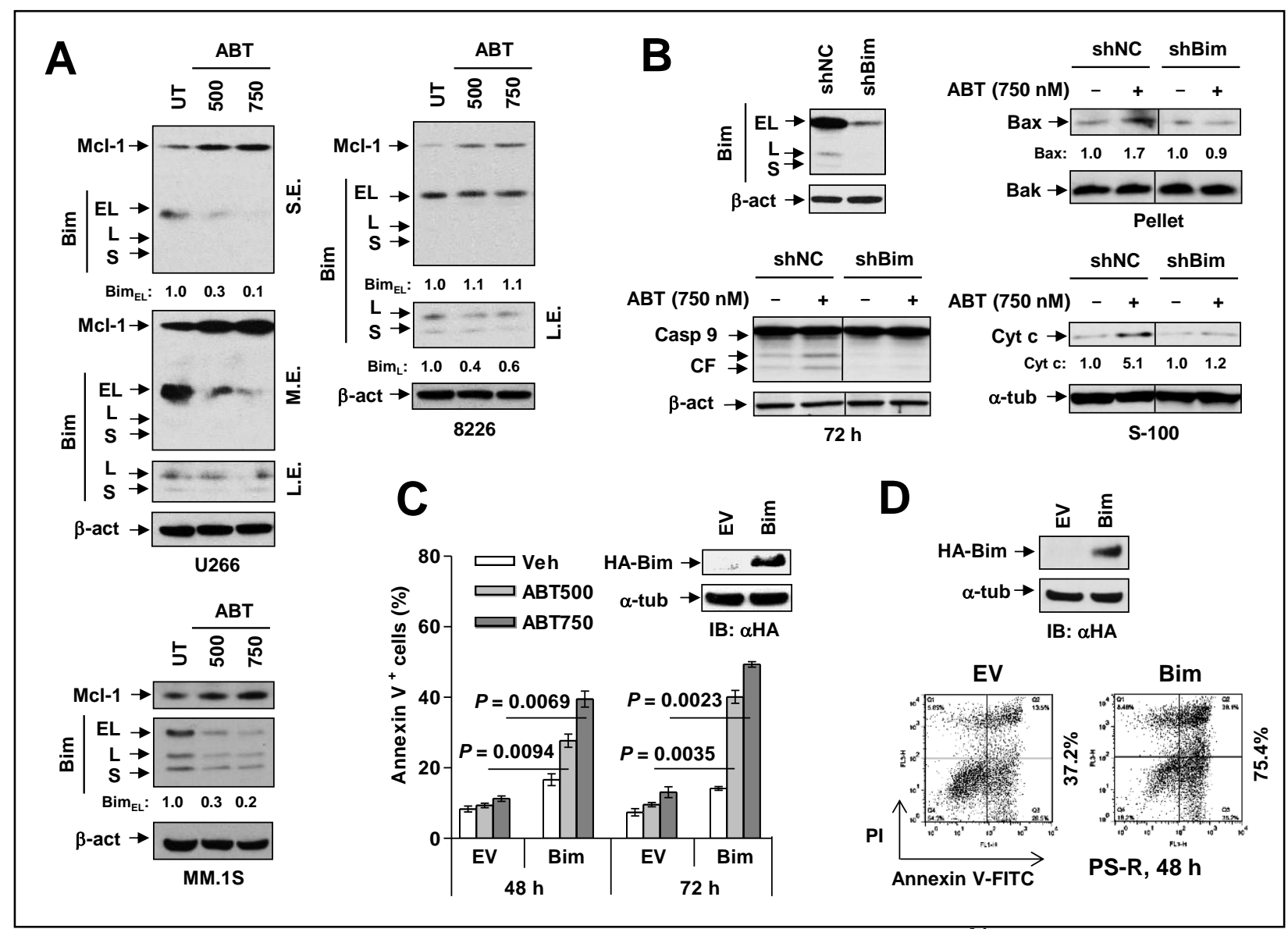

Figure 2. Bim acts as a determinant of ABT-737 sensitivity in Bim ${ }^{\text {hi }}$ MM cells. (A) U266 (upper left), RPMI8226 (upper right), and MM.1S (lower) were treated with the indicated concentrations (nM) of ABT-737 for 24 or $48 \mathrm{hr}$, after which expression of Bim and Mcl-1 was monitored by immunoblotting analysis. S.E., short exposure; M.E., medium exposure; L.E., long 
exposure. (B) U266 cells stably transfected with Bim shRNA (left upper panels) were treated $750 \mathrm{nM}$ ABT-737 for $72 \mathrm{hr}$, followed by immunoblotting analysis for monitoring caspase 9 cleavage (left lower panels), Bax translocation (to mitochondria, right upper panels) and cytochrome c release (to cytosol, right lower panels). Bak was probed for loading control of the mitochondria-enriched fraction. The vertical lines indicate the splice site in the composite image derived from a single blot. (C) RPMI8226 cells were stably transfected with HA-tagged human full-length Bim (inset, using an anti-HA antibody) or an empty vector (EV). Cells were then exposed to 500 - $750 \mathrm{nM}$ ABT-737 for $48 \mathrm{hr}$ and $72 \mathrm{hr}$, after which the percentage of apoptotic cells was determined by flow cytometry. Numbers indicate P value. (D) Bortezomib-resistant U266 cells (PS-R) were transiently transfected with an empty vector or HA-tagged Bim construct. After $48 \mathrm{hr}$, untreated cells were lysed and subjected to Western blot analysis for HABim (inset, using anti-HA antibody) or flow cytometry to determine the percentage of apoptotic (Annexin $\mathrm{V}^{+}$) cells.

\subsubsection{Bim up-regulation primes bortezomib-resistant MM cells to BH3-mimetic lethality}

Treating drug-resistant tumor cells with BH3 (particularly Bim) peptides lowers the death threshold and increases sensitivity to anti-cancer agents (e.g., ABT-737) (41), i.e., cell death priming (42). Attempts were therefore made to test whether Bim up-regulation could mimic BH3 peptides in priming btz-resistant MM cells displaying loss of Bim to ABT-737- induced death, using HDACIs, known to up-regulate Bim in myeloma cells $(21,22)$. Exposure of either PS-R (Fig. 3A) or 8226/VR cells (Fig. 3B) to the HDACI SBHA, particularly in combination with ABT-737, clearly up-regulated Bim (principally the EL isoform), accompanied by markedly increased caspase-3, -9 , and PARP cleavage, and pronounced increases in apoptosis $(P<0.01$ versus SBHA alone; Fig. 3C and 3D). Similar results were obtained when the clinically-relevant BH3-mimetic ABT-199 (43) was employed (Supplemental Fig. S2D).

To extend findings to primary btz-resistant $\mathrm{MM}$ specimens, $\mathrm{CD} 138^{+}$cells were isolated from the bone marrow of a patient with relapsed MM following btz treatment. These cells exhibited resistance to btz ex vivo (Supplemental Fig. S2E). Notably, whereas ABT-737 or SBHA, administered individually, induced little or no cell death, combined treatment strikingly increased apoptosis $(70-90 \%)$ of $\mathrm{CD}_{138^{+}}$cells (Fig 3E, upper). In marked contrast, agents 
alone or in combination displayed little or no toxicity toward bone marrow non-myeloma CD138- cells (Supplemental Fig. S2F). Similar results were observed in six additional primary samples including three derived from relapsed patients (arrowhead; Fig. 3E, lower). These findings argue that a dual Bim-targeting strategy combining HDACIs, which up-regulate Bim, with $\mathrm{BH} 3$-mimetics that unleash Bim from anti-apoptotic proteins (e.g., Bcl-2/Bcl-xL) may be effective against adaptively btz-resistant MM cells, and raise the possibility that this strategy may preferentially target primary MM cells.

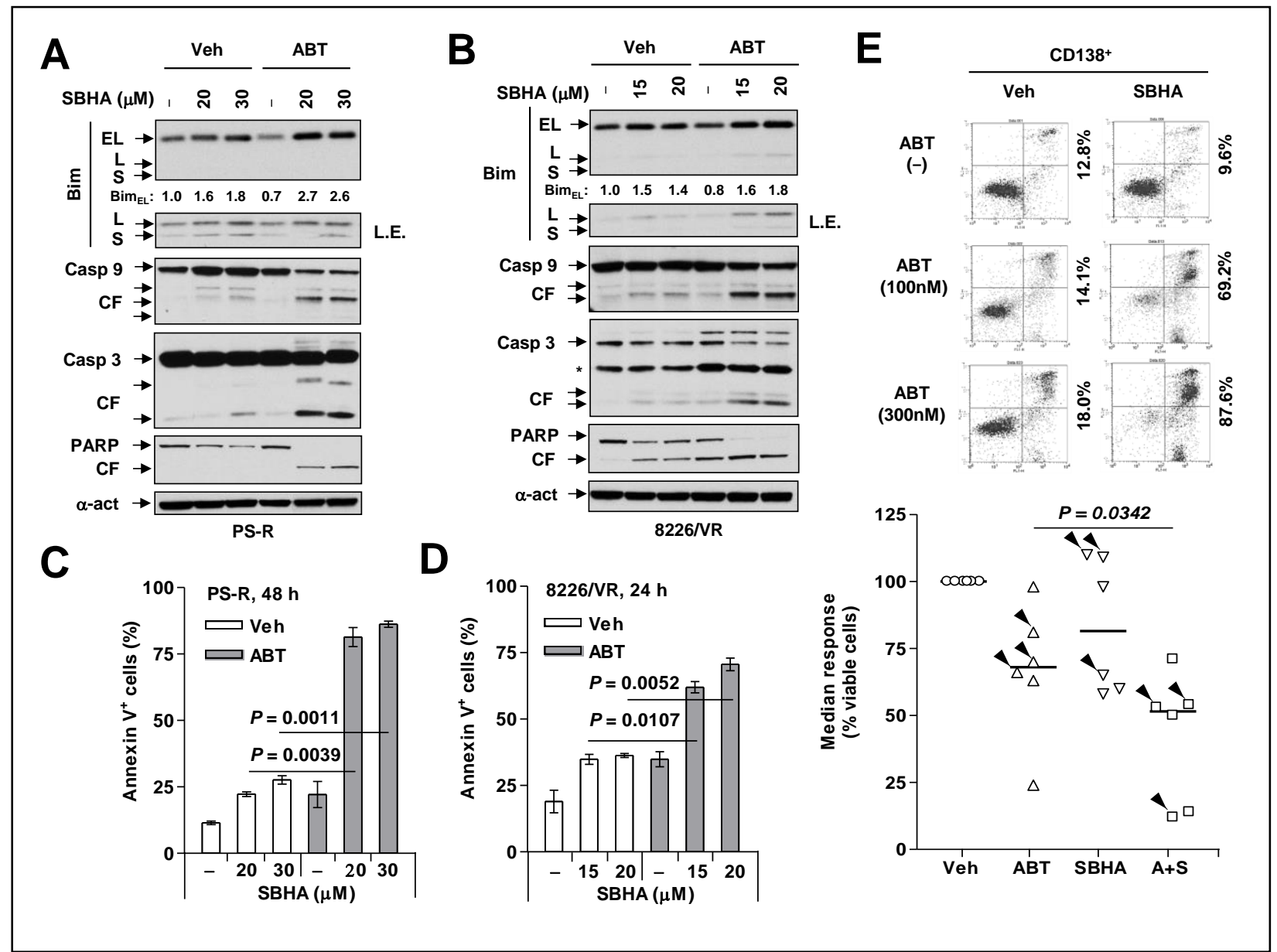

Figure 3. Up-regulation of Bim by SBHA potentiates ABT-737 lethality in bortezomibresistant MM cells. (A-D) Bortezomib-resistant PS-R or 8226/VR cells were treated with ABT737 (PS-R, $500 \mathrm{nM}$; 8226/VR, 300nM) +/- the indicated concentrations $(\mu \mathrm{M})$ of SBHA for 48 hr or $24 \mathrm{hr}$, respectively. After drug treatment, immunoblotting analysis and flow cytometry were 
performed to determine levels of Bim and cleavage of caspases and PARP (A, B), or percentage of apoptosis $(\mathrm{C}, \mathrm{D})$. (E) Primary $\mathrm{CD} 138^{+}$cells were isolated from a bone marrow sample from a patient with relapsed MM. Cells were then treated with the indicated concentrations of ABT-737 $(\mathrm{nM})+/-$ SBHA $(\mu \mathrm{M})$ for $24 \mathrm{hr}$, after which flow cytometry was conducted to monitor percentage of early (annexin $\mathrm{V}^{+} / \mathrm{PI}^{-}$) and late (annexin $\mathrm{V}^{+} / \mathrm{PI}^{+}$) apoptosis. Values indicate the percentage of total annexin $\mathrm{V}^{+}$cells. Parallel experiments were performed in additional primary samples derived from newly diagnosed or relapsed following btz (arrowhead) MM patients $(\mathrm{n}=$ 6,3 each for Dx and R). $P<0.05$ for combination treatment versus each single agent.

\subsubsection{Autophagy disruption contributes functionally to HDACI/BH3-mimetic lethality}

Recent findings indicate that in addition to triggering apoptosis $(44,45)$, Bim also inhibits autophagy by localizing Beclin-1 to microtubules (20). Notably, BH3-mimetics such as ABT737 potently induce autophagy by dissociating Beclin-1 from Bcl-2 (17). Moreover, HDACIs also modulate autophagic responses $(25-27,46)$. ABT-737 markedly increased levels of lipidated LC3-II, an event largely blocked by SBHA in btz-naïve U266 cells and -resistant PS-R cells (Fig. 4A), findings confirmed by analysis of autophagic flux using bafilomycin A1 (36) (Supplemental Fig. S3A). Consistent with these results, ABT-737 robustly increased the number of GFP-LC3 puncta, whereas SBHA alone had little effect. However, in both lines, SBHA sharply reduced ABT-737-induced GFP-LC3 puncta formation (Fig. 4B). Interestingly, untreated PS-R cells exhibited modest increases in basal autophagy, reflected by both increased LC3-II expression and GFP-LC3 puncta, compared to parental U266 cells (Fig. 4A and 4B). Moreover, $\mathrm{CD} 138^{+}$cells derived from relapsed MM patients also exhibited relatively higher basal levels of autophagy compared to bortezomib-naïve patients (Supplemental Fig. S3B). However, clear changes in the expression of key proteins (e.g., ULK1, Beclin-1, and ATG5) involved in autophagy initiation (18) were not observed (Supplemental Fig. S3C). 


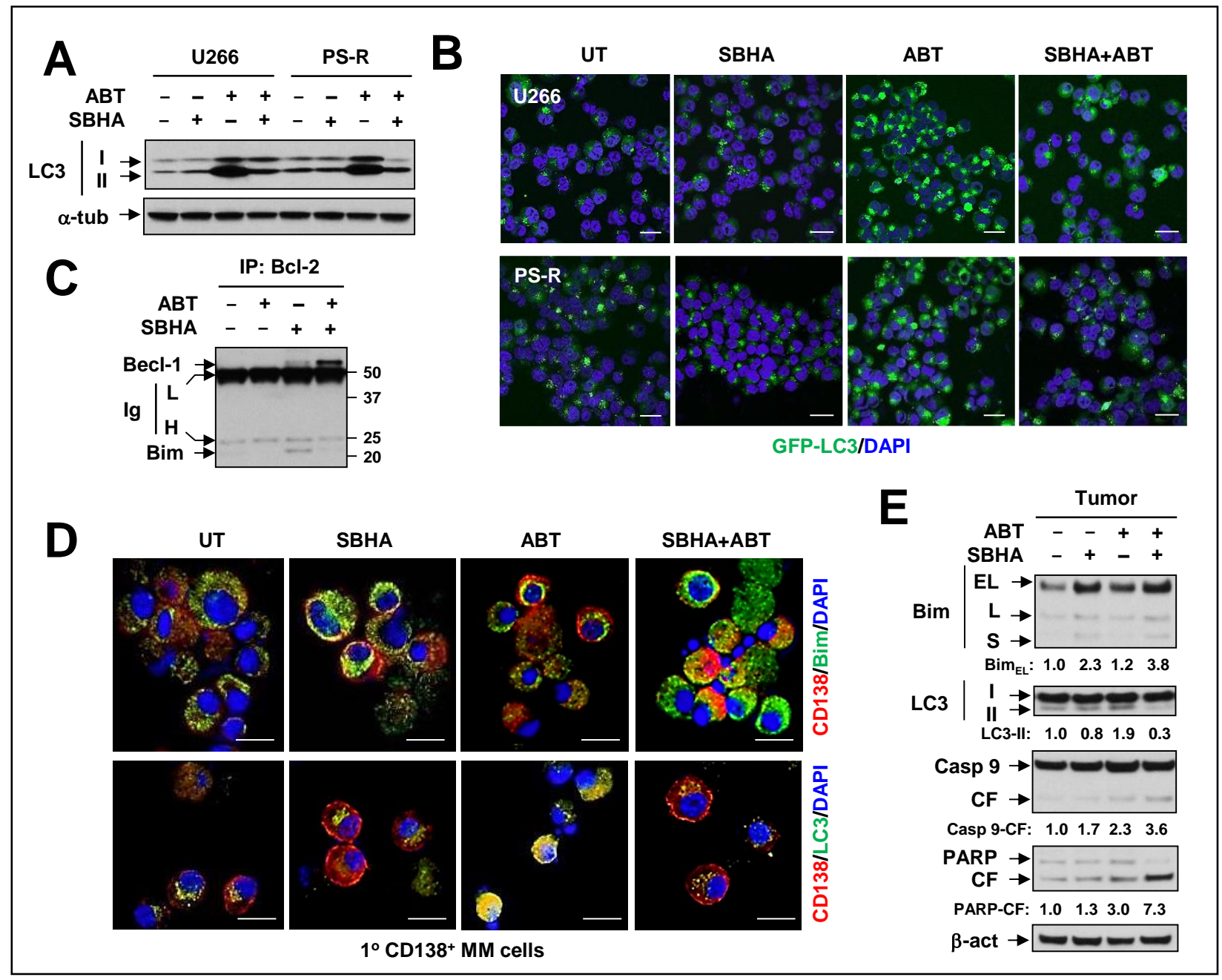

Figure 4. Bim up-regulated by SBHA attenuates ABT-737-induced autophagy. (A) Drugnaïve (U266) and bortezomib-resistant (PS-R) cells were treated with $500 \mathrm{nM} \mathrm{ABT-737} \mathrm{+/-} 20$ $\mu \mathrm{M}$ SBHA for $16 \mathrm{hr}$, followed by immunoblotting analysis to monitor LC3 processing. (B) U266 and PS-R cells stably expressing GFP-LC3 were treated (6 hr) as described in 4A, and then analyzed for GFP-LC3 puncta by confocal microscopy. Scale bar $=10 \mathrm{~mm}$ (magnification x 20). (C) U266 cells were treated as described in panel 4A, after which cells were lysed in the CHAPS buffer and subjected to immunoprecipitation (IP) with anti-Bcl-2 antibody, and subsequent immunoblotting analyses using anti-Beclin-1 and anti-Bim antibodies. L and $\mathrm{H}$, light and heavy chain of immunoglobulin (Ig). (D) Primary CD138 ${ }^{+}$cells derived from a patient with relapsed MM were treated with $100 \mathrm{nM}$ ABT-737 +/- $10 \mu \mathrm{M}$ SBHA for $16 \mathrm{hr}$, after which immunofluorescence staining was performed to monitor expression of Bim or LC3 (both AlexaFluor 488, green) in CD138- $\mathrm{PE}^{+}$cells. Scale bar $=10 \mu \mathrm{m}$ (magnification $\mathrm{x} 40$ ). (E) Tumor tissues obtained from PS-R cell mouse xenografts following the indicated treatments were subjected to Western blot analysis to monitor expression of Bim and LC3, as well as cleavage of caspase 9 and PARP. 
Although Bim has been reported to interact directly with and sequester Beclin-1 (20), coimmunoprecipitation (co-IP) with either anti-Bim or anti-Beclin-1 antibodies did not detect direct Bim/Beclin-1 associations in either parental U266 cells (not shown) or btz-resistant PS-R cells with or without drug treatment (Supplemental Fig. S3D). In contrast, marked Bim/Bcl-2 binding was observed on the same membrane, an event dramatically blocked by ABT-737 (Supplemental Fig. S3D). Notably, co-IP with anti-Bcl-2 antibody revealed that SBHA alone increased Bim/Bcl-2 binding, presumably secondary to Bim up-regulation, while ABT-737 clearly released Bim from binding to Bcl-2 (Fig. 4C), as previously reported (16). Interestingly, whereas SBHA alone modestly increased Beclin-1/Bcl-2 binding, co-administration of SBHA with ABT-737 induced a marked increase in Beclin-1/Bcl-2 association (Fig 4C), which prevents Beclin-1-induced autophagy (47). Similar results were observed in PS-R cells (not shown). These findings raise the possibility that release of Bcl-2 from Bim may contribute to increased Bcl-2/Beclin-1 binding. Notably, SBHA co-administration also up-regulated Bim and diminished ABT-737-induced autophagy in primary $\mathrm{CD} 138^{+} \mathrm{MM}$ cells derived from relapsed MM patients, as shown by the representative images obtained from one patient (Fig. 4D), as well as in tumor tissues obtained from bortezomib-resistant MM cell xenografts (Fig. 4E).

\subsubsection{Bim plays a functional role in autophagy disruption}

The role of Bim in regulation of autophagy was then assessed. SBHA clearly reduced ABT737-induced LC3-II expression in shNC cells (Fig. 5A), consistent with previous results involving untransfected U266 cells. Notably, shBim cells, with or without drug treatment, exhibited striking increases in LC3-II levels and marked reductions in caspase-3 and PARP 
cleavage induced by SBHA +/- ABT-737. Similar results were obtained with tunicamycin, a classic autophagy inducer (Supplemental Fig. S3E).

To define the functional significance of autophagy disruption, RPMI8226 cells with stable shRNA knockdown of LAMP2, a key protein required for autophagosome maturation/lysosome fusion (48), were employed. Two separate shLAMP2 clones (designated E3 and C3; inset) displayed significantly increased ABT-737 sensitivity (for each clone, $P<0.05$ vs shNC cells; Fig. 5B). These findings are consistent with previous results demonstrating potentiation of ABT737 lethality by chloroquine (CQ), which disrupts autophagosome maturation through inhibition of lysosomal acidification (49), in lung cancer cells (19). However, whereas SBHA significantly increased ABT-737 lethality in shNC cells $(P<0.01$ vs ABT-737 alone), it failed to potentiate ABT-737 lethality in shLAMP2 cells $(P>0.05$ vs ABT-737 alone), presumably because autophagy had already been disabled in these cells. These findings argue that HDACI-induced Bim negatively regulates ABT-737-induced autophagy, and that Bim-mediated suppression of a cytoprotective autophagic response plays a significant functional role in potentiation of $\mathrm{BH} 3$ mimetic lethality by HDACIs in both btz-naïve and -resistant MM cells.

To define requirements for Bim in HDACI/BH3-mimetic interactions, bim gene knockout $\left(\mathrm{Bim}^{-/-}\right) \mathrm{MEF}$ were employed. Following ABT-737 exposure, wild-type $\left(\mathrm{Bim}^{+/+}\right)$MEFs stained with acridine orange (AO) displayed a clear increase in acidic vesicular organelles (AVO, orange or red; Fig 5C), including autophagosome/lysosomes, reflecting enhanced autophagy (37). SBHA clearly inhibited ABT-737-induced autophagy. In sharp contrast, SBHA failed to attenuate ABT-737-induced autophagy in $\mathrm{Bim}^{-/-}$MEFs (Fig. 5C). Moreover, ABT-737/SBHA markedly induced apoptosis in $\mathrm{Bim}^{+/+} \mathrm{MEFs}$, a phenomenon enhanced by CQ. However, bim gene knockout $\left(\mathrm{Bim}^{-/-}\right)$MEFs displayed sharply diminished ABT-737/SBHA-mediated 
apoptosis, even in the presence of CQ (Fig. 5D). These findings argue that the presence of the bim gene is required for Bim-mediated inhibition of cytoprotective autophagy as well as the effectiveness of a strategy combining HDAC inhibitors with BH3-mimetics.

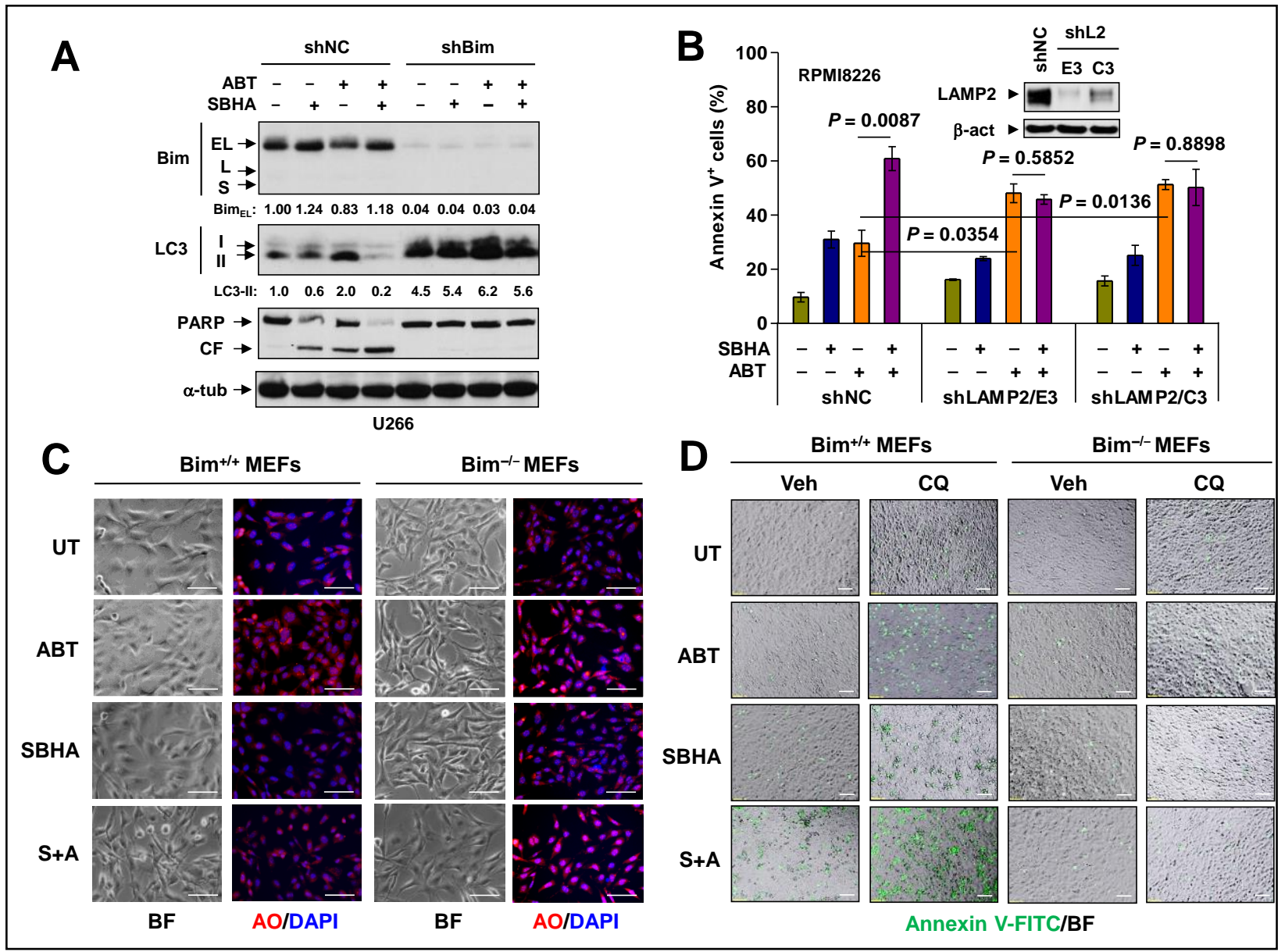

Figure 5. Bim is required for disruption of autophagy and induction of apoptosis induced by ABT-737. (A) U266 cells stably transfected with Bim or scrambled sequence shRNA were incubated with $300 \mathrm{nM}$ ABT-737 +/- $20 \mu \mathrm{M}$ SBHA for $24 \mathrm{hr}$. Following treatment, immunoblotting analysis was performed to monitor Bim expression, LC3 processing, and PARP cleavage. (B) RPMI8226 cells stably transfected with LAMP2 (two subclones designated E3 and

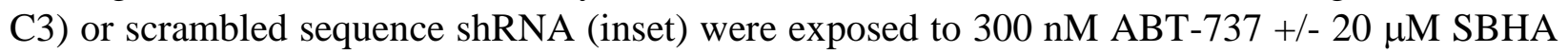
for $24 \mathrm{hr}$, followed by flow-cytometry to determine the percentage of apoptotic cells. (C) MEFs (mouse embryonic fibroblasts) derived from wild type $\left(\mathrm{Bim}^{+/+}\right)$or bim knockout $\left(\mathrm{Bim}^{-/}\right)$mice were treated with $500 \mathrm{nM}$ ABT-737 +/- $20 \mu \mathrm{M}$ SBHA for $16 \mathrm{hr}$, after which cells were stained with acridine orange (AO). (D) MEFs were exposed to $500 \mathrm{nM}$ ABT-737 +/- $20 \mu \mathrm{M}$ SBHA in the presence or absence of $50 \mu \mathrm{M} C Q$ for $24 \mathrm{hr}$, after which cells were stained with annexin VFITC. For both $6 \mathrm{~A}$ and $6 \mathrm{~B}$, images were captured by inverted fluorescence microscopy. BF, bright field. Scale bar $=10 \mu \mathrm{m}$ (magnification $\times 10)$. 


\subsubsection{Autophagy disruption is required for enhanced HDACI/BH3-mimetic lethality in Bim $^{\text {low }}$ MM cells}

To determine whether analogous events also occur in Bim ${ }^{\text {low }}$ MM cells, H929 cells intrinsically expressing low levels of Bim (Fig. 1A) were employed. In contrast to Bim ${ }^{\text {hi }}$ cells, SBHA failed to up-regulate Bim in H929 cells, while SBHA/ABT-737 co-exposure induced very modest increases in Bim expression and PARP cleavage in these Bim ${ }^{\text {low }}$ cells (Fig 6A). Consistent with these results, SBHA/ABT-737 minimally induced apoptosis in H929 cells (Fig 6B). However, CQ disrupted autophagosome maturation, reflected by LC3-II accumulation, and sharply up-regulated Bim in H929 cells (Fig. 6A), presumably due to interference with autophagic degradation of ubiquitinated proteins (50), including Bim $(9,10)$. Interestingly, in the presence of CQ, SBHA +/- ABT-737 treatment further increased Bim expression (Fig. 6A). Moreover, co-IP revealed that Bim up-regulation by CQ alone (lane 8) or SBHA+CQ (lane 10) induced increased binding of Bim to Bcl-2, an established mechanism of Bim neutralization (51). Notably, such binding was essentially abrogated by ABT-737 (lanes 9 and 11 respectively; Fig. 6C), thereby unleashing and activating Bim (16). These events were associated with pronounced potentiation of SBHA/ABT-737-mediated apoptosis by CQ (Fig. 6B, $P<0.0001$ vs SBHA/ABT-737 treatment without CQ) and PARP cleavage (Fig. 6A). In contrast to H929 cells, in adaptively btz-resistant cells (e.g., PS-R) characterized by acquired Bim loss, SBHA clearly up-regulated Bim and significantly increased ABT-737-mediated apoptosis (Fig. 3A and 3C). However, CQ co-administration induced a pronounced further increase in cell death in PS-R cells (Fig. 6D, $\mathrm{P}<0.01$ versus SBHA/ABT-737 treatment without CQ), but not in parental U266 cells (not shown). Moreover, CQ also enhanced Bim up-regulation induced by SBHA+/-ABT737 in PS-R cells (not shown), while ABT-737 diminished Bim/Bcl-2 associations 
(Supplemental Fig S3D). Together, these findings indicate that disrupting autophagy (e.g., by $\mathrm{CQ}$ ) plays a critical role in potentiating HDACI/BH3-mimetic lethality in Bim $^{\text {low }} \mathrm{MM}$ cells displaying minimal Bim up-regulation following HDACI exposure, but also significantly enhances anti-MM activity of this strategy in cells with acquired btz-resistance.

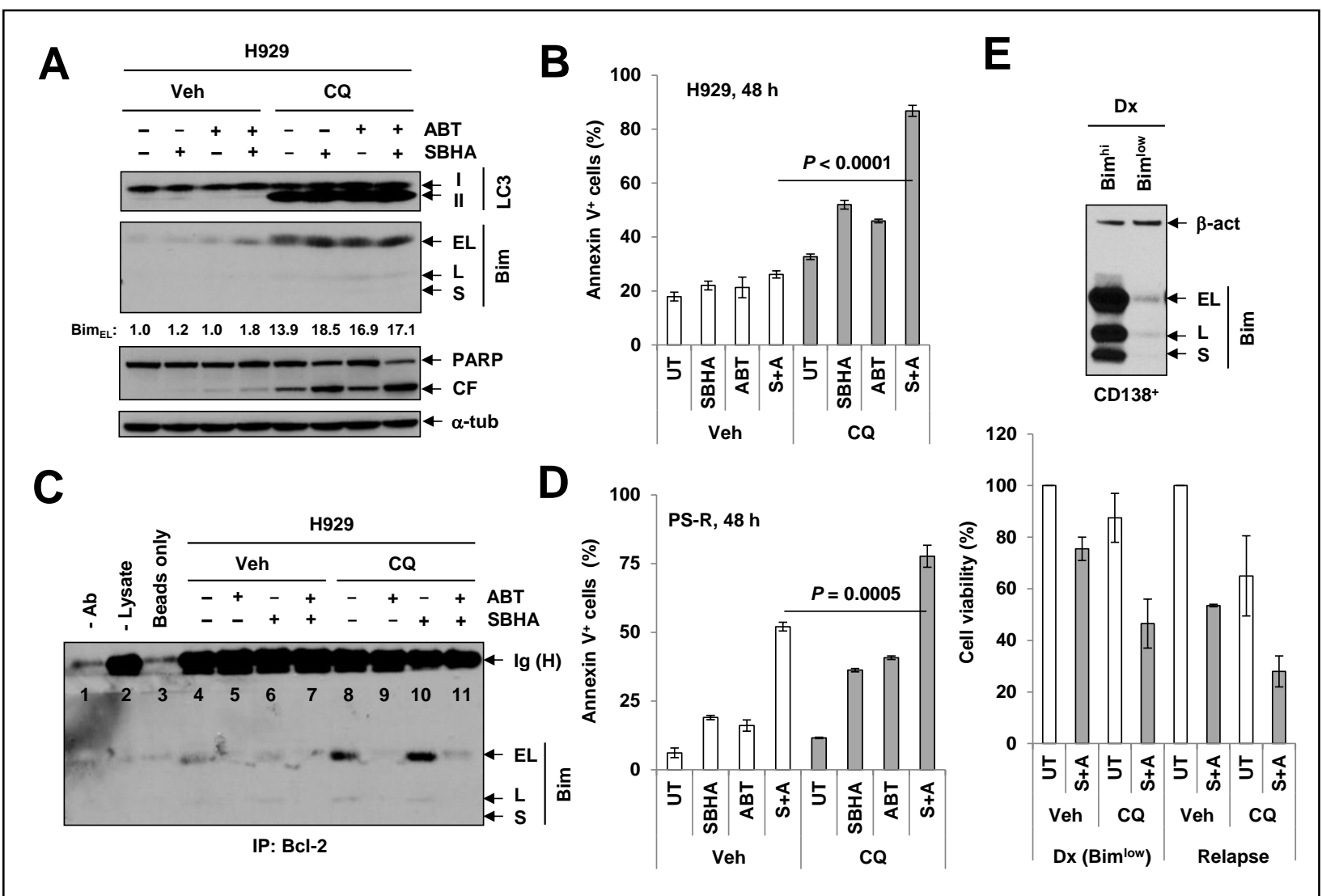

Figure 6. Chloroquine disrupts autophagy and sensitizes Bim $^{\text {low }} \mathrm{MM}$ cells to the HDACI/BH3 mimetic regimen. (A) H929 cells were exposed to $300 \mathrm{nM}$ ABT-737 +/- $30 \mu \mathrm{M}$ SBHA in the presence or absence of $50 \mu \mathrm{M}$ chloroquine (CQ), after which immunoblotting analysis was performed to monitor LC3 processing, Bim expression, and PARP cleavage. (B) In parallel, flow cytometry was performed to determine the percentage of apoptotic H929 cells. (C) Alternatively, cells were lysed in the CHAPS buffer and subjected to co-IP (IP with anti-Bcl-2, immunoblotting with anti-Bim). IP without anti-Bcl-2 (lane 1), cell lysate (lane 2), or both (lane 3) was performed as controls. (D) Similarly, PS-R cells were incubated with relatively lower concentrations of ABT-737 $(300 \mathrm{nM})+/$ - SBHA $(15 \mu \mathrm{M})$ with or without $50 \mu \mathrm{M}$ CQ for $48 \mathrm{hr}$, followed by flow cytometry to monitor apoptosis. (E) Primary CD $138^{+}$cells derived from newly diagnosed (Dx, displaying low basal Bim levels, inset) or relapsed (R) MM patients $(\mathrm{n}=4,2$ samples each for Dx and R) were treated with $100 \mathrm{nM}$ ABT-737 + $10 \mu \mathrm{M}$ SBHA in the presence 
or absence of $10 \mu \mathrm{M}$ CQ for $24 \mathrm{hr}$, after which flow cytometry was performed to determine the percentage of viable cells (7AAD-negative).

\subsubsection{The HDACI/BH3-mimetic regimen is active in vivo, but inactivated by Bim shRNA}

\section{knockdown}

Finally, the in vivo activity of this regimen was examined in mouse xenograft models. Coadministration of ABT-737 with SBHA significantly reduced tumor burden (Fig. 7A) and prolonged animal survival (not shown) in a bortezomib-resistant (PS-R) MM cell xenograft. In contrast, the same regimen was ineffective in a U266/shBim cell xenograft (Fig. 7B), in which SBHA failed to up-regulate Bim (Supplemental Fig. S3F). These findings suggest that Bim also plays a functional role in the in vivo activity of the HDACI/BH3-mimetic regimen.

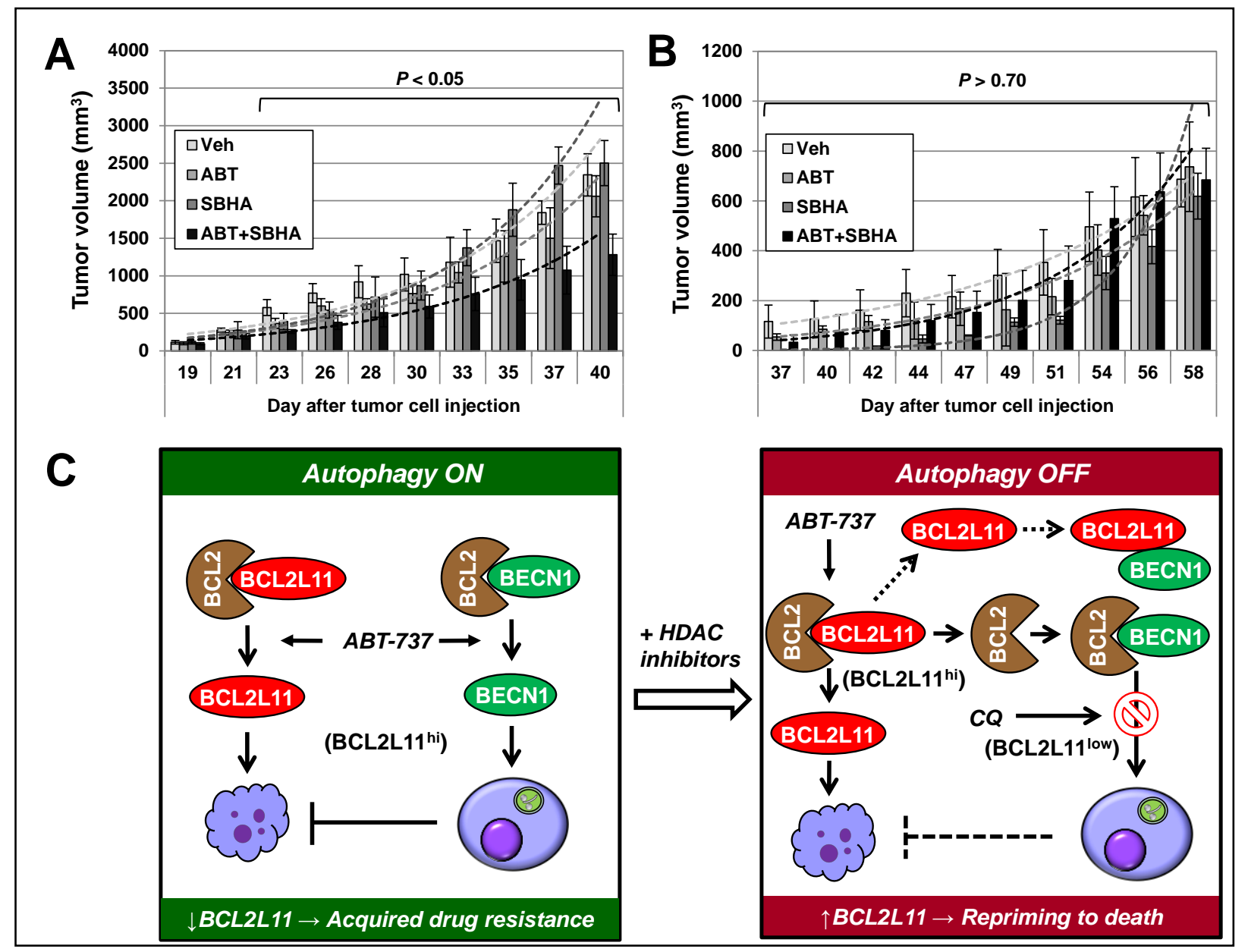


Figure 7. The HDACI/BH3-mimetic regimen displays activity in vivo which is blocked by Bim shRNA knockdown. (A-B) NOD/SCID-gamma mice were subcutaneously inoculated in the flank with $5 \times 10^{6}$ PS-R (A) or U266/shBim cells (B). $100 \mathrm{mg} / \mathrm{kg}$ ABT-737 and $200 \mathrm{mg} / \mathrm{kg}$ SBHA were administrated (i.p.) individually or in combination $(\mathrm{n}=5$ per group) three days a week. Control animals were administered equal volumes of vehicle. Tumor size was measured by caliper and volumes calculated using the formula $\left(\mathrm{Lx} \mathrm{W}^{2}\right) / 2$, with $\mathrm{L}=$ length and $\mathrm{W}=$ width. (C) A mechanistic model for the roles of Bim in adaptive drug-resistance and priming resistant MM cells to death. Left: BH3 mimetics (e.g., ABT-737) simultaneously activate apoptosis and autophagy by releasing Bim and Beclin-1 from Bcl-2, respectively. However, whereas the former action is therapeutically beneficial, it is opposed by the latter cytoprotective response (autophagy $\mathrm{ON}$ ), which raises the cell death threshold and promotes drug resistance. In this setting, Bim down-regulation is associated with adaptive resistance to targeted agents such as bortezomib. Right: HDACIs up-regulate Bim in MM cells, including those resistant to bortezomib due to Bim down-regulation, and thereby re-prime them to BH3-mimetic-induced apoptosis. The latter event is related, at least in part, to disruption of cytoprotective autophagy (autophagy OFF) through release of Bcl-2 from Bim and resulting enhanced sequestration of Beclin-1 by Bcl-2. Notably, inhibition of autophagy (e.g., by CQ) significantly increases HDACI/BH3 mimetic regimen lethality, particularly in Bim ${ }^{\text {low }}$ MM cells. Thus, loss of Bim expression can contribute to an adaptive form of bortezomib resistance, and a Bim-targeting strategy combining HDACIs, which up-regulate Bim, with BH3-mimetics, which release Bim from anti-apoptotic Bcl-2 family proteins, may represent an effective approach to this problem.

\subsection{DISCUSSION}

Despite the introduction of effective therapies in MM, including front-line treatment with btz, nearly all patients eventually relapse (2). One approach to this problem involves the use of second-generation proteasome inhibitors (e.g., carfilzomib), which are effective in some btzrefractory patients $(12,52)$. However, there is a pressing need to understand mechanisms of resistance to proteasome inhibitors such as btz, and to develop strategies active against such resistant cells. Previous efforts have highlighted the contribution of the anti-apoptotic Bcl-2 family protein Mcl-1 to MM cell survival and btz-resistance (53). However, recent attention has focused on the role of pro-apoptotic BH3-only proteins (e.g., Bim) in MM responsiveness to btz (54). Moreover, Bim down-regulation correlates with poor prognosis in MM (55). However, the precise role that Bim plays in btz-resistance has not yet been defined. The present studies emphasize an important contribution of Bim to adaptive (or acquired), rather than intrinsic, 
forms of btz-resistance in MM. They also describe a Bim-targeting strategy combining HDACIs, which up-regulate Bim (21,22), with BH3-mimetics that unleash Bim from anti-apoptotic proteins (e.g., Bcl-2, Bcl-xL) (16) which may overcome such forms of btz-resistance.

The present results suggest that Bim down-regulation contributes functionally to adaptive (but not intrinsic) btz-resistance in MM cells. Recent gene expression profiling (GEP) data reveals that BCL2L11 (Bim) is consistently and highly expressed in four MM subtypes (i.e., HY, CCND1, MEF, and MMSET) (56). Consistent with these findings, most MM cell lines and primary MM samples tested displayed high basal Bim levels (i.e., Bim ${ }^{\text {hi }}$ ), suggesting that MM cells are primed by BH3-only proteins (e.g., Bim) for cell death ${ }^{41}$. Interestingly, MM cells (e.g., H929) exhibiting low basal levels of Bim (Bim $\left.{ }^{\text {low }}\right)$ were fully sensitive to btz, arguing against a role for Bim in intrinsic btz-resistance. However, in Bim ${ }^{\text {hi }} \mathrm{MM}$ cells, shRNA knock-down of Bim dramatically reduced btz sensitivity. Significantly, apoptosis pathway-targeted GEP identified BCL2L11 (Bim) as one of the genes down-regulated in btz-resistant MM cells, supported by clearly diminished Bim protein levels in these cells. Collectively, these observations argue that Bim down-regulation is primarily involved in adaptive btz-resistance in which it raises the death threshold (i.e., loss of priming) (51). In addition, perturbations in the expression of other Bcl-2 family members (e.g., Mcl-1, Hrk) may also contribute to or cooperate with Bim down-regulation in conferring btz-resistance. For example, interactions between Bim and Mcl-1 may regulate MM cell survival (57) or determine sensitivity to anti-MM agents (e.g., melphalan) (58). Efforts to test these hypotheses are underway.

A corollary of these findings is that agents that up-regulate Bim may re-prime btz-resistant MM cells to death. Bim BH3 peptides prime neoplastic cells (including MM cells) for apoptosis induced by ABT-737 (41). However, the therapeutic use of peptides represents a challenge. 
Alternatively, HDACIs up-regulate Bim in tumor cells, including MM cells $(21,22)$, while BH3 mimetics (e.g., ABT-737) unleash Bim from Bcl-2/Bcl-xL (16). Interestingly, ABT-737 induced a modest but discernible decline in Bim levels, accompanied by increased Mcl-1 expression (40), presumably representing compensatory responses to Bcl-2/Bcl-xL inhibition. Moreover, shRNA Bim knockdown markedly diminished ABT-737 lethality, while Bim over-expression increased ABT-737 sensitivity, arguing that Bim is critical for ABT-737 sensitivity (59). Notably, BH3mimetics are effective against certain molecular MM subtypes harboring $\mathrm{t}(11 ; 14)$ and a Bcl$2^{\text {hi }} / \mathrm{Mcl}-1^{\text {low }}$ profile (60). Thus, the MOAs of HDACIs (e.g., Bim up-regulation) and BH3mimetics (e.g., unleashing Bim from Bcl-2/Bcl-xL) provide a specific rationale for combining these two classes of agents. While we and other groups have described synergistic interactions between HDACIs and BH3-mimetics in various hematopoietic malignant cells $(29,61-63)$, the ability of such a Bim-targeting strategy to re-prime btz-resistant MM cells to death has not previously been examined. Significantly, HDACIs, particularly when combined with BH3mimetics, increased Bim expression, and sharply increased BH3-mimetic lethality in btzresistant cells. Collectively, these findings indicate that as described in the case of Bim peptides (41), an alternative Bim-targeting strategy combining HDACIs and BH3 mimetics may be feasible and effective against certain adaptive forms of proteasome inhibitor resistance.

Apoptosis (type I) and autophagy (type II) represent two major forms of programmed cell death (64). While excessive autophagy has been implicated in cell death in some settings, autophagy represents a cytoprotective mechanism conferring drug-resistance in most circumstances (18). In this context, BH3 mimetics (including ABT-737) trigger autophagy by unleashing Beclin-1 from its inhibitory association with Bcl-2 (17), while disruption of this event enhances BH3-mimetic lethality (19). Analogously, HDACIs induce autophagy in certain tumor 
cell types such as glioblastoma cells (25) and breast cancer cells (26). Moreover, interference with autophagy (e.g., by chloroquine or 3-MA, which disrupt autophagosome maturation (65)) enhances HDACI lethality (27). However, HDACIs may also inhibit autophagy under some conditions $(46,66)$. Notably, in the present study, HDACI co-administration predominantly attenuated BH3 mimetic-induced autophagy in MM cells.

The present results argue that the mechanism by which HDACIs disrupt autophagy in this setting involves Bim up-regulation. A recent study demonstrated that Bim bridges the Beclin1/LC8 interaction and thereby inhibits autophagy (20). Thus, HDACIs may inhibit BH3mimetic-induced autophagy by up-regulating Bim. Indeed, shRNA Bim knockdown induced a pronounced increase in autophagy and reduced the ability of SBHA to attenuate ABT-737mediated autophagy in MM cells. Moreover, SBHA also failed to prevent ABT-737-induced autophagy in Bim knockout MEFs. Furthermore, genetic disruption of autophagy (e.g., by LAMP2 shRNA) significantly sensitized MM cells to ABT-737, but diminished potentiation of ABT-737 lethality by SBHA, presumably because autophagy had already been disrupted. Interestingly, while SBHA minimally up-regulated Bim and increased ABT-737 lethality in Bim $^{\text {low }}$ MM cells (e.g., H929), disruption of autophagy by CQ strikingly increased apoptosis in association with pronounced Bim up-regulation. Bim is a substrate for ubiquitination and degradation via the proteasome (67) and autophagy (68). Notably, CQ also further increased HDACI/BH3-mimetic activity in btz-resistant MM cells. In marked contrast, bim gene knockout $\left(\mathrm{Bim}^{-/}\right) \mathrm{MEF}$ were strikingly resistant to this regimen, even with $\mathrm{CQ}$, indicating that the presence of the bim gene is required for this Bim-targeting strategy. Collectively, these findings argue that potentiation of BH3-mimetic lethality by HDACIs stems, at least in part, from 
impairment in a cytoprotective autophagic response secondary to Bim up-regulation in MM cells.

In summary, the present findings underscore the importance of Bim as a determinant of adaptive btz-resistance in MM cells, and describe a Bim-targeting strategy designed to overcome such btz-resistance through Bim-mediated autophagy attenuation. A model illustrating these concepts is illustrated in Fig. 7. In this model, BH3-mimetics (e.g., ABT-737) release Bim from Bcl-2, favoring apoptosis, an event attenuated by autophagy induction (i.e., autophagy ON) secondary to release of Beclin-1 from Bcl-2. HDACIs up-regulate Bim, which in addition to potentiating apoptosis, attenuates autophagy (Autophagy OFF). Alternatively, up-regulated Bim may directly associate with and inactivate Beclin-1 (20). A corollary of these finding is that this Bim-targeting strategy may be particularly effective against Bim ${ }^{\text {hi }} \mathrm{MM}$ cells, including those exhibiting adaptive btz-resistance stemming from loss of Bim. Finally, in Bim ${ }^{\text {low }} \mathrm{MM}$ cells displaying impairment in HDACI-mediated Bim up-regulation, disruption of autophagy (e.g., by CQ) may be required to induce Bim expression and apoptosis by this regimen. Consequently, efforts to develop this Bim-targeting strategy further in btz-resistant MM are currently underway. 


\subsection{REFERENCES}

1. Munshi NC, Anderson KC. New strategies in the treatment of multiple myeloma. Clin Cancer Res 19:3337-3344, 2013.

2. Kumar SK, Lee JH, Lahuerta JJ, et al. Risk of progression and survival in multiple myeloma relapsing after therapy with IMiDs and bortezomib: a multicenter international myeloma working group study. Leukemia 26:149-157, 2012.

3. Chauhan D, Velankar M, Brahmandam M, et al. A novel Bcl-2/Bcl-X(L)/Bcl-w inhibitor ABT-737 as therapy in multiple myeloma. Oncogene 26:2374-2380, 2007.

4. Chipuk JE, Moldoveanu T, Llambi F, Parsons MJ, Green DR. The BCL-2 family reunion. Mol Cell 37:299-310, 2010.

5. Elkholi R, Floros KV, Chipuk JE. The Role of BH3-Only Proteins in Tumor Cell Development, Signaling, and Treatment. Genes Cancer 2:523-537, 2011.

6. Kuroda J, Taniwaki M. Involvement of BH3-only proteins in hematologic malignancies. Crit Rev Oncol Hematol 71:89-101, 2009.

7. Gillings AS, Balmanno K, Wiggins CM, Johnson M, Cook SJ. Apoptosis and autophagy: BIM as a mediator of tumour cell death in response to oncogene-targeted therapeutics. FEBS $\mathrm{J}$ 276:6050-6062, 2009.

8. Hubner A, Barrett T, Flavell RA, Davis RJ. Multisite phosphorylation regulates Bim stability and apoptotic activity. Mol Cell 30:415-425, 2008.

9. Ley R, Balmanno K, Hadfield K, Weston C, Cook SJ. Activation of the ERK1/2 signaling pathway promotes phosphorylation and proteasome-dependent degradation of the $\mathrm{BH} 3$-only protein, Bim. J Biol Chem 278:18811-18816, 2003.

10. Meller R, Cameron JA, Torrey DJ, et al. Rapid degradation of Bim by the ubiquitinproteasome pathway mediates short-term ischemic tolerance in cultured neurons. J Biol Chem 281:7429-7436, 2006.

11. Akiyama T, Dass CR, Choong PF. Bim-targeted cancer therapy: a link between drug action and underlying molecular changes. Mol Cancer Ther 8:3173-3180, 2009.

12. Kortuem KM, Stewart AK. Carfilzomib. Blood 121:893-897, 2013.

13. Kline MP, Rajkumar SV, Timm MM, et al. ABT-737, an inhibitor of Bcl-2 family proteins, is a potent inducer of apoptosis in multiple myeloma cells. Leukemia 21:1549-1560, 2007.

14. Souers AJ, Leverson JD, Boghaert ER, et al. ABT-199, a potent and selective BCL-2 inhibitor, achieves antitumor activity while sparing platelets. Nat Med 19:202-208, 2013.

15. Pan R, Hogdal LJ, Benito JM, et al. Selective BCL-2 Inhibition by ABT-199 Causes OnTarget Cell Death in Acute Myeloid Leukemia. Cancer Discov 4:362-375, 2014.

16. Del GM, V, Brown JR, Certo M, et al. Chronic lymphocytic leukemia requires BCL2 to sequester prodeath BIM, explaining sensitivity to BCL2 antagonist ABT-737. J Clin Invest 117:112-121, 2007. 
17. Maiuri MC, Le TG, Criollo A, et al. Functional and physical interaction between Bcl-X(L) and a BH3-like domain in Beclin-1. EMBO J 26:2527-2539, 2007.

18. Janku F, McConkey DJ, Hong DS, Kurzrock R. Autophagy as a target for anticancer therapy. Nat Rev Clin Oncol 8:528-539, 2011.

19. Zinn RL, Gardner EE, Dobromilskaya I, et al. Combination treatment with ABT-737 and chloroquine in preclinical models of small cell lung cancer. Mol Cancer 12:16, 2013.

20. Luo S, Garcia-Arencibia M, Zhao R, et al. Bim inhibits autophagy by recruiting Beclin 1 to microtubules. Mol Cell 47:359-370, 2012.

21. Fandy TE, Shankar S, Ross DD, Sausville E, Srivastava RK. Interactive effects of HDAC inhibitors and TRAIL on apoptosis are associated with changes in mitochondrial functions and expressions of cell cycle regulatory genes in multiple myeloma. Neoplasia 7:646-657, 2005.

22. De BE, Bos TJ, Schuit F, et al. IGF-1 suppresses Bim expression in multiple myeloma via epigenetic and posttranslational mechanisms. Blood 115:2430-2440, 2010.

23. Prince HM, Dickinson M. Romidepsin for cutaneous T-cell lymphoma. Clin Cancer Res 18:3509-3515, 2012.

24. Khan O, La Thangue NB. HDAC inhibitors in cancer biology: emerging mechanisms and clinical applications. Immunol Cell Biol 90:85-94, 2012.

25. Gammoh N, Lam D, Puente C, et al. Role of autophagy in histone deacetylase inhibitorinduced apoptotic and nonapoptotic cell death. Proc Natl Acad Sci U.S.A 109:6561-6565, 2012.

26. Rao R, Balusu R, Fiskus W, et al. Combination of pan-histone deacetylase inhibitor and autophagy inhibitor exerts superior efficacy against triple-negative human breast cancer cells. Mol Cancer Ther 11:973-983, 2012.

27. Carew JS, Nawrocki ST, Kahue CN, et al. Targeting autophagy augments the anticancer activity of the histone deacetylase inhibitor SAHA to overcome Bcr-Abl-mediated drug resistance. Blood 110:313-322, 2007.

28. Torgersen ML, Engedal N, Boe SO, Hokland P, Simonsen A. Targeting autophagy potentiates the apoptotic effect of histone deacetylase inhibitors in $t(8 ; 21)$ AML cells. Blood 122:2467-2476, 2013.

29. Chen S, Dai Y, Pei XY, Grant S. Bim upregulation by histone deacetylase inhibitors mediates interactions with the Bcl-2 antagonist ABT-737: evidence for distinct roles for Bcl2, Bcl-xL, and Mcl-1. Mol Cell Biol 29:6149-6169, 2009.

30. Dai Y, Landowski TH, Rosen ST, Dent P, Grant S. Combined treatment with the checkpoint abrogator UCN-01 and MEK1/2 inhibitors potently induces apoptosis in drug-sensitive and resistant myeloma cells through an IL-6-independent mechanism. Blood 100:3333-3343, 2002.

31. Miller AV, Hicks MA, Nakajima W, et al. Paclitaxel-induced apoptosis is BAK-dependent, but BAX and BIM-independent in breast tumor. PLoS One 8:e60685, 2013. 
32. Oltersdorf T, Elmore SW, Shoemaker AR, et al. An inhibitor of Bcl-2 family proteins induces regression of solid tumours. Nature 435:677-681, 2005.

33. Marks PA, Richon VM, Rifkind RA. Histone deacetylase inhibitors: inducers of differentiation or apoptosis of transformed cells. J Natl Cancer Inst 92:1210-1216, 2000.

34. Jackson WT, Giddings TH, Jr., Taylor MP, et al. Subversion of cellular autophagosomal machinery by RNA viruses. PLoS Biol 3:e156, 2005.

35. Klionsky DJ, Abeliovich H, Agostinis P, et al. Guidelines for the use and interpretation of assays for monitoring autophagy in higher eukaryotes. Autophagy 4:151-175, 2008.

36. Mizushima N, Yoshimori T, Levine B. Methods in mammalian autophagy research. Cell 140:313-326, 2010.

37. Jiang H, White EJ, Conrad C, Gomez-Manzano C, Fueyo J. Autophagy pathways in glioblastoma. Methods Enzymol 453:273-286, 2009.

38. Zhu Y, Swanson BJ, Wang M, et al. Constitutive association of the proapoptotic protein Bim with Bcl-2-related proteins on mitochondria in T cells. Proc Natl Acad Sci U.S.A 101:76817686, 2004.

39. Deng J, Carlson N, Takeyama K, et al. BH3 profiling identifies three distinct classes of apoptotic blocks to predict response to ABT-737 and conventional chemotherapeutic agents. Cancer Cell 12:171-185, 2007.

40. Yecies D, Carlson NE, Deng J, Letai A. Acquired resistance to ABT-737 in lymphoma cells that up-regulate MCL-1 and BFL-1. Blood 115:3304-3313, 2010.

41. Ni CT, Sarosiek KA, Vo TT, et al. Pretreatment mitochondrial priming correlates with clinical response to cytotoxic chemotherapy. Science 334:1129-1133, 2011.

42. Reed JC. Cancer. Priming cancer cells for death. Science 334:1075-1076, 2011.

43. Souers AJ, Leverson JD, Boghaert ER, et al. ABT-199, a potent and selective BCL-2 inhibitor, achieves antitumor activity while sparing platelets. Nat Med 19:202-208, 2013.

44. Kuwana T, Bouchier-Hayes L, Chipuk JE, et al. BH3 domains of BH3-only proteins differentially regulate Bax-mediated mitochondrial membrane permeabilization both directly and indirectly. Mol Cell 17:525-535, 2005.

45. Ren D, Tu HC, Kim H, et al. BID, BIM, and PUMA are essential for activation of the BAXand BAK-dependent cell death program. Science 330:1390-1393, 2010.

46. El-Khoury V, Pierson S, Szwarcbart E, et al. Disruption of autophagy by the histone deacetylase inhibitor MGCD0103 and its therapeutic implication in B-cell chronic lymphocytic leukemia. Leukemia 28:1636-1646, 2014.

47. Pattingre S, Tassa A, Qu X, et al. Bcl-2 antiapoptotic proteins inhibit Beclin 1-dependent autophagy. Cell 122:927-939, 2005.

48. Saftig P, Beertsen W, Eskelinen EL. LAMP-2: a control step for phagosome and autophagosome maturation. Autophagy 4:510-512, 2008. 
49. Bonapace L, Bornhauser BC, Schmitz M, et al. Induction of autophagy-dependent necroptosis is required for childhood acute lymphoblastic leukemia cells to overcome glucocorticoid resistance. J Clin Invest 120:1310-1323, 2010.

50. Kirkin V, McEwan DG, Novak I, Dikic I. A role for ubiquitin in selective autophagy. Mol Cell 34:259-269, 2009.

51. Sarosiek KA, Ni CT, Letai A. Mitochondria: gatekeepers of response to chemotherapy. Trends Cell Biol 23:612-619, 2013.

52. Herndon TM, Deisseroth A, Kaminskas E, et al. U.s. Food and Drug Administration approval: carfilzomib for the treatment of multiple myeloma. Clin Cancer Res 19:4559-4563, 2013.

53. Podar K, Gouill SL, Zhang J, et al. A pivotal role for Mcl-1 in Bortezomib-induced apoptosis. Oncogene 27:721-731, 2008.

54. Chauhan D, Singh AV, Ciccarelli B, et al. Combination of novel proteasome inhibitor NPI0052 and lenalidomide trigger in vitro and in vivo synergistic cytotoxicity in multiple myeloma. Blood 115:834-845, 2010.

55. Romagnoli M, Seveno C, Wuilleme-Toumi S, et al. The imbalance between Survivin and Bim mediates tumour growth and correlates with poor survival in patients with multiple myeloma. Br J Haematol 145:180-189, 2009.

56. Gomez-Bougie P, Amiot M. Apoptotic Machinery Diversity in Multiple Myeloma Molecular Subtypes. Front Immunol 4:467, 2013.

57. Gomez-Bougie P, Bataille R, Amiot M. The imbalance between Bim and Mcl-1 expression controls the survival of human myeloma cells. Eur J Immunol 34:3156-3164, 2004.

58. Gomez-Bougie P, Oliver L, Le Gouill S, Bataille R, Amiot M. Melphalan-induced apoptosis in multiple myeloma cells is associated with a cleavage of Mcl-1 and Bim and a decrease in the Mcl-1/Bim complex. Oncogene 24:8076-8079, 2005.

59. Morales AA, Kurtoglu M, Matulis SM, et al. Distribution of Bim determines Mcl-1 dependence or codependence with Bcl-xL/Bcl-2 in Mcl-1-expressing myeloma cells. Blood 118:1329-1339, 2011.

60. Bodet L, Gomez-Bougie P, Touzeau C, et al. ABT-737 is highly effective against molecular subgroups of multiple myeloma. Blood 118:3901-3910, 2011.

61. Whitecross KF, Alsop AE, Cluse LA, et al. Defining the target specificity of ABT-737 and synergistic antitumor activities in combination with histone deacetylase inhibitors. Blood 113:1982-1991, 2009.

62. Matthews GM, Lefebure M, Doyle MA, et al. Preclinical screening of histone deacetylase inhibitors combined with ABT-737, rhTRAIL/MD5-1 or 5-azacytidine using syngeneic Vk*MYC multiple myeloma. Cell Death Dis 4:e798, 2013.

63. Thompson RC, Vardinogiannis I, Gilmore TD. The sensitivity of diffuse large B-cell lymphoma cell lines to histone deacetylase inhibitor-induced apoptosis is modulated by BCL-2 family protein activity. PLoS One 8:e62822, 2013. 
64. Levine B, Sinha S, Kroemer G. Bcl-2 family members: dual regulators of apoptosis and autophagy. Autophagy 4:600-606, 2008.

65. Boya P, Gonzalez-Polo RA, Casares N, et al. Inhibition of macroautophagy triggers apoptosis. Mol Cell Biol 25:1025-1040, 2005.

66. Cao DJ, Wang ZV, Battiprolu PK, et al. Histone deacetylase (HDAC) inhibitors attenuate cardiac hypertrophy by suppressing autophagy. Proc Natl Acad Sci U.S.A 108:4123-4128, 2011.

67. Delgado ME, Dyck L, Laussmann MA, Rehm M. Modulation of apoptosis sensitivity through the interplay with autophagic and proteasomal degradation pathways. Cell Death Dis 5:e1011, 2014.

68. Wong E, Cuervo AM. Integration of clearance mechanisms: the proteasome and autophagy. Cold Spring Harb Perspect Biol 2:a006734, 2010. 


\subsection{Supplemental data}

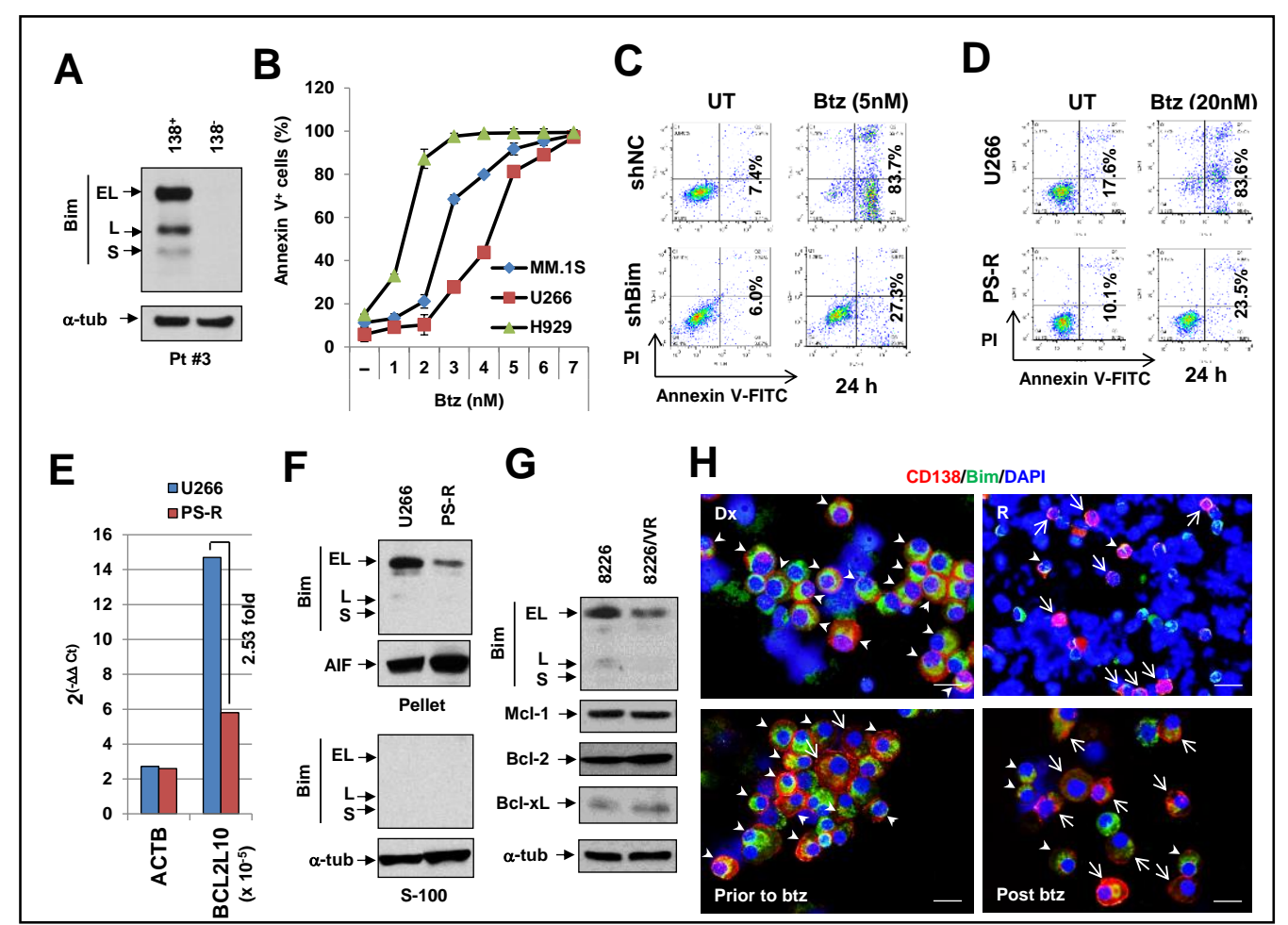

Figure S1. (A) Primary $\mathrm{CD} 138^{+}$MM cells display high basal Bim levels. CD138 ${ }^{+}$and CD138- cells were isolated from a newly diagnosed MM patient (\#3), after which Western blot analysis was performed to monitor Bim expression in untreated cells. (B) Human MM cells displaying high or low basal levels of Bim are both sensitive to bortezomib. Bim ${ }^{\text {hi }}$ (U266 and MM.1S) and Bim ${ }^{\text {low }}$ (H929) human MM cells were treated with the indicated concentrations of bortezomib for $24 \mathrm{hr}$, after which the percentage of apoptotic (Annexin $\mathrm{V}^{+}$) cells was determined by flow cytometry. (C) Bim plays a functional role in bortezomib sensitivity of Bim ${ }^{\text {hi }} \mathbf{M M}$ cells. U266 cells stably transfected with constructs encoding shRNA targeting Bim (shBim) or scrambled sequence as a negative control (shNC) were exposed to $5 \mathrm{nM}$ bortezomib for $24 \mathrm{hr}$, followed by flow cytometry to determine the percentage of apoptotic (annexin $\mathrm{V}^{+}$) cells. (D) PS$R$ cells are highly resistant to bortezomib. PS-R and parental U266 cells were exposed to 20 $\mathrm{nM}$ bortezomib for $24 \mathrm{hr}$, after which flow cytometry was performed to determine the percentage of apoptotic (annexin $\mathrm{V}^{+}$) cells. (E) Bim mRNA is down-regulated in bortezomib-resistant MM cells. Quantitative RT-PCR was performed to determine mRNA levels of Bim (BCL2L10, $\left.2^{(-\Delta \Delta \mathrm{ct})} \times 10^{5}\right)$ in bortezomib-naïve (U266) and -resistant (PS-R) cells, using $\beta$-actin as control. (F) Bim localizes on mitochondria. Immunoblotting analysis was conducted to monitor protein levels of Bim in subcellular fractions (including pellet enriched with mitochondria and S-100 cytosol) in untreated U266 and PS-R cells. AIF (apoptosis inducing factor) was probed as loading control for the mitochondria-enriched fraction. (G) Bim is down-regulated in other bortezomib-resistant MM cell lines. Immunoblotting analysis was performed to detect expression of Bim (including EL, L and S isoforms), Mcl-1, Bcl-2, and Bcl-xL in bortezomibnaïve (RPMI8226) and -resistant (8226/VR) cells. (H) Primary CD138 ${ }^{+}$MM cells derived 
from relapsed patients display lower basal Bim levels than those from newly-diagnosed

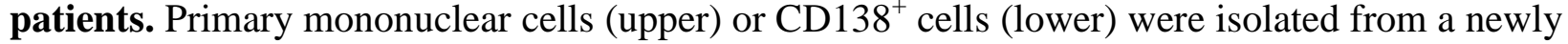
diagnosed (Dx) or a relapsed ( $\mathrm{R}$, who had received prior bortezomib) $M M$ patients (upper panels), as well as a MM patient prior to and relapsed (post) after bortezomib therapy (lower panels), after which immunofluorescence staining (IF) was performed to monitor expression of Bim (AlexaFluor 488, green) in untreated $\mathrm{CD}_{138^{+}}$(PE, red) cells. Arrows and arrowheads indicate $\mathrm{CD} 138^{+}$cells displaying low and high Bim positivity, respectively. Scale bar $=10 \mu \mathrm{m}$ (magnification $\mathrm{x} 40$ ).

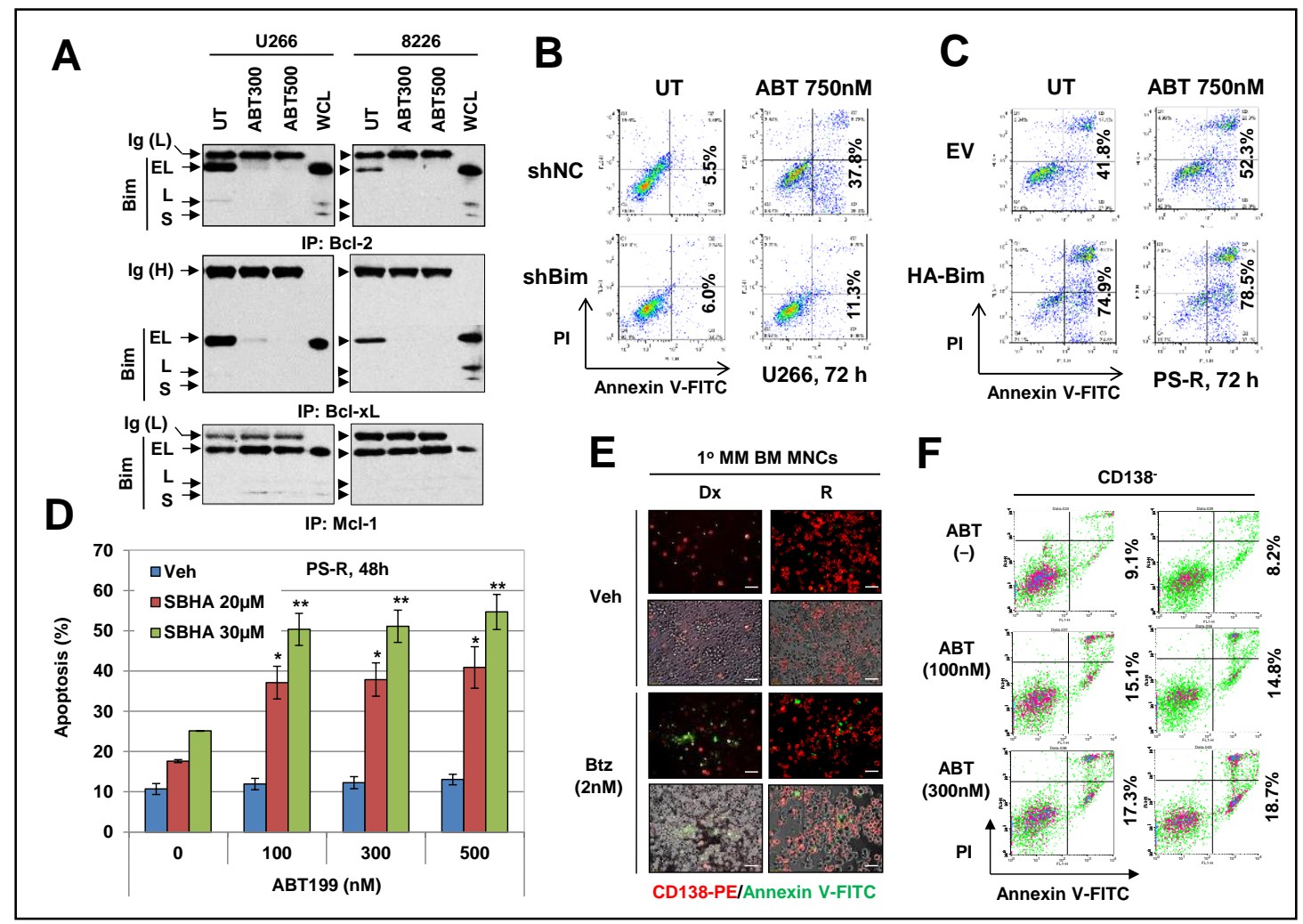

Figure S2. (A) ABT-737 unleashes Bim from Bcl-2 and Bcl-xL, but not Mcl-1. U266 and RPMI8226 cells were incubated with $300-500 \mathrm{nM}$ ABT-737 for $24 \mathrm{hr}$, after which coimmunoprecipitation was performed to monitor associations between Bim and Bcl-2, Bcl-xL, or Mcl-1. Ig, immunoglobulin; H, heavy chain, L, light chain. (B) Bim shRNA knockdown protects Bim ${ }^{\text {hi }}$ MM cells from ABT-737 lethality. U266 cells were stably transfected with constructs encoding shRNA targeting Bim (shBim) or scrambled sequence as a negative control (shNC). Cells were then exposed to $5 \mathrm{nM}$ bortezomib for $24 \mathrm{hr}$, followed by immunoblotting for expression of Bim and cleavage of PARP (left panels) or flow cytometry to determine the percentage of apoptotic (annexin $\mathrm{V}^{+}$) cells. (C) Ectopic expression of Bim is lethal to bortezomib-resistant MM cells displaying Bim down-regulation. PS-R cells were transiently transfected with HA-tagged human full-length Bim or an empty vector (EV), after which cells were exposed to $750 \mathrm{nM}$ ABT-737 for $72 \mathrm{hr}$, followed by flow cytometry to determine the percentage of apoptotic (Annexin $\mathrm{V}^{+}$) cells. (D) SBHA significantly potentiates lethality of the 
clinically-relevant BH3-mimetic ABT-199 in bortezomib-resistant MM cells. PS-R cells were exposed to 100 - $500 \mathrm{nM}$ ABT-199 +/- $20 \mu \mathrm{M}$ SBHA for $48 \mathrm{hr}$, after which the percentage of apoptotic (Annexin $\mathrm{V}^{+}$) cells were determined by flow cytometry. $* \mathrm{P}<0.05$, ** $\mathrm{P}<0.01$. (E) $\mathrm{CD}$ 138 $^{+} \mathrm{MM}$ cells from a patient with relapsed $\mathrm{MM}$ are resistant to bortezomib. Mononuclear cells (MNCs) isolated from primary bone marrow (BM) specimens obtained from patients with newly-diagnosed ( $\mathrm{Dx}$, left) or relapsed $\mathrm{MM}(\mathrm{R}$, who received prior treatment including bortezomib; right) were exposed to $2 \mathrm{nM}$ bortezomib for $24 \mathrm{hr}$, after which cells were double-stained with CD138-PE (red) and Annexin V-FITC (green), and images captured under inverted fluorescent microscopy. (F) $\mathrm{CD}_{138^{-}}$cells isolated from a bone marrow sample from a patient with relapsed MM were treated with the indicated concentrations of ABT-737 $(\mathrm{nM})+/-$ SBHA $(\mu \mathrm{M})$ for $24 \mathrm{hr}$, after which flow cytometry was conducted to monitor the percentage of early (annexin $\mathrm{V}^{+} / \mathrm{PI}^{-}$) and late (annexin $\mathrm{V}^{+} / \mathrm{PI}^{+}$) apoptosis. Values indicate the percentage of total annexin $\mathrm{V}^{+}$cells.

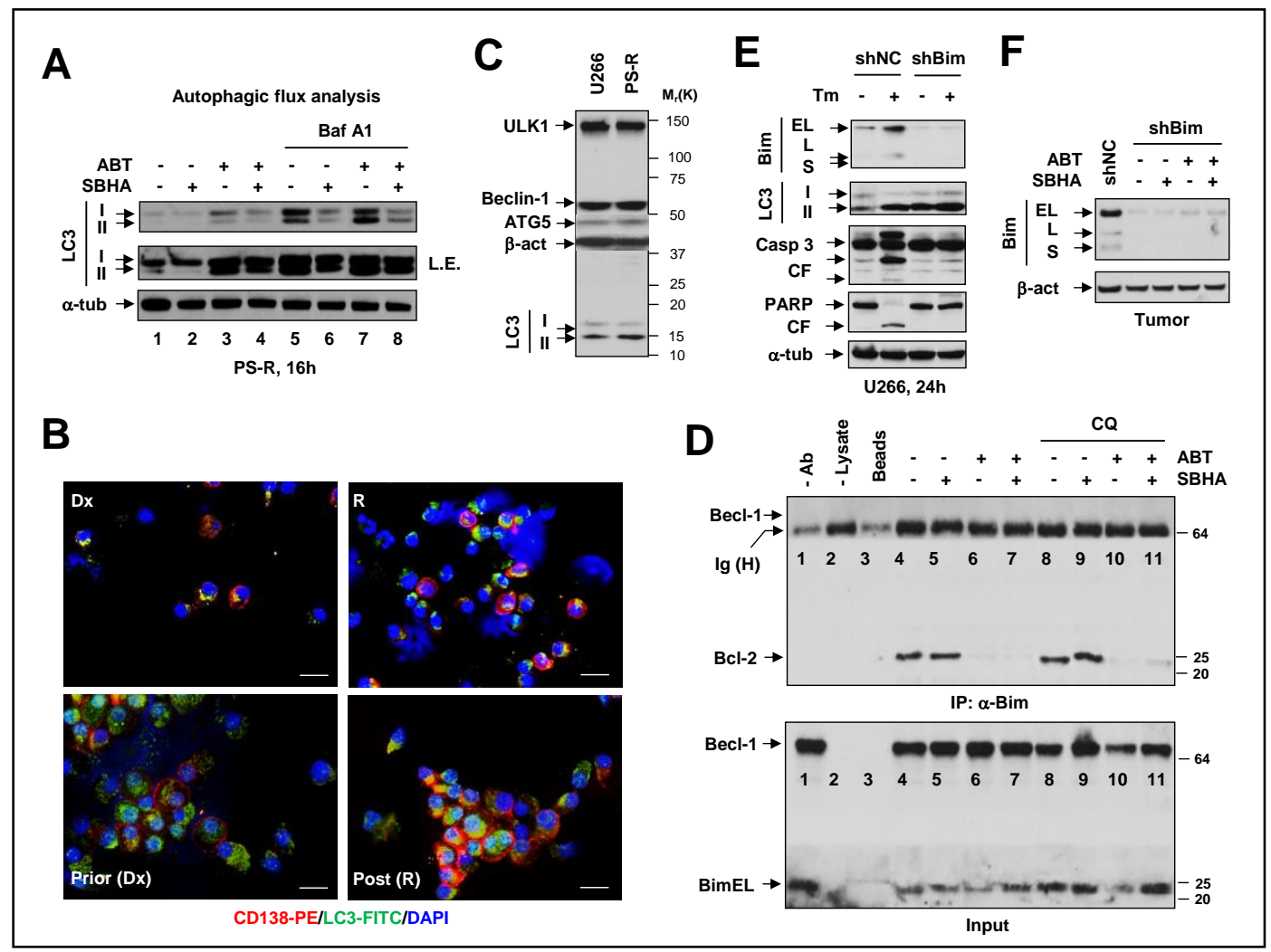

Figure S3. (A) Analysis of autophagic flux reveals inhibition of ABT-737-tiggered autophagy initiation by SBHA. PS-R cells were incubated with $500 \mathrm{nM}$ ABT-737 +/- $20 \mu \mathrm{M}$ SBHA for $16 \mathrm{hr}$ in the absence or presence of $10 \mathrm{nM}$ bafilomycin A1, after which immunoblotting analysis was performed to assess autophagic flux by monitoring LC3-II expression. Compared to bafilomycin A1 alone (lane 5), LC3-II elevation (e.g., ABT-737, lane 7) or reduction (e.g., ABT-737+SBHA, lane 8) indicates promotion or inhibition of autophagy initiation, respectively. L.E. = long exposure. (B) Primary CD138 ${ }^{+}$MM cells derived from relapsed patients display higher basal autophagy than those from newly-diagnosed 
patients. Primary mononuclear cells (upper) or $\mathrm{CD} 138^{+}$cells (lower) were isolated from a newly diagnosed (Dx) or a relapsed ( $\mathrm{R}$, who had received prior bortezomib) MM patient (upper panels), as well as a MM patient prior to and post-relapse following bortezomib therapy (lower panels). Immunofluorescence staining (IF) was performed to monitor expression of LC3 (AlexaFluor 488, green) in untreated CD138 ${ }^{+}$(PE, red) cells. (C) Bortezomib-resistant PS-R cells display modestly increased basal autophagy. Immunoblotting analysis was conducted to monitor protein levels of LC3-II, as well as the key pro-autophagic proteins ULK-1, Beclin-1, and ATG5 in U266 and PS-R cells. (D) ABT-737 releases Bim from Bcl-2 in bortezomib-resistant PS-

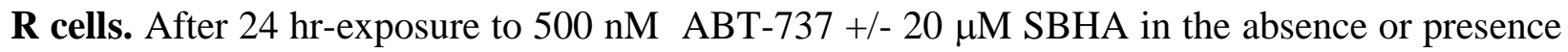
of $50 \mu \mathrm{M}$ chloroquine (CQ), co-immunoprecipitation analysis was performed to monitor associations between Bim and Bcl-2 and Beclin-1 in PS-R cells. Whereas Bim bound to Bcl-2, a phenomenon disrupted by ABT-737, binding of Bim with Beclin-1 was not detectable under any conditions. (E) Bim shRNA knockdown prevents apoptosis induced by the autophagy inducer tunicamycin. U266 stably transfected with constructs encoding shRNA targeting Bim (shBim) or scrambled sequence as a negative control (shNC) were exposed to tunicamycin (TM, $1 \mu \mathrm{g} / \mathrm{ml}$ ) for $24 \mathrm{hr}$, followed by immunoblotting for expression of Bim and LC3-II, as well as cleavage of caspase 3 and PARP. (F) Tumor tissues obtained from U266/shBim cell mouse xenografts after the indicated treatment were subjected to Western blot analysis to monitor expression of Bim. A tumor tissue sample from an untreated U266/shNC (negative control for Bim shRNA) xenograft was loaded for comparison. 


\section{Appendix: Abbreviations}

7AAD, 7-aminoactinomycin D; Ab, antibody; AKT, RAC-alpha serine/threonine-protein kinase; ATCC, American Type Culture Collection; AIF, apoptosis inducing factor; AO, acridine orange; ATG, autophagy protein; AV, autophagic vacuole; AVO, acidic vesicular organelle; Bad, Bcl-2associated death promoter; Bak, Bcl-2 homologous antagonist/killer; Bax, bcl-2-like protein 4; Bcl-2, B-cell lymphoma 2; Bcl-w, Bcl-2-like 2; Bcl-xL, B-cell lymphoma-extra large; Bfl1/A1, Bcl-2-related protein A1; BH3, Bcl-2 homology 3 domain; Bid, BH3 interacting domain death agonist; Bim, Bcl-2-like 11; BM, bone marrow; Bmf, Bcl-2-modifying factor; BSA, bovine serum albumin; btz, bortezomib; Cdk, cyclin-dependent kinase; CHX, cycloheximide; CQ, chloroquine; CTD, C-terminal domain; DN, dominant-negative; DAPI, 4',6-diamidino-2phenylindole; DTT, dithiothreitol; Dx, newly diagnosed; EM, electron microscope; ER, endoplasmic reticulum; ERK, extracellular signal-regulated kinases; EV, empty vector; FBS, fetal bovine serum; FITC, fluorescein isothiocyanate; FP, flavopiridol or alvocidib; GEP, gene expression profiling; GFP, green fluorescent protein; GX, GX-015-070 or obatoclax; HA, hemagglutinin; HDAC, histone deacetylase; HDACI, histone deacetylase inhibitor; HM, heavy membrane fraction; Hrk, activator of apoptosis hara-kiri; IF, immunofluorescence; IHC, immunohistochemistry; IMiD, immunomodulatory agent; IP, immunoprecipitation; ko, knockout; i.v., intravenous injection; LAMP2, lysosome-associated membrane protein 2; LC3, Light Chain 3; LM, light membrane fraction; 3-MA, 3-methyladenine; Mcl-1, myeloid cell leukemia 1; MEF, mouse embryonic fibroblast; MEK, mitogen-activated protein kinase kinase; MM, multiple myeloma; MNCs, mononuclear cells; MOA, mechanism of action; NAF-1, nutrient-deprivation autophagy factor-1; NBK/Bik, natural born killer/Bcl-2-interacting killer; $\mathrm{NC}$, negative control; NF-kB, nuclear factor kappa-light-chain-enhancer of activated B cells; 
Noxa, phorbol-12-myristate-13-acetate-induced protein; NSG, NOD/SCID-gamma mouse, PAGE, polyacrylamide gel electrophoresis; PARP, poly (ADP-ribose) polymerase; PBS, phosphate buffered saline; PE, phycoerythrin; PI, propidium iodide; PI3K, phosphoinositide kinase-3; PMSF, phenylmethanesulfonylfluoride or phenylmethylsulfonyl fluorid; PS-R, bortezomib-resistant U266 cell line; $\mathrm{P}-\mathrm{TEFb}$, positive transcription elongation factor $\mathrm{b}$ (Cdk9/cyclin T complex); Puma, p53 upregulated modulator of apoptosis; qPCR, quantitative or real-time polymerase chain reaction; R, relapse; SBHA, suberoyl bishydroxamic acid; SDS, sodium dodecyl sulfate; shRNA, small hairpin RNA or short hairpin RNA; SPT, spautin-1; SQSTM1, sequestosome 1; TFEB, transcription factor EB; TUNEL, terminal deoxynucleotidyl transferase mediated dUTP nick end labeling assay; ULK1, Unc-51 like autophagy activating kinase 1; USP, ubiquitin specific peptidase; 8226/VR, bortezomib-resistant RPMI8226 cell line; wt, wild type. 